\title{
Chemically fueled transient geometry changes in diphenic acids
}

\author{
Supporting Information
}

Isuru M. Jayalath, Hehe Wang, Georgia Mantel, Lasith S. Kariyawasam, and C. Scott Hartley*

Department of Chemistry \& Biochemistry, Miami University, Oxford, $\mathrm{OH} 45056$, United States

Table of Contents

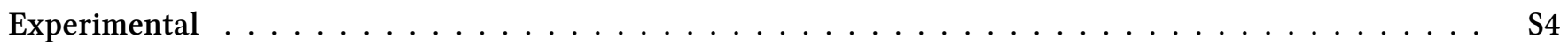

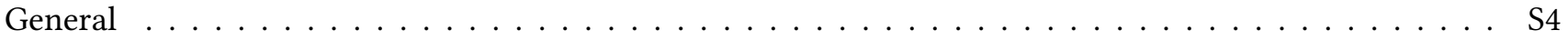

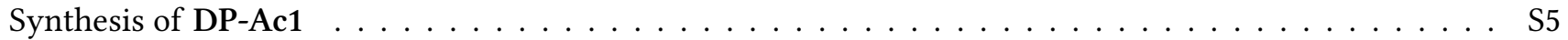

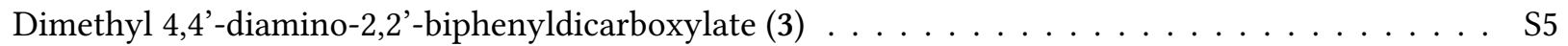

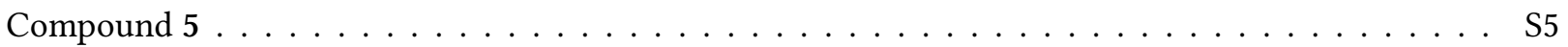

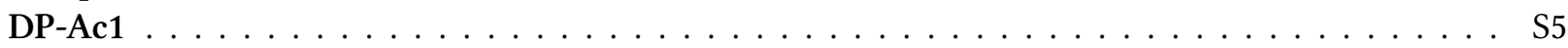

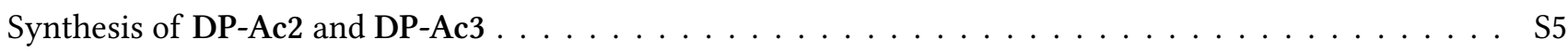

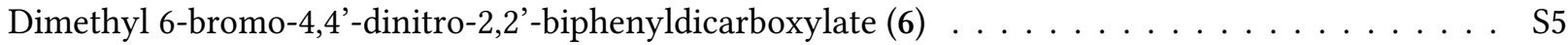

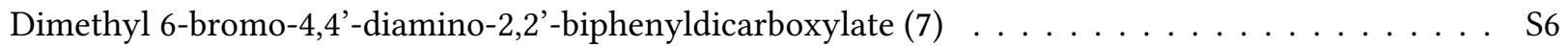

Dimethyl 6-bromo-4,4'-dihydroxy-2,2'-biphenyldicarboxylate $(8) \ldots \ldots \ldots \ldots$. . . . . . S6

Dimethyl 6-(trimethylsilyl)ethynyl-4,4'-dihydroxy-2,2'-biphenyldicarboxylate (9) . . . . . . . S6

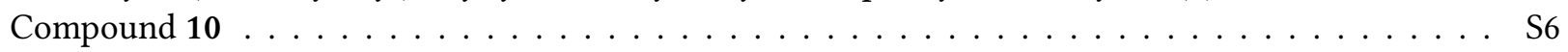

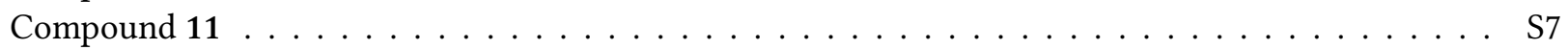

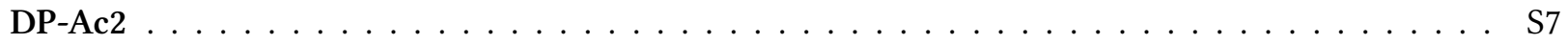

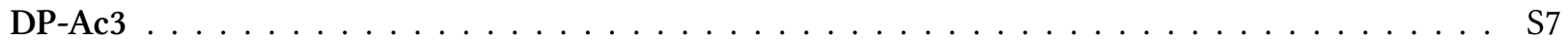

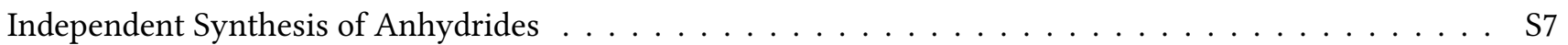

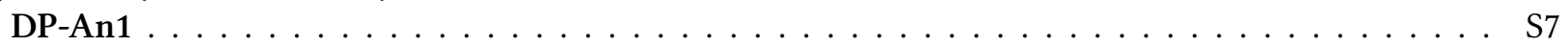

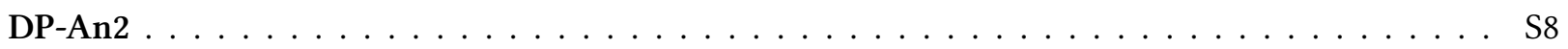

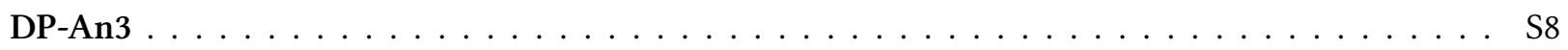

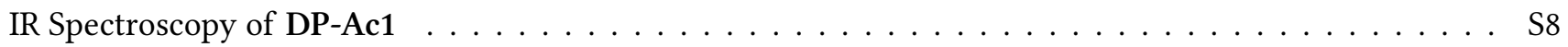

Reaction monitoring by ${ }^{1} \mathrm{H}$ NMR spectroscopy $\ldots \ldots \ldots \ldots \ldots \ldots \ldots \ldots \ldots \ldots$

Reactions for DP-Ac1 in $\mathrm{D}_{2} \mathrm{O} \ldots \ldots \ldots \ldots \ldots \ldots \ldots \ldots \ldots$

Reactions for DP-Ac1, DP-Ac2, and DP-Ac3 in $\mathrm{D}_{2} \mathrm{O}$ acetone- $d_{6} \ldots \ldots \ldots \ldots \ldots$. . . . . . .

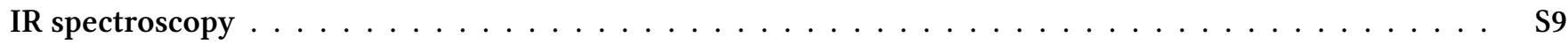

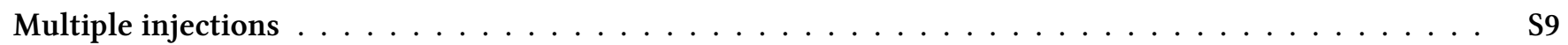

DFT geometry optimizations $\ldots \ldots \ldots \ldots \ldots \ldots \ldots \ldots \ldots \ldots \ldots \ldots \ldots \ldots \ldots$

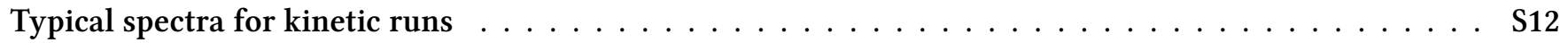

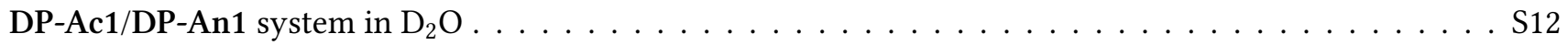

DP-Ac2/DP-An2 and DP-Ac3/DP-An3 $\mathrm{D}_{2} \mathrm{O}$ a acetone- $d_{6}$ at $276 \mathrm{~K} \ldots \ldots \ldots \ldots \ldots \ldots$

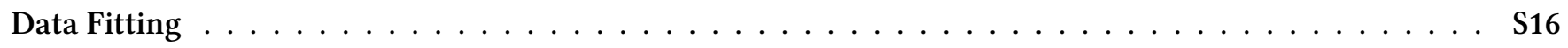

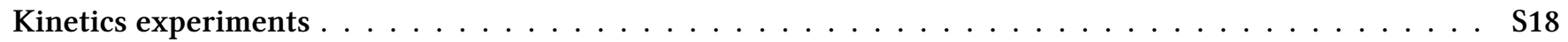

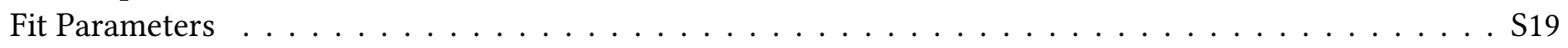




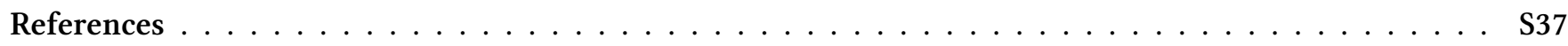

\section{List of Figures}

S1 IR spectroscopy (absorbance) of DP-An1 formation on the treatment of DP-Ac1 (100 mM) with EDC $(0.5$ equiv $)$ in $\mathrm{H}_{2} \mathrm{O}$ at $278 \mathrm{~K} \ldots \ldots \ldots \ldots \ldots \ldots \ldots \ldots \ldots \ldots \ldots \ldots$

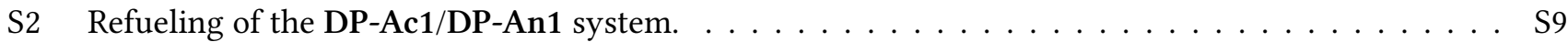

S3 Optimized geometries of (a) DP-Ac2' and (b) DP-An2' at the B97-D3(BJ)/TZV(2d,2p) level and

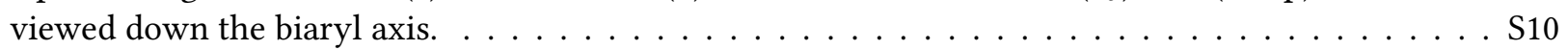

S4 Optimized geometries of (a) DP-Ac3' and (b) DP-An3' at the B97-D3(BJ)/TZV(2d,2p) level and

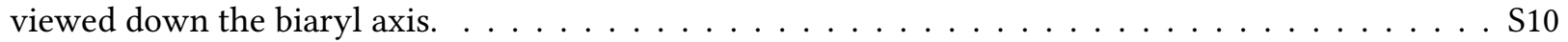

S5 PES scans for DP-Ac1', DP-Ac2', and DP-Ac3' with respect to rotation about the biaryl bond. . . . S11

S6 $\quad{ }^{1} \mathrm{H}$ NMR spectra of DP-An1 formation from DP-Ac1 treated with 0.5 eq. of EDC at $276 \mathrm{~K}$ in $\mathrm{D}_{2} \mathrm{O}$. . S12

S7 $\quad{ }^{1}$ H NMR spectra of DP-An1 formation from DP-Ac1 treated with 1 eq. of EDC at $276 \mathrm{~K} . \ldots \ldots$. . . . S13

S8 $\quad{ }^{1} \mathrm{H}$ NMR spectra of DP-An1 formation from DP-Ac1 treated with 1.5 eq. of EDC after adjusting the

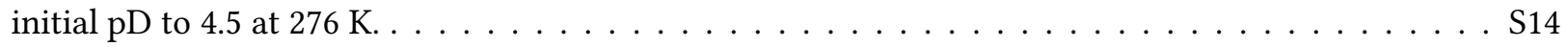

S9 Appearance and disappearance of minor broad peaks in DP-Ac2/DP-An2 system. . . . . . . . . S15

S10 $\quad{ }^{1}$ H NMR spectra of DP-An2 formation from DP-Ac2 acquired during a typical kinetic run. . . . . . S16

S11 ${ }^{1}$ H NMR spectra of DP-An3 formation from DP-Ac3 acquired during a typical kinetic run. . . . . . S16

S12 ${ }^{1} \mathrm{H}$ NMR spectroscopy monitoring of the treatment of $25 \mathrm{mM}$ DP-Ac1 with (a) $12 \mathrm{mM}$, (b) $20 \mathrm{mM}$,

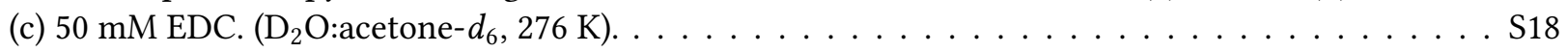

S13 Heat map of the response of the regression error function to variation of $\alpha$ and $k_{1}$ for the DP-

Ac1/DP-An1 system. . . . . . . . . . . . . . . . . . . . . . . . S19

S14 Heat map of the response of the regression error function to variation of $k_{1}$ and $k_{2}$ for the DP-

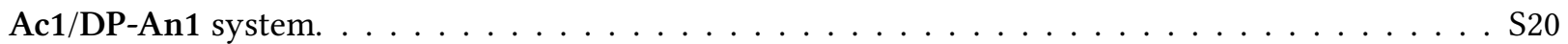

S15 Heat map of the response of the regression error function to variation of for $k_{2}$ and $\alpha$ the DP-

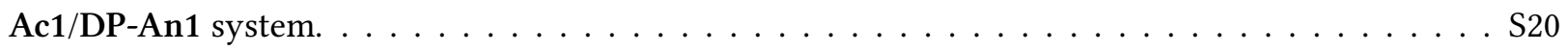

S16 ${ }^{1} \mathrm{H}$ NMR spectroscopy monitoring of the treatment of DP-Ac2 with EDC (a) 0.5 eq. (b) 1.0 eq. (c)

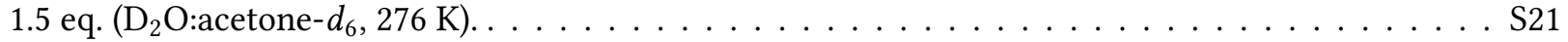

S17 ${ }^{1}$ H NMR spectroscopy monitoring of the treatment of DP-Ac3 with EDC (a) 0.5 eq. (b) 1.0 eq. (c)

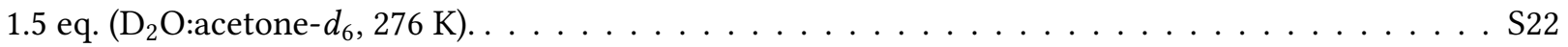

S18 ${ }^{1} \mathrm{H}$ NMR spectrum (DMSO- $d_{6}, 500 \mathrm{MHz}$ ) of dimethyl 4,4'-diamino-2,2'-biphenyldicarboxylate (3). . S23

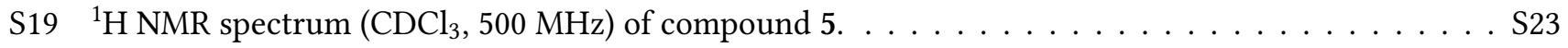

$\mathrm{S} 20{ }^{13} \mathrm{C}\left\{{ }^{1} \mathrm{H}\right\}$ NMR spectrum $\left(\mathrm{CDCl}_{3}, 126 \mathrm{MHz}\right)$ of compound $5 \ldots \ldots \ldots \ldots \ldots \ldots$. . . . . . . . . . . 24

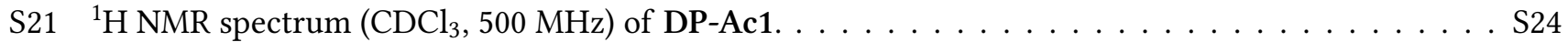

S22 ${ }^{13} \mathrm{C}\left\{{ }^{1} \mathrm{H}\right\}$ NMR spectrum $\left(\mathrm{CDCl}_{3}, 126 \mathrm{MHz}\right)$ of DP-Ac1 . . . . . . . . . . . . . . . . . . . . S25

S23 ${ }^{1} \mathrm{H}$ NMR spectrum (DMSO- $d_{6}, 500 \mathrm{MHz}$ ) of dimethyl 6-bromo-4,4'-dinitro-2,2'-biphenyldicarboxylate

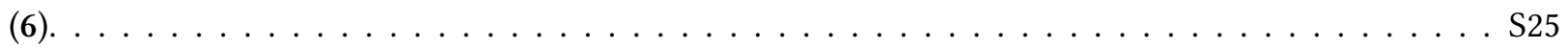

S24 ${ }^{13} \mathrm{C}\left\{{ }^{1} \mathrm{H}\right\}$ NMR spectrum (DMSO- $d_{6}, 126 \mathrm{MHz}$ ) of dimethyl 6-bromo-4,4'-dinitro-2,2'-biphenyldicarboxylate

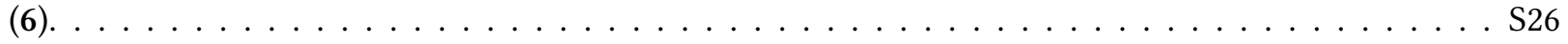

S25 ${ }^{1} \mathrm{H}$ NMR spectrum (DMSO- $d_{6}, 500 \mathrm{MHz}$ ) of dimethyl 6-bromo-4,4'-diamino-2,2'-biphenyldicarboxylate

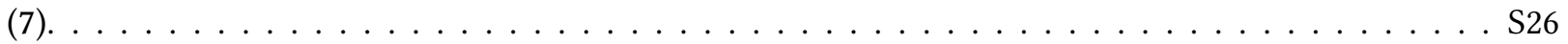

S26 ${ }^{13} \mathrm{C}\left\{{ }^{1} \mathrm{H}\right\}$ NMR spectrum (DMSO- $d_{6}, 126 \mathrm{MHz}$ ) of dimethyl 6-bromo-4,4'-diamino-2,2'-biphenyldicarboxylate

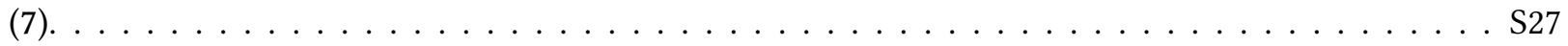

S27 ${ }^{1}$ H NMR spectrum (DMSO- $d_{6}, 500 \mathrm{MHz}$ ) of dimethyl 6-bromo-4,4'-dihydroxy-2,2'-biphenyldicarboxylate

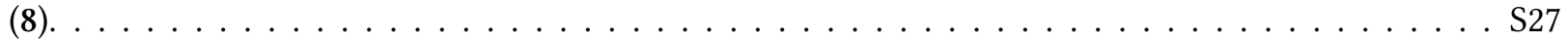

S28 ${ }^{13} \mathrm{C}\left\{{ }^{1} \mathrm{H}\right\}$ NMR spectrum (DMSO- $d_{6}, 126 \mathrm{MHz}$ ) of dimethyl 6-bromo-4,4'-dihydroxy-2,2'-biphenyldicarboxylate

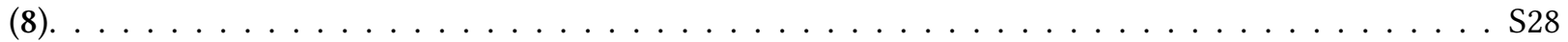


S29 ${ }^{1} \mathrm{H}$ NMR spectrum (DMSO- $d_{6}, 500 \mathrm{MHz}$ ) of dimethyl 6-(trimethylsilyl)ethynyl-4,4'-dihydroxy-2,2'-

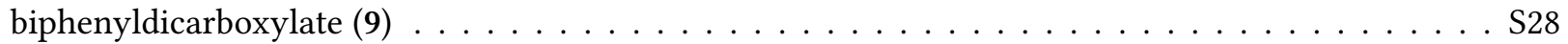

S30 ${ }^{13} \mathrm{C}\left\{{ }^{1} \mathrm{H}\right\}$ NMR spectrum (10o MHz, DMSO- $d_{6}$ ) of dimethyl 6-(trimethylsilyl)ethynyl-4,4'-dihydroxy-

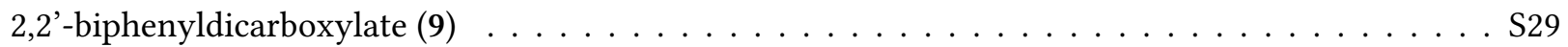

S31 ${ }^{1} \mathrm{H}$ NMR spectrum $\left(\mathrm{CDCl}_{3}, 500 \mathrm{MHz}\right)$ of compound 10. . . . . . . . . . . . . . . . . . S29

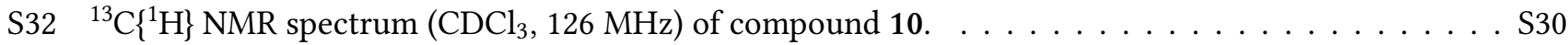

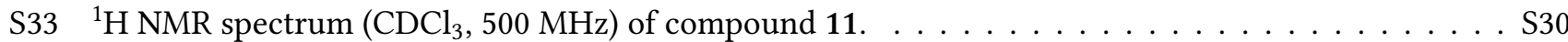

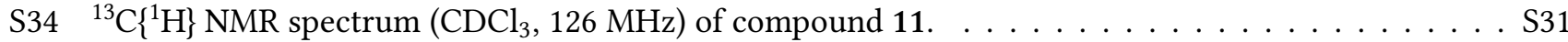

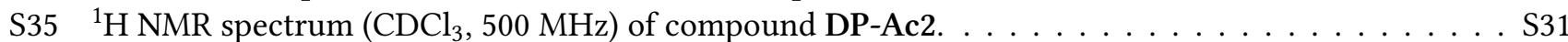

S36 ${ }^{13} \mathrm{C}\left\{{ }^{1} \mathrm{H}\right\}$ NMR spectrum $\left(\mathrm{CDCl}_{3}, 126 \mathrm{MHz}\right)$ of DP-Ac2 . . . . . . . . . . . . . . . . . S32

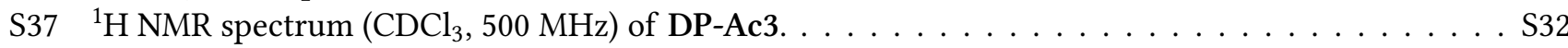

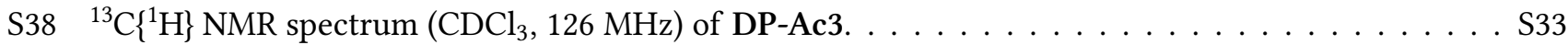

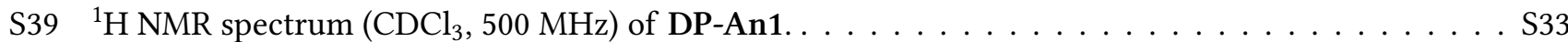

S40 ${ }^{13} \mathrm{C}\left\{{ }^{1} \mathrm{H}\right\}$ NMR spectrum $\left(\mathrm{CDCl}_{3}, 126 \mathrm{MHz}\right)$ of DP-An1 . . . . . . . . . . . . . . . . . . . S S34

$\mathrm{S} 41{ }^{1} \mathrm{H}$ NMR spectrum $\left(\mathrm{CDCl}_{3}, 500 \mathrm{MHz}\right)$ of DP-An2 . . . . . . . . . . . . . . . . . . . . S S34

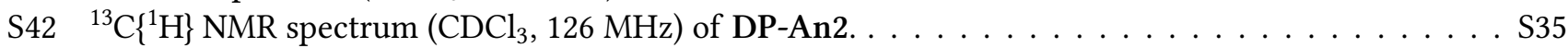

S43 ${ }^{1} \mathrm{H}$ NMR spectrum (aromatic region) $\left(\mathrm{CDCl}_{3}, 500 \mathrm{MHz}\right)$ of DP-An3 . . . . . . . . . . . . . . S35

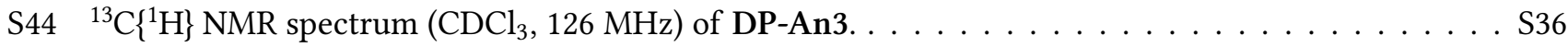

\section{List of Schemes}

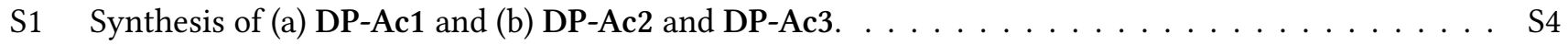

\section{List of Tables}

S1 Data for geometry optimizations $(\mathrm{B} 97-\mathrm{D} 3(\mathrm{BJ}) / \mathrm{TZV}(2 \mathrm{~d}, 2 \mathrm{p})) \ldots \ldots \ldots \ldots \ldots \ldots \ldots \ldots$. . . . . . . . . . . .

S2 Fit parameters for the DP-Ac1/DP-An1 system for anhydride formation and hydrolysis. . . . . . . S19 


\section{Experimental}

(a)

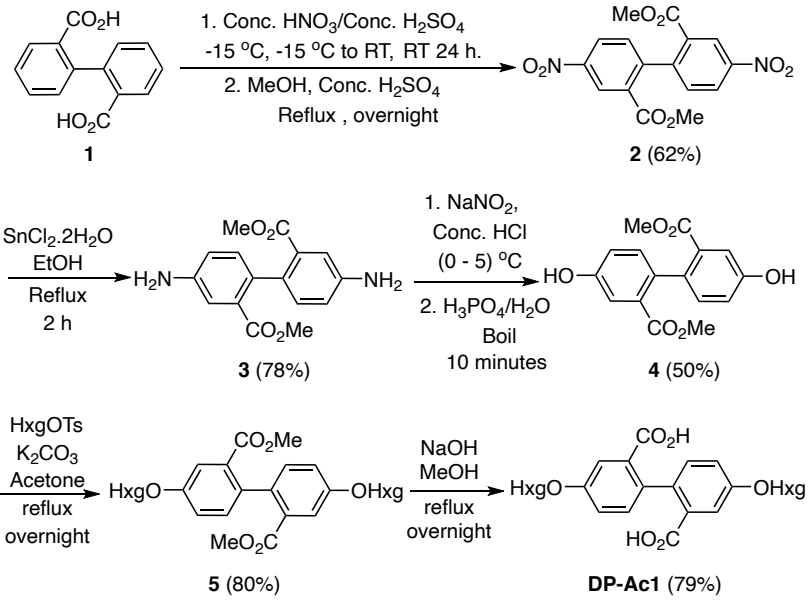

(b)
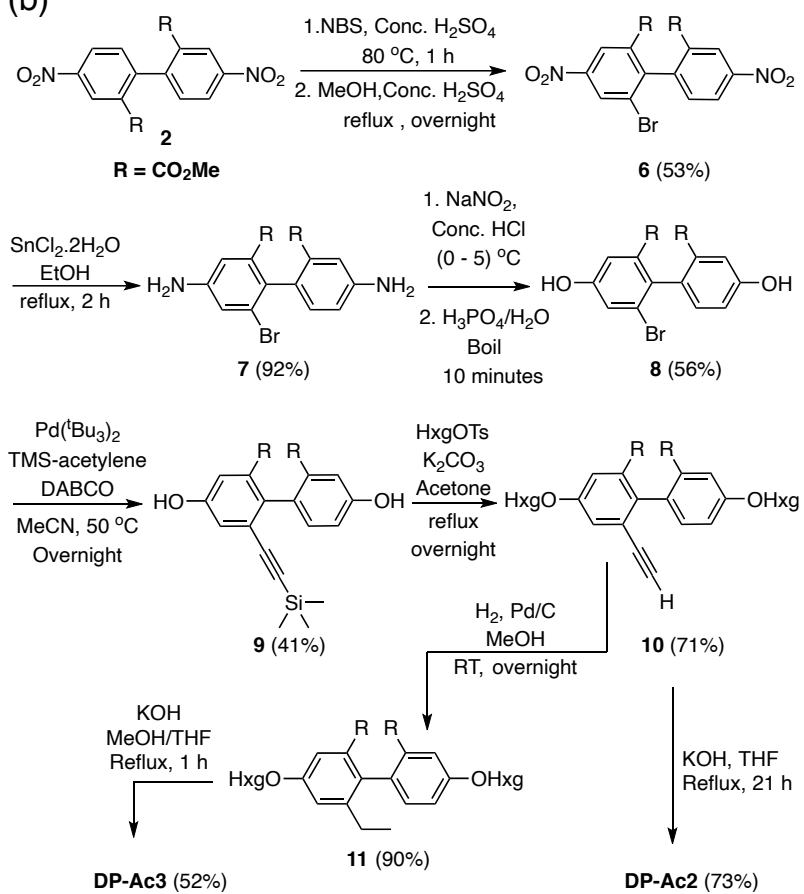

Scheme S1. Synthesis of (a) DP-Ac1 and (b) DP-Ac2 and DP-Ac3.

\section{General}

Unless otherwise noted, all starting materials, reagents, and solvents were purchased from commercial sources and used without further purification. NMR spectra for characterization were measured for $\mathrm{CDCl}_{3}$ or DMSO- $d_{6}$ solutions using Bruker Avance $500 \mathrm{MHz}$ or Bruker Avance NEO $400 \mathrm{MHz}$ NMR spectrometers. NMR spectra for kinetics were measured for $\mathrm{D}_{2} \mathrm{O}$ or $\mathrm{D}_{2} \mathrm{O}$ /acetone- $d_{6}$ solutions using a Bruker Avance III $600 \mathrm{MHz}$ NMR spectrometer. IR spectra were recorded in a Mettler Toledo ReactIR 15 IR spectrophotometer. Melting points were determined using a Thermal Analysis Q20 differential scanning calorimeter at a heating rate of $10{ }^{\circ} \mathrm{C} / \mathrm{min}$. Semi-preparative gel permeation chromatography was performed using a Waters Breeze 2 HPLC equipped with a $19 \times 300 \mathrm{~mm}$ Ultrastyragel $500 \AA$ GPC column with toluene as the eluent. High-resolution mass spectra were acquired using a Thermo Scientific LTQ Orbitrap XL mass spectrometer. 


\section{Synthesis of DP-Ac1}

Dimethyl 4,4'-dinitro-2,2'-biphenyldicarboxylate (2) and dimethyl 4,4'-dihydroxy-2,2'-biphenyldicarboxylate (4) were synthesized as previously reported. ${ }^{1}$

\section{Dimethyl 4,4'-diamino-2,2'-biphenyldicarboxylate (3)}

Dimethyl 4,4'-dinitro-2,2'-biphenyldicarboxylate $2(1.47 \mathrm{~g}, 4.08 \mathrm{mmol})$ was dissolved in EtOH $(95 \mathrm{~mL})$ in a 250 $\mathrm{mL}$ round-bottomed flask. $\mathrm{SnCl}_{2} \cdot 2 \mathrm{H}_{2} \mathrm{O}(9.2 \mathrm{~g}, 40.28 \mathrm{mmol})$ was added and the reaction mixture was stirred and heated to reflux using an aluminum bead bath for $2 \mathrm{~h}$, then cooled to room temperature. Excess EtOH was removed under reduced pressure and sat. $\mathrm{Na}_{2} \mathrm{CO}_{3}(\mathrm{aq})$ was added to adjust the $\mathrm{pH}$ to 8 . The yellow precipitate was set aside and the liquid was decanted and extracted with EtOAc $(3 \times)$. The combined organic extracts were washed with water $(1 \times)$ and brine $(1 \times)$ then dried over $\mathrm{MgSO}_{4}$ and filtered. The solvent was removed under reduced pressure to afford compound $3(0.96 \mathrm{~g}, 78.8 \%)$ as a pale yellow solid: ${ }^{1} \mathrm{H}$ NMR (DMSO- $\left.d_{6}, 500 \mathrm{MHz}\right): \delta 6.96(\mathrm{~d}, J=2.3 \mathrm{~Hz}, 2 \mathrm{H}$ ), $6.79(\mathrm{~d}, J=8.2 \mathrm{~Hz}, 2 \mathrm{H}), 6.68(\mathrm{dd}, J=8.2,2.3 \mathrm{~Hz}, 2 \mathrm{H}), 5.26(\mathrm{~s}, 4 \mathrm{H}), 3.48(\mathrm{~s}, 6 \mathrm{H})$. The observed characterization data was consistent with that previously reported. ${ }^{1}$

\section{Compound 5}

Dimethyl 4,4'-dihydroxy-2,2'-biphenyldicarboxylate $4(1.75 \mathrm{~g}, 5.79 \mathrm{mmol})$ in dry acetone $(165 \mathrm{~mL})$ was treated with $\mathrm{K}_{2} \mathrm{CO}_{3}(8.0 \mathrm{~g} .57 .0 \mathrm{mmol})$ followed by a solution of $\mathrm{HxgOTs}^{2}(8.0 \mathrm{~g}, 17.36 \mathrm{mmol})$ in dry acetone $(10 \mathrm{~mL})$. The mixture was stirred and heated to reflux using an aluminum bead bath under argon overnight, cooled to room temperature, and partitioned between brine and EtOAc. The aqueous layer was extracted with EtOAc $(3 \times)$ and the combined organic extracts were washed with brine (1×), dried over $\mathrm{MgSO}_{4}$, and filtered. The resulting solution was concentrated under reduced pressure and the crude was purified on a silica column eluted with 95:5 DCM:MeOH to afford the compound $5(3.96 \mathrm{~g}, 79.5 \%)$ as a colorless oil: ${ }^{1} \mathrm{H}$ NMR $\left(\mathrm{CDCl}_{3}, 500 \mathrm{MHz}\right): \delta 7.49(\mathrm{~d}, J=1.8 \mathrm{~Hz}, 2 \mathrm{H})$, 7.10-7.04 (m, 4H), $4.19(\mathrm{t}, J=4.6 \mathrm{~Hz}, 4 \mathrm{H}), 3.87(\mathrm{t}, J=4.6 \mathrm{~Hz}, 4 \mathrm{H}), 3.76-3.72(\mathrm{~m}, 4 \mathrm{H}), 3.71-3.62(\mathrm{~m}, 32 \mathrm{H}), 3.60(\mathrm{~s}, 6 \mathrm{H})$, 3.52-3.55 (m, 4H), $3.37(\mathrm{~s}, 6 \mathrm{H}) .{ }^{13} \mathrm{C}\left\{{ }^{1} \mathrm{H}\right\} \mathrm{NMR}\left(\mathrm{CDCl}_{3}, 126 \mathrm{MHz}\right): \delta 167.3,157.4,135.3,131.6,130.5,118.0,115.1,71.9$, 70.8, 70.57, 70.51, 70.48, 70.4, 69.6, 67.5, 59.0, 51.8. HRMS (ESI-Orbitrap) calcd for $\mathrm{C}_{42} \mathrm{H}_{66} \mathrm{O}_{18} \mathrm{Na}\left(\left[\mathrm{M}+\mathrm{Na}^{+}\right]\right) 881.4147$, found 881.4109 .

\section{DP-Ac1}

Compound $5(3.74 \mathrm{~g}, 4.35 \mathrm{mmol})$ in $\mathrm{MeOH}(200 \mathrm{~mL})$ was treated with $\mathrm{NaOH}(\mathrm{aq})(2 \mathrm{M}, 40 \mathrm{~mL}, 80 \mathrm{mmol})$ and the resulting mixture was stirred and heated to reflux using an aluminum bead bath overnight. This was concentrated under reduced pressure to remove methanol and acidified with $2 \mathrm{M} \mathrm{HCl}$ to $\mathrm{pH}$ 2. The resulting mixture was saturated with $\mathrm{NaCl}$ and extracted with EtOAc $(5 \times)$ and the combined organic extracts were washed with brine (1×), dried over $\mathrm{MgSO}_{4}$, and filtered. The resulting solution was concentrated under reduced pressure and the crude was purified on a silica column eluted with 95:5-90:10 DCM:MeOH to afford DP-Ac1 (3.4 g, 78.5\%) as a buff-colored oil: ${ }^{1} \mathrm{H}$ NMR $\left(\mathrm{CDCl}_{3}, 500 \mathrm{MHz}\right): \delta 7.46(\mathrm{~d}, J=1.83 \mathrm{~Hz}, 2 \mathrm{H}) .7 .06-7.00(\mathrm{~m}, 4 \mathrm{H}), 4.19-4.14(\mathrm{~m}, 4 \mathrm{H})$, 3.87-3.82 (m, 4H), 3.73-3.69 (m, 4H), 3.67-3.58 (m, 32H), 3.53-3.49 (m, 4H), 3.34 (s, 6H), ${ }^{13} \mathrm{C}\left\{{ }^{1} \mathrm{H}\right\} \mathrm{NMR}\left(\mathrm{CDCl}_{3}, 126\right.$ $\mathrm{MHz}): \delta 170.3,157.5,134.6,131.8,131.3,118.1,115.2,71.73,70.71,70.45,70.37,70.36,70.34,70.32,70.2,69.6,67.6$, 58.9. HRMS (ESI-Orbitrap) calcd for $\mathrm{C}_{40} \mathrm{H}_{62} \mathrm{O}_{18} \mathrm{Na}\left(\left[\mathrm{M}+\mathrm{Na}^{+}\right]\right) 853.3834$, found 853.3819.

\section{Synthesis of DP-Ac2 and DP-Ac3}

\section{Dimethyl 6-bromo-4,4'-dinitro-2,2'-biphenyldicarboxylate (6)}

Dimethyl 4,4'-dinitro-2,2'-biphenyldicarboxylate 2 (13.3 g, $37 \mathrm{mmol})$ was dissolved in conc. $\mathrm{H}_{2} \mathrm{SO}_{4}(130 \mathrm{~mL})$ and NBS (6.6 g, $37 \mathrm{mmol}$ ) was added. This mixture was stirred and slowly heated to $80^{\circ} \mathrm{C}$ using an aluminum bead bath, then kept at $80{ }^{\circ} \mathrm{C}$ for $1 \mathrm{~h}$. The reaction mixture was then cooled to room temperature and added to crushed ice $(1$ L). The mixture was extracted with EtOAc $(3 \times)$ and the combined organic extracts were washed with water $(1 \times)$ and brine (1×), dried over $\mathrm{MgSO}_{4}$, and filtered. The resulting solution was concentrated under reduced pressure. The product was dissolved in $\mathrm{MeOH}(130 \mathrm{~mL})$ and conc. $\mathrm{H}_{2} \mathrm{SO}_{4}(10 \mathrm{~mL})$ was added dropwise after cooling in an ice bath. The mixture was heated to reflux using an aluminum bead bath with stirring overnight, then excess $\mathrm{MeOH}$ was removed under reduced pressure and the white precipitate was collected by vacuum filtration and washed with cold $\mathrm{MeOH}$. Purification on a silica column eluted with 90:10 cyclohexane:EtOAc afforded dimethyl 6-bromo4,4'-dinitro-2,2'-biphenyldicarboxylate $(8.69 \mathrm{~g}, 53 \%)$ as a white solid: mp $127.26{ }^{\circ} \mathrm{C} .{ }^{1} \mathrm{H}$ NMR (DMSO- $\left.d_{6}, 500 \mathrm{MHz}\right)$ : 
$\delta 8.80(\mathrm{~d}, J=2.3 \mathrm{~Hz}, 1 \mathrm{H}), 8.78(\mathrm{~d}, J=2.3 \mathrm{~Hz}, 1 \mathrm{H}), 8.71(\mathrm{~d}, J=2.3 \mathrm{~Hz}, 1 \mathrm{H}), 8.56(\mathrm{dd}, J=8.2,2.3 \mathrm{~Hz}, 1 \mathrm{H}), 7.57(\mathrm{~d}, J=$ $8.2 \mathrm{~Hz}, 1 \mathrm{H}), 3.70(\mathrm{~s}, 3 \mathrm{H}), 3.63(\mathrm{~s}, 3 \mathrm{H}) .{ }^{13} \mathrm{C}\left\{{ }^{1} \mathrm{H}\right\}$ NMR (DMSO- $\left.d_{6}, 126 \mathrm{MHz}\right): \delta$ 163.9, 163.7, 147.5, 147.4, 147.3, 146.3, 131.5, 131.3, 130.2, 129.9, 127.2, 124.5, 124.3, 123.7, 52.9, 52.8. HRMS (ESI-MS) calcd for $\mathrm{C}_{16} \mathrm{H}_{11} \mathrm{BrN}_{2} \mathrm{O}_{8} \mathrm{Na}\left(\left[\mathrm{M}+\mathrm{Na}^{+}\right]\right)$ 460.9596, found 460.9589 .

\section{Dimethyl 6-bromo-4,4'-diamino-2,2'-biphenyldicarboxylate (7)}

The procedure for compound 3 was followed using dimethyl 6-bromo-4,4'-dinitro-2,2'-biphenyldicarboxylate 6 $(7 \mathrm{~g}, 15.93 \mathrm{mmol})$ to give compound $7(5.56 \mathrm{~g}, 92 \%)$ as a light yellow solid: mp $172.54{ }^{\circ} \mathrm{C} .{ }^{1} \mathrm{H}$ NMR (DMSO- $d_{6}, 500$ MHz): $\delta 7.10(\mathrm{~d}, J=2.3 \mathrm{~Hz}, 1 \mathrm{H}), 6.99(\mathrm{~d}, J=2.3 \mathrm{~Hz}, 1 \mathrm{H}), 6.94(\mathrm{~d}, J=2.3 \mathrm{~Hz}, 1 \mathrm{H}), 6.69(\mathrm{dd}, J=8.2,2.3 \mathrm{~Hz}, 1 \mathrm{H}), 6.65(\mathrm{~d}$, $J=8.2 \mathrm{~Hz}, 1 \mathrm{H}), 5.51(\mathrm{~s}, 2 \mathrm{H}), 5.33(\mathrm{~s}, 2 \mathrm{H}), 3.52(\mathrm{~s}, 3 \mathrm{H}), 3.44(\mathrm{~s}, 3 \mathrm{H}) .{ }^{13} \mathrm{C}\left\{{ }^{1} \mathrm{H}\right\} \mathrm{NMR}$ (DMSO- $\left.d_{6}, 126 \mathrm{MHz}\right): \delta$ 167.1, 166.7, 148.2, 147.6, 132.6, 131.8, 130.1, 129.3, 128.5, 125.5, 119.3, 116.9, 114.5, 113.5, 51.6, 51.4. HRMS (ESI-Orbitrap) calcd for $\mathrm{C}_{16} \mathrm{H}_{15} \mathrm{BrN}_{2} \mathrm{O}_{4}\left([\mathrm{M}+\mathrm{H}]^{+}\right)$379.0293, found 379.0286.

Dimethyl 6-bromo-4,4'-dihydroxy-2,2'-biphenyldicarboxylate (8)

Dimethyl 6-bromo-4,4'-diamino-2,2'-biphenyldicarboxylate 7 (7.63 g, $20.12 \mathrm{mmol})$ was dissolved in a mixture of conc. $\mathrm{HCl}(44.0 \mathrm{~mL})$ and water $(220.0 \mathrm{~mL})$. This was cooled in an ice bath and an ice-cold mixture of $\mathrm{NaNO}_{2}$ $(2.90 \mathrm{~g}, 42.25 \mathrm{mmol})$ dissolved in water $(84.6 \mathrm{~mL})$ was added dropwise while maintaining the temperature between $0-5{ }^{\circ} \mathrm{C}$. The resulting yellow solution was stirred under cold conditions for $10 \mathrm{~min}$ and poured into an ice-cold solution of conc. $\mathrm{H}_{3} \mathrm{PO}_{4}(44.0 \mathrm{~mL})$ in water $(3.3 \mathrm{~L})$. The resulting light-yellow solution was stirred for 10 min under cold conditions then boiled on a hotplate for $10 \mathrm{~min}$. After cooling the reaction mixture to room temperature, it was extracted with EtOAc $(3 \times)$ and the combined organic extracts washed with $2 \mathrm{M} \mathrm{NaOH}(\mathrm{aq})(2 \times)$. The aqueous extracts were acidified to $\mathrm{pH} 4 \mathrm{using}$ conc. $\mathrm{HCl}$ and the resulting solution was extracted with EtOAc $(2 \times)$. The combined organic extracts were washed with water $(1 \times)$ and brine $(1 \times)$, dried over $\mathrm{MgSO}_{4}$, and filtered. The resulting solution was concentrated under reduced pressure and the crude was purified on a silica column eluted with 75:25 hexanes:acetone to afford compound $8(4.13 \mathrm{~g}, 56 \%)$ as a light orange solid: mp $202.37{ }^{\circ} \mathrm{C} .{ }^{1} \mathrm{H}$ NMR (DMSO- $d_{6}, 500$ MHz): $\delta 10.17(\mathrm{~s}, 1 \mathrm{H}), 9.83(\mathrm{~s}, 1 \mathrm{H}), 7.32(\mathrm{~d}, J=2.8 \mathrm{~Hz}, 1 \mathrm{H}), 7.23(\mathrm{~d}, J=2.8 \mathrm{~Hz}, 1 \mathrm{H}), 7.19(\mathrm{~d}, J=2.8 \mathrm{~Hz}, 1 \mathrm{H}), 6.96(\mathrm{dd}$, $J=8.2,2.8 \mathrm{~Hz}, 1 \mathrm{H}), 6.85(\mathrm{~d}, J=8.2 \mathrm{~Hz}, 1 \mathrm{H}), 3.55(\mathrm{~s}, 3 \mathrm{H}), 3.46(\mathrm{~s}, 3 \mathrm{H}) .{ }^{13} \mathrm{C}\left\{{ }^{1} \mathrm{H}\right\}$ NMR (DMSO- $\left.d_{6}, 126 \mathrm{MHz}\right): \delta 166.2$, 166.0, 156.5, 132.9, 132.5, 132.1, 131.6, 130.4, 125.2, 121.8, 118.9, 116.0, 115.3, 51.9, 51.7. HRMS (ESI-Orbitrap) calcd for $\mathrm{C}_{16} \mathrm{H}_{13} \mathrm{BrO}_{6} \mathrm{Na}\left(\left[\mathrm{M}+\mathrm{Na}^{+}\right]\right) 402.9793$, found 402.9790 .

\section{Dimethyl 6-(trimethylsilyl)ethynyl-4,4'-dihydroxy-2,2'-biphenyldicarboxylate (9)}

A dry Schlenk vacuum tube containing 8 (1.03 g, $2.70 \mathrm{mmol}), \mathrm{Pd}\left(\mathrm{P}^{t} \mathrm{Bu}_{3}\right)_{2}(34.5 \mathrm{mg}, 67.5 \mu \mathrm{mol})$, and DABCO $(1.21 \mathrm{~g}$, $10.8 \mathrm{mmol})$ was evacuated and backfilled with argon $(3 \times)$. To this solid mixture was added TMS-acetylene $(573 \mu \mathrm{L}$, $4.05 \mathrm{mmol})$ and dry $\mathrm{MeCN}(10.8 \mathrm{~mL})$. The reaction mixture was degassed by three freeze-pump-thaw cycles and then stirred and heated at $50{ }^{\circ} \mathrm{C}$ using a silicone oil bath for $16 \mathrm{~h}$, cooled to room temperature, and filtered through a Celite pad. The filtrate was diluted with water, acidified to $\mathrm{pH} 4$ with $2 \mathrm{M} \mathrm{HCl}(\mathrm{aq})$, and extracted with EtOAc $(3 \times)$. The combined organic extracts were washed with water $(1 \times)$, brine $(1 \times)$, dried over $\mathrm{MgSO}_{4}$, and filtered. The resulting solution was concentrated under reduced pressure and the crude was purified on a silica column eluted with 75:25 hexanes:acetone to afford compound $9(441 \mathrm{mg}, 41 \%)$ as a pale yellow solid: $\mathrm{mp} 169.5{ }^{\circ} \mathrm{C} .{ }^{1} \mathrm{H}$ NMR (DMSO$\left.d_{6}, 500 \mathrm{MHz}\right): \delta 9.94(\mathrm{~s}, 1 \mathrm{H}), 9.70(\mathrm{~s}, 1 \mathrm{H}), 7.32(\mathrm{~d}, J=2.3 \mathrm{~Hz}, 1 \mathrm{H}), 7.21(\mathrm{~d}, J=2.3 \mathrm{~Hz}, 1 \mathrm{H}), 6.96-6.91(\mathrm{~m}, 2 \mathrm{H}), 6.85(\mathrm{~d}, J$ $=8.2 \mathrm{~Hz}, 1 \mathrm{H}), 3.53(\mathrm{~s}, 3 \mathrm{H}), 3.48(\mathrm{~s}, 3 \mathrm{H}),-0.05(\mathrm{~s}, 9 \mathrm{H}) .{ }^{13} \mathrm{C}\left\{{ }^{1} \mathrm{H}\right\}$ NMR (DMSO- $\left.d_{6}, 100 \mathrm{MHz}\right): \delta 166.6,166.3,156.3,155.5$, 136.5, 132.1, 131.4, 131.3, 130.4, 124.4, 120.6, 118.5, 116.6, 115.8, 103.8, 97.7, 51.8, 51.6, -0.5. HRMS (ESI-Orbitrap) calcd for $\mathrm{C}_{21} \mathrm{H}_{23} \mathrm{O}_{6} \mathrm{Si}\left(\left[\mathrm{M}+\mathrm{H}^{+}\right]\right) 399.1264$, found 399.1262 .

\section{Compound 10}

Dimethyl 6-(trimethylsilyl)ethynyl-4,4'-dihydroxy-2,2'-biphenyldicarboxylate 9 (680 $\mathrm{mg}, 1.70 \mathrm{mmol})$ in dry acetone $(40 \mathrm{~mL})$ was treated with $\mathrm{K}_{2} \mathrm{CO}_{3}(2.83 \mathrm{~g} .20 .47 \mathrm{mmol})$ followed by a solution of HxgOTs $(1.53,3.4 \mathrm{mmol})$ in dry acetone $(5 \mathrm{~mL})$. This mixture was heated to reflux using an aluminum bead bath under argon overnight, cooled to room temperature, and partitioned between brine and EtOAc. The aqueous layer was extracted with EtOAc $(3 \times)$ and the combined organic extracts were washed with brine (1×), dried over $\mathrm{MgSO}_{4}$, and filtered. The resulting solution was concentrated under reduced pressure and the crude was purified on a silica column eluted with 70:30 DCM:acetone to afford the compound $10(1.2 \mathrm{~g}, 71 \%)$ as a light yellow oil: ${ }^{1} \mathrm{H}$ NMR $\left(\mathrm{CDCl}_{3}, 500 \mathrm{MHz}\right): \delta 7.59(\mathrm{~d}$, 
$J=2.8 \mathrm{~Hz}, 1 \mathrm{H}), 7.51(\mathrm{~d}, J=2.8 \mathrm{~Hz}, 1 \mathrm{H}), 7.25(\mathrm{~d}, J=2.8 \mathrm{~Hz}, 1 \mathrm{H}), 7.08(\mathrm{dd}, J=8.3,2.7 \mathrm{~Hz}, 1 \mathrm{H}), 7.05(\mathrm{~d}, J=8.3 \mathrm{~Hz}$, $1 \mathrm{H}), 4.17-4.14(\mathrm{~m}, 4 \mathrm{H}), 3.93-3.86(\mathrm{~m}, 4 \mathrm{H}), 3.78-3.73(\mathrm{~m}, 4 \mathrm{H}), 3.73-3.63(\mathrm{~m}, 35 \mathrm{H}), 3.59(\mathrm{~s}, 3 \mathrm{H}), 3.57-3.53(\mathrm{~m}, 4 \mathrm{H}), 3.38$ (s, 6H), $2.86(\mathrm{~s}, 1 \mathrm{H}) .{ }^{13} \mathrm{C}\left\{{ }^{1} \mathrm{H}\right\}$ NMR $\left(\mathrm{CDCl}_{3}, 126 \mathrm{MHz}\right): \delta 166.79,166.75,157.7,156.9,138.2,133.4,131.7,131.1,130.5$, 124.0, 121.6, 118.2, 116.6, 115.2, 81.6, 81.0, 71.8, 70.81, 70.78, 70.55, 70.49, 70.47, 70.42, 69.59, 69.47, 69.6, 69.5, 67.7, 67.4, 58.9, 51.6, 51.8. HRMS (ESI-Orbitrap) calcd for $\mathrm{C}_{44} \mathrm{H}_{66} \mathrm{O}_{18} \mathrm{Na}\left(\left[\mathrm{M}+\mathrm{Na}^{+}\right]\right) 905.4147$, found 905.4108.

\section{Compound 11}

Compound 10 (984 mg, $1.11 \mathrm{mmol})$ was dissolved in $\mathrm{MeOH}(50 \mathrm{~mL})$ and the solution treated with Pd on activated carbon $(5 \% \mathrm{w} / \mathrm{w}, 100 \mathrm{mg})$. This mixture was stirred at room temperature under $\mathrm{H}_{2}(\mathrm{~g})$ overnight and filtered through Celite, washing the Celite pad with $\mathrm{MeOH}$. The filtrate was concentrated under reduced pressure and the crude purified on a silica column eluted with 70:30 DCM:acetone to afford compound $11(881.6 \mathrm{mg}, 89.6 \%)$ as a strawcolored oil: ${ }^{1} \mathrm{H} \mathrm{NMR}\left(\mathrm{CDCl}_{3}, 500 \mathrm{MHz}\right): \delta 7.55(\mathrm{~d}, J=2.8 \mathrm{~Hz}, 1 \mathrm{H}), 7.30(\mathrm{~d}, J=2.8 \mathrm{~Hz}, 1 \mathrm{H}), 7.06(\mathrm{dd}, J=8.2,2.8 \mathrm{~Hz}, 1 \mathrm{H})$, $7.01(\mathrm{~d}, J=2.8 \mathrm{~Hz}, 1 \mathrm{H}), 6.98(\mathrm{~d}, J=8.2 \mathrm{~Hz}, 1 \mathrm{H}), 4.22-4.16(\mathrm{~m}, 4 \mathrm{H}), 3.91-3.86(\mathrm{~m}, 4 \mathrm{H}), 3.77-3.72(\mathrm{~m}, 4 \mathrm{H}), 3.71-3.62(\mathrm{~m}$, $32 \mathrm{H}), 3.60(\mathrm{~s}, 3 \mathrm{H}), 3.56-3.52(\mathrm{~m}, 7 \mathrm{H}), 3.37(\mathrm{~s}, 6 \mathrm{H}), 2.27-2.16(\mathrm{~m}, 2 \mathrm{H}), 0.97(\mathrm{t}, J=7.6 \mathrm{~Hz}, 3 \mathrm{H}) .{ }^{13} \mathrm{C}\left\{{ }^{1} \mathrm{H}\right\} \mathrm{NMR}\left(\mathrm{CDCl}_{3}, 126\right.$ $\mathrm{MHz}): \delta 167.7,166.9,157.4,157.3,144.4,134.2,133.7,131.8,130.9,130.7,118.5,118.2,115.1,112.0,71.9,70.80,70.79$, 70.59, 70.54, 70.51, 70.45, 69.7, 69.6, 67.5, 67.4, 59.0, 51.8, 51.7, 26.4, 14.6. HRMS (ESI-Orbitrap) calcd for $\mathrm{C}_{44} \mathrm{H}_{70} \mathrm{O}_{18} \mathrm{Na}$ $\left(\left[\mathrm{M}+\mathrm{Na}^{+}\right]\right) 909.4460$, found 909.4427 .

\section{DP-Ac2}

Compound $10(1.0 \mathrm{~g}, 1.13 \mathrm{mmol})$ in THF $(30 \mathrm{~mL})$ was treated with $\mathrm{KOH}(\mathrm{aq})(2 \mathrm{M}, 11.3 \mathrm{~mL}, 22.6 \mathrm{mmol})$ and the resulting mixture was stirred and heated at reflux using an aluminum bead bath for $21 \mathrm{~h}$. This was concentrated under reduced pressure to remove THF and acidified with $2 \mathrm{M} \mathrm{HCl}(\mathrm{aq})$ to $\mathrm{pH} 2$. The resulting mixture was saturated with $\mathrm{NaCl}$ and extracted with EtOAc (5×). The combined organic extracts were washed with brine $(1 \times)$, dried over $\mathrm{MgSO}_{4}$, and filtered. The resulting solution was concentrated under reduced pressure and the crude was purified on a silica column eluted with 90:10 DCM:MeOH to afford DP-Ac2 (706 mg, 73\%) as a buff-colored oil: ${ }^{1} \mathrm{H}$ NMR $\left(\mathrm{CDCl}_{3}, 500 \mathrm{MHz}\right): \delta 7.45(\mathrm{~s}, 1 \mathrm{H}), 7.38(\mathrm{~d}, J=2.8 \mathrm{~Hz}, 1 \mathrm{H}), 7.17(\mathrm{~d}, J=2.8 \mathrm{~Hz}, 1 \mathrm{H}), 7.04-7.02(\mathrm{~m}, 2 \mathrm{H}), 4.23-4.15(\mathrm{~m}$, $4 \mathrm{H}), 3.89-3.83(\mathrm{~m}, 4 \mathrm{H}), 3.75-3.69(\mathrm{~m}, 4 \mathrm{H}), 3.69-3.59(\mathrm{~m}, 32 \mathrm{H}), 3.56-3.49(\mathrm{~m}, 4 \mathrm{H}), 3.36(\mathrm{~s}, 6 \mathrm{H}), 2.87(\mathrm{~s}, 1 \mathrm{H}) .{ }^{13} \mathrm{C}\left\{{ }^{1} \mathrm{H}\right\}$ NMR ( $\left.\mathrm{CDCl}_{3}, 126 \mathrm{MHz}\right): \delta$ 170.5, 170.1, 157.9, 157.2, 136.5, 133.9, 132.8, 132.0, 131.8, 124.2, 121.1, 117.8, 115.8, 114.9, 81.5, 81.3, 71.7, 70.73, 70.69, 70.46, 70.43, 70.38, 70.36, 70.34, 70.32, 70.30, 70.28, 70.26, 70.18, 70.17, 69.64, 69.56, 67.8, 67.5, 58.9. HRMS (ESI-Orbitrap) calcd for $\mathrm{C}_{42} \mathrm{H}_{62} \mathrm{O}_{18} \mathrm{Na}\left(\left[\mathrm{M}+\mathrm{Na}^{+}\right]\right)$877.3834, found 877.3825.

\section{DP-Ac3}

Compound $11(881.6 \mathrm{mg}, 0.99 \mathrm{mmol})$ in THF $(26 \mathrm{~mL})$ and $\mathrm{MeOH}(5 \mathrm{~mL})$ was treated with $2 \mathrm{M} \mathrm{KOH}(\mathrm{aq})(12.4 \mathrm{~mL}$, $24.8 \mathrm{mmol}$ ) and the resulting mixture was stirred and heated at reflux using an aluminum bead bath for $1 \mathrm{~h}$. The mixture was concentrated under reduced pressure and acidified with $2 \mathrm{M} \mathrm{HCl}(\mathrm{aq})$ to $\mathrm{pH}$ 2. The resulting mixture was saturated with $\mathrm{NaCl}$ and extracted with EtOAc $(5 \times)$. The combined organic extracts were washed with brine $(1 \times)$, dried over $\mathrm{MgSO}_{4}$, and filtered. The resulting solution was concentrated under reduced pressure and the crude purified on a silica column eluted with 90:10 DCM:MeOH to afford DP-Ac3 (440 mg, 52\%) as a buff-colored oil: ${ }^{1} \mathrm{H}$ NMR $\left(\mathrm{CDCl}_{3}, 500 \mathrm{MHz}\right): \delta 7.29(\mathrm{~d}, J=2.2 \mathrm{~Hz}, 1 \mathrm{H}), 7.10(\mathrm{~d}, J=2.2 \mathrm{~Hz}, 1 \mathrm{H}), 6.96(\mathrm{dd}, J=8.1,2.20 \mathrm{~Hz}, 1 \mathrm{H}), 6.92(\mathrm{~d}, J$ $=8.1 \mathrm{~Hz}, 1 \mathrm{H}), 6.89(\mathrm{~d}, J=2.2 \mathrm{~Hz}, 1 \mathrm{H}), 4.18-4.13(\mathrm{~m}, 4 \mathrm{H}), 3.87-3.82(\mathrm{~m}, 4 \mathrm{H}), 3.73-3.69(\mathrm{~m}, 4 \mathrm{H}), 3.67-3.58(\mathrm{~m}, 32 \mathrm{H})$, 3.53-3.50 (m, 4H), $3.35(\mathrm{~s}, 6 \mathrm{H}), 2.22-2.08(\mathrm{~m}, 2 \mathrm{H}), 0.95(\mathrm{t}, J=7.34 \mathrm{~Hz}, 3 \mathrm{H}) .{ }^{13} \mathrm{C}\left\{{ }^{1} \mathrm{H}\right\} \mathrm{NMR}\left(\mathrm{CDCl}_{3}, 126 \mathrm{MHz}\right): \delta 174.4$, 174.2, 157.7, 144.7, 139.6, 139.2, 131.5, 130.0, 129.5, 115.6, 115.5, 112.9, 110.0, 71.39, 71.37, 70.4, 70.0, 69.98, 69.93, 69.87, 69.68, 69.63, 69.59, 69.52, 67.3, 67.2, 58.80, 58.79, 26.4, 15.0. HRMS (ESI-Orbitrap) calcd for $\mathrm{C}_{42} \mathrm{H}_{66} \mathrm{O}_{18} \mathrm{Na}\left(\left[\mathrm{M}+\mathrm{Na}^{+}\right]\right)$ 881.4147 , found 881.4145 .

\section{Independent Synthesis of Anhydrides}

DP-An1

DP-Ac1 $(50 \mathrm{mg}, 0.06 \mathrm{mmol})$ was treated with $\mathrm{CCl}_{4}(1 \mathrm{~mL})$ and dicyclohexyl carbodiimide (DCC) (18.5 mg, 0.09 $\mathrm{mmol}$ ). This mixture was stirred at room temperature for $1 \mathrm{~h}$. The resulting solution was filtered and concentrated under reduced pressure. The crude was purified by semi-preparative GPC (toluene as eluent, $5 \mathrm{~mL} / \mathrm{min}$ ) to afford DP-An1 (15.6 mg, 32\%) as a yellow oil: ${ }^{1} \mathrm{H} \mathrm{NMR}\left(\mathrm{CDCl}_{3}, 500 \mathrm{MHz}\right): \delta 7.50(\mathrm{~d}, J=8.7 \mathrm{~Hz}, 2 \mathrm{H}), 7.31(\mathrm{~d}, J=2.8 \mathrm{~Hz}, 2 \mathrm{H})$, $7.25(\mathrm{dd}, J=8.7,2.8 \mathrm{~Hz}, 2 \mathrm{H}), 4.24-4.20(\mathrm{~m}, 4 \mathrm{H}), 3.92-3.88(\mathrm{~m}, 4 \mathrm{H}), 3.76-3.72(\mathrm{~m}, 4 \mathrm{H}), 3.71-3.62(\mathrm{~m}, 32 \mathrm{H}), 3.57-3.53$ 
(m, 4H), $3.38(\mathrm{~s}, 6 \mathrm{H}) .{ }^{13} \mathrm{C}\left\{{ }^{1} \mathrm{H}\right\} \mathrm{NMR}\left(\mathrm{CDCl}_{3}, 126 \mathrm{MHz}\right): \delta$ 162.7, 158.6, 130.7, 130.1, 127.9, 121.07, 115.17, 71.90, 70.88, 70.62, 70.60, 70.57, 70.55, 70.53, 70.48, 69.46, 68.0, 59.0. HRMS (ESI-Orbitrap) calcd for $\mathrm{C}_{40} \mathrm{H}_{60} \mathrm{O}_{17} \mathrm{Na}\left(\left[\mathrm{M}+\mathrm{Na}^{+}\right]\right)$ 835.3728 , found 835.3691 .

\section{DP-An2}

DP-Ac2 $(50 \mathrm{mg}, 0.058 \mathrm{mmol})$ was treated with $\mathrm{CHCl}_{3}\left(1 \mathrm{~mL}\right.$, passed through basic $\left.\mathrm{Al}_{2} \mathrm{O}_{3}\right)$ and dicyclohexyl carbodiimide (DCC) $(18.1 \mathrm{mg}, 0.088 \mathrm{mmol})$ and this mixture was stirred at room temperature for $1 \mathrm{~h}$. The resulting solution was cooled in the freezer overnight, filtered, and concentrated under reduced pressure. The crude was purified by semi-preparative GPC (toluene as eluent, $5 \mathrm{~mL} / \mathrm{min}$ ) to afford the DP-An2 as a mixture with the starting acid (DP-An2 was the major component) $(13.2 \mathrm{mg}, 19 \%)$ as a yellow oil: ${ }^{1} \mathrm{H}$ NMR $\left(\mathrm{CDCl}_{3}, 500 \mathrm{MHz}\right): \delta 7.90(\mathrm{~d}, J=$ $8.7 \mathrm{~Hz}, 1 \mathrm{H}), 7.39(\mathrm{~d}, J=2.8 \mathrm{~Hz}, 1 \mathrm{H}), 7.27-7.24(\mathrm{~m}, 2 \mathrm{H}), 7.17(\mathrm{dd}, J=8.7,2.8 \mathrm{~Hz}, 1 \mathrm{H}), 4.26-4.14(\mathrm{~m}, 4 \mathrm{H}), 3.92-3.85$ (m, 4H), 3.76-3.58 (m, 36H), 3.57-3.50 (m, 4H), $3.37(\mathrm{~s}, 6 \mathrm{H}), 3.14(\mathrm{~s}, 1 \mathrm{H}) .{ }^{13} \mathrm{C}\left\{{ }^{1} \mathrm{H}\right\} \mathrm{NMR}\left(\mathrm{CDCl}_{3}, 126 \mathrm{MHz}\right): \delta 162.6$, 162.5, 158.8, 157.7, 133.3, 133.0, 131.6, 129.3, 125.03, 125.01, 123.0, 119.1, 116.0, 114.4, 82.1, 71.9, 70.89, 70.86, 70.58, 70.53, 70.51, 70.44, 70.37, 70.28, 69.43, 69.37, 68.2, 67.9, 58.98, 58.91. HRMS (ESI-Orbitrap) calcd for $\mathrm{C}_{42} \mathrm{H}_{60} \mathrm{O}_{17} \mathrm{Na}$ $\left(\left[\mathrm{M}+\mathrm{Na}^{+}\right]\right) 859.3728$, found 859.3719 .

\section{DP-An3}

The procedure for DP-An2 was followed using DP-Ac3 $(42 \mathrm{mg}, 0.058 \mathrm{mmol}$ ) to afford DP-Ac3 ( $6.2 \mathrm{mg})$ as a yellow oil as a mixture with an unknown compound: ${ }^{1} \mathrm{H}$ NMR $\left(\mathrm{CDCl}_{3}, 500 \mathrm{MHz}\right)$ (Figure S43) and ${ }^{13} \mathrm{C}\left\{{ }^{1} \mathrm{H}\right\} \mathrm{NMR}$ spectroscopy $\left(\mathrm{CDCl}_{3}, 126 \mathrm{MHz}\right)$ (S44) support the formation of the title compound (see Figures S43 and S44). HRMS (ESI-Orbitrap) calcd for $\mathrm{C}_{42} \mathrm{H}_{64} \mathrm{O}_{17} \mathrm{Na}\left(\left[\mathrm{M}+\mathrm{Na}^{+}\right]\right)$863.4041, found 863.4042.

\section{IR Spectroscopy of DP-Ac1}

DP-Ac1 (415.46 mg, $0.5 \mathrm{mmol}, 1.0 \mathrm{eq})$ was dissolved in water $(4.0 \mathrm{~mL})$. EDC (48 $\mathrm{mg}, 0.25 \mathrm{mmol}, 0.5 \mathrm{eq})$ was dissolved separately in water $(1 \mathrm{~mL})$. Both solutions were chilled in an ice bath before mixing. The two solutions were mixed $(t=0)$ and immediately monitored using a ReactIR 15 IR spectrometer, with stirring and keeping a constant temperature $(278 \mathrm{~K})$. The background spectrum of water was subtracted from each spectrum. The peak at $1775 \mathrm{~cm}^{-1}$ is assigned to the symmetric stretch of the anhydride and the peak at $1738 \mathrm{~cm}^{-1}$ is assigned to the asymmetric stretch of the anhydride. The peak(s) at $\sim 1700 \mathrm{~cm}^{-1}$ correspond(s) to both the acid and the EDC; after an initial decrease, this peak grows back in. The peaks at $1573 \mathrm{~cm}^{-1}$ and $1607 \mathrm{~cm}^{-1}$ correspond to the urea.

\section{Reaction monitoring by ${ }^{1} \mathrm{H}$ NMR spectroscopy \\ Reactions for DP-Ac1 in $\mathrm{D}_{2} \mathrm{O}$}

The reactions were monitored by ${ }^{1} \mathrm{H}$ NMR spectroscopy $(600 \mathrm{MHz})$. All concentrations were referenced to the methyl peak of the acetyl group of $\mathrm{N}, \mathrm{N}$-dimethylacetamide (DMA), included as an internal standard (this peak was also used to calibrate the chemical shift scale). Stock solutions $(5.00 \mathrm{~mL})$ were prepared for DP-Ac1 (37.5 mM) with DMA (37.5 mM). The pD of the solution was adjusted depending on the specific experiment being run. A separate solution of EDC in $\mathrm{D}_{2} \mathrm{O}$ was also prepared at such a concentration that $200 \mu \mathrm{L}$ would deliver the target stoichiometry.

\section{Reactions for DP-Ac1, DP-Ac2, and DP-Ac3 in $\mathrm{D}_{2} \mathrm{O}$ :acetone- $d_{6}$}

The reactions were monitored by ${ }^{1} \mathrm{H}$ NMR spectroscopy $(600 \mathrm{MHz})$. All concentrations were referenced to the methylene peak of the ethylene carbonate, included as an internal standard (this peak was also used to calibrate the chemical shift scale). Stock solutions $(5.00 \mathrm{~mL})$ were prepared for the appropriate carboxylic acid $(37.5 \mathrm{mM})$ and ethylene carbonate $(37.5 \mathrm{mM})$. A separate solution of EDC in $\mathrm{D}_{2} \mathrm{O}$ :acetone- $d_{6}$ was also prepared at such a concentration that $200 \mu \mathrm{L}$ would deliver the target stoichiometry.

For all NMR experiments, all of the solutions were cooled in an ice bath until immediately before beginning a run. The NMR spectrometer was locked and shimmed on a $600 \mu \mathrm{L}$ sample of the stock solution $(25 \mathrm{mM}$, after being equilibrated at the appropriate temperature). For each run, a standard NMR tube was charged with $400 \mu \mathrm{L}$ of the acid-containing solution, then treated with $200 \mu \mathrm{L}$ of the EDC solution. The reaction mixture was quickly mixed, inserted into the spectrometer, and acquisition started. The time of first mixing was taken as $t=0$. Each time point constitutes a single scan, with the time taken as the midpoint of acquisition. 


\section{IR spectroscopy}

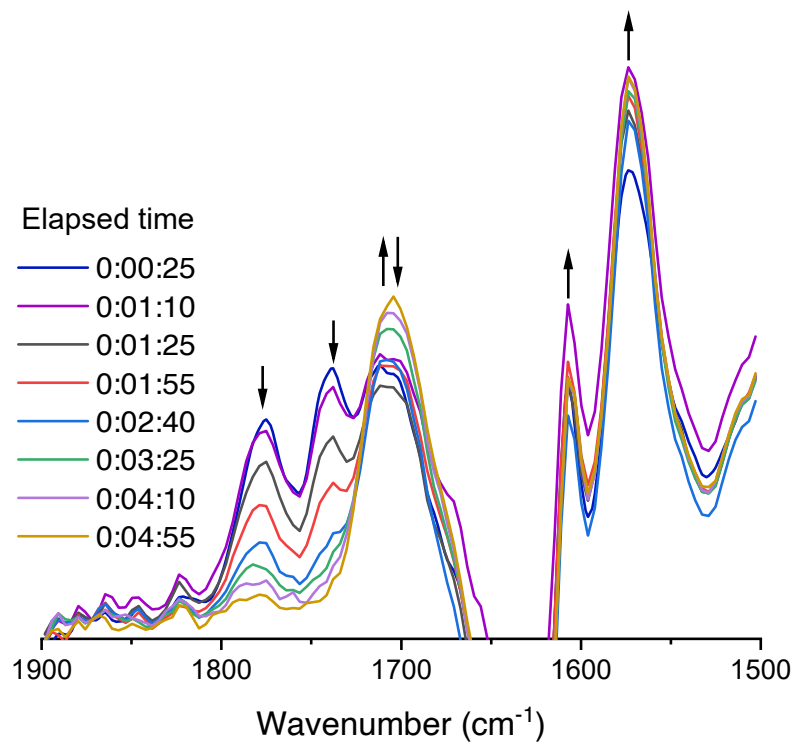

Figure S1. IR spectroscopy (absorbance) of DP-An1 formation on the treatment of DP-Ac1 (100 mM) with $\mathrm{EDC}\left(0.5\right.$ equiv) in $\mathrm{H}_{2} \mathrm{O}$ at $278 \mathrm{~K}$.

\section{Multiple injections}

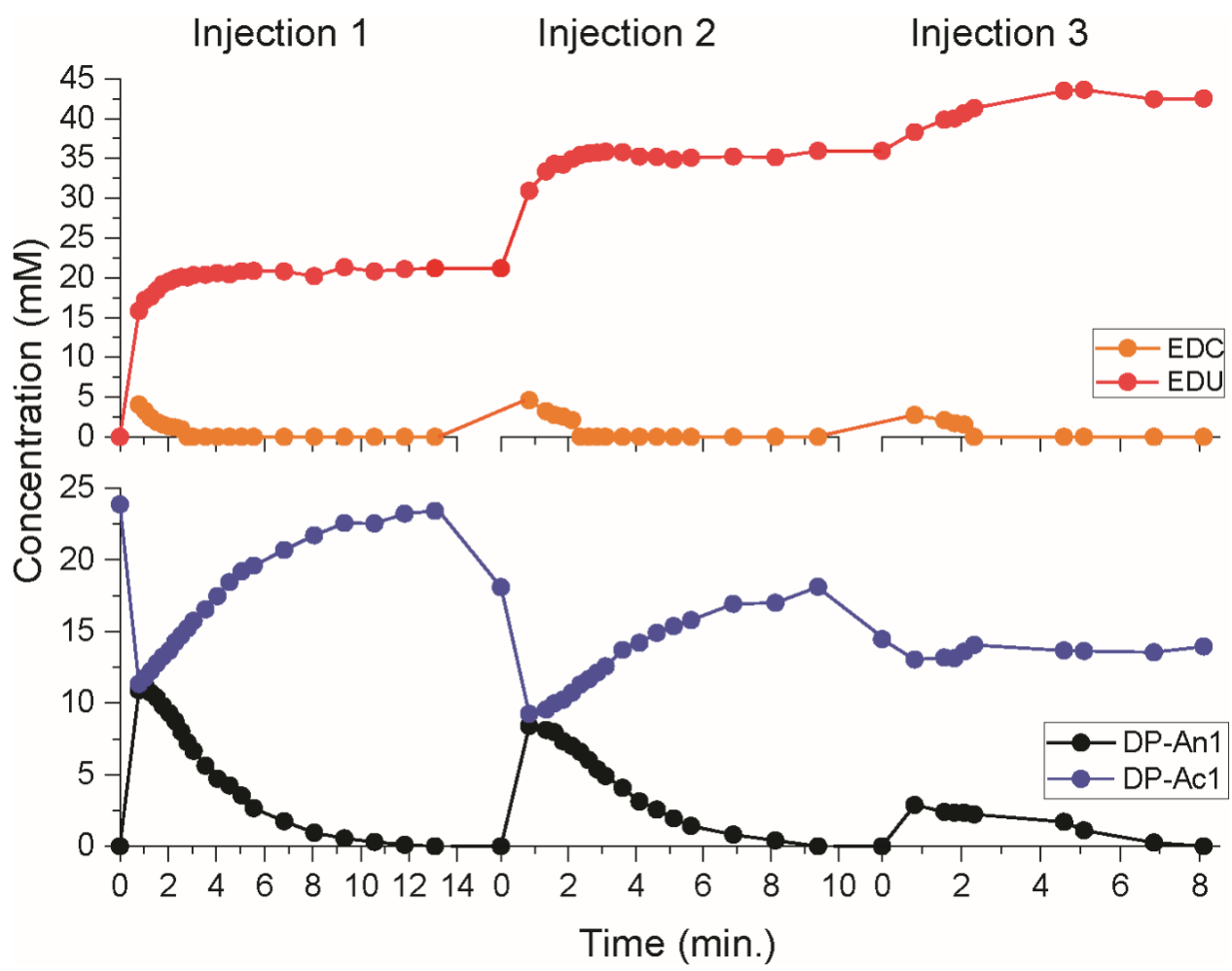

Figure S2. Refueling of the DP-Ac1/DP-An1 system (25 mM, EDC 1 equiv., $\mathrm{D}_{2} \mathrm{O}$ /acetone- $d_{6}$ 7:3, $\left.276 \mathrm{~K}\right)$. Note that the reaction mixtures are diluted at each step upon addition of $200 \mu \mathrm{L}$ EDC (from 0.60 to $0.80 \mathrm{~mL}$ to $1.00 \mathrm{~mL}$ ), hence the drops in concentration at each step. 


\section{DFT geometry optimizations}

For simplicity, the hexyloxy groups were removed for geometry optimizations, giving structures DP-Ac1', DPAn1', etc.

(a)

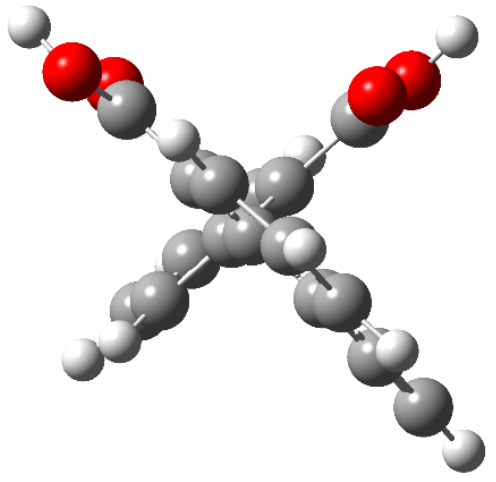

(b)

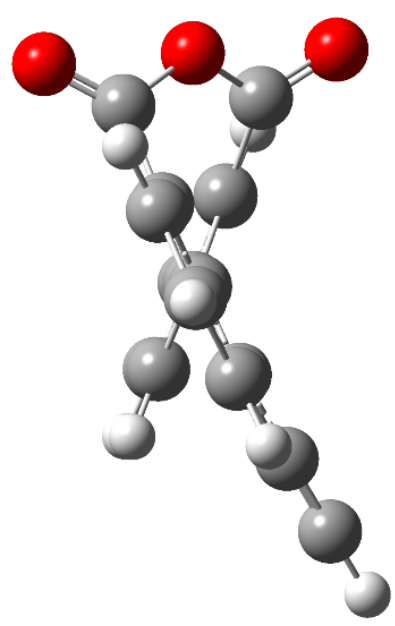

Figure S3. Optimized geometries of (a) DP-Ac2' and (b) DP-An2' at the B97-D3(BJ)/TZV(2d,2p) level and viewed down the biaryl axis.

(a)

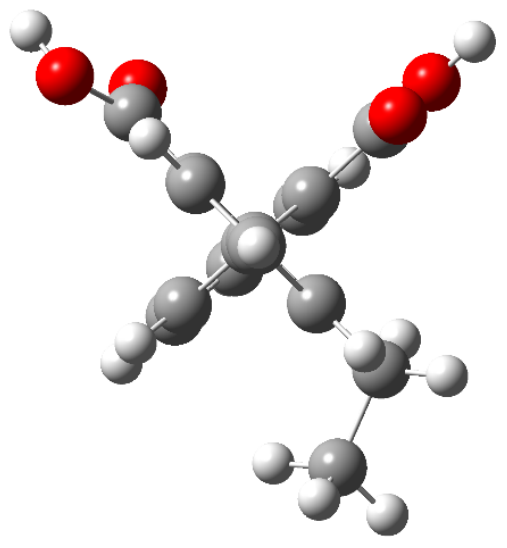

(b)

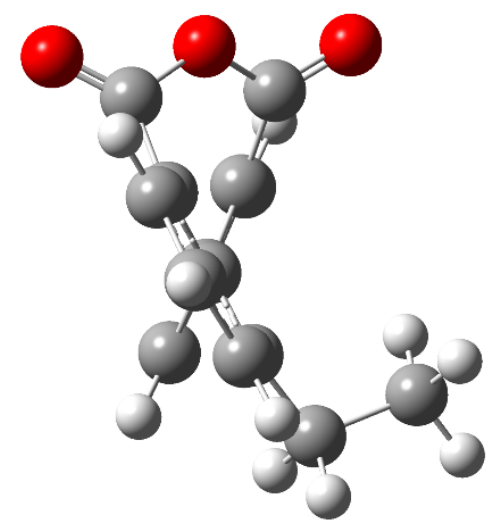

Figure S4. Optimized geometries of (a) DP-Ac3' and (b) DP-An3' at the B97-D3(BJ)/TZV(2d,2p) level and viewed down the biaryl axis.

All three possible orientations of the acid groups in DP-Ac1 were explicitly optimized. The "out-out" orientation (H's directed outwards) was found to be the most stable. Similarly, the two possible orientations of the ethyl group in DP-Ac3 were explicitly considers (most stable orientation shown in Figure S4). Cartesian coordinates for the optimized geometries are provided in a separate plain text file. 


\begin{tabular}{lrr}
\hline Structure & Energy $\left(E_{h}\right)$ & IF \\
\hline DP-Ac1' & -840.234778 & 0 \\
DP-An1' $^{\prime}$ & -763.780878 & 0 \\
DP-Ac2' $^{\prime}$ & -916.353402 & 0 \\
DP-An2' $^{\prime}$ & -839.896053 & 0 \\
DP-Ac3' $^{\prime}$ & -918.844795 & 0 \\
DP-An3' $^{\prime}$ & -842.386079 & 0 \\
\hline
\end{tabular}

Table S1. Data for geometry optimizations (B97-D3(BJ)/TZV(2d,2p)). IF = number of imaginary frequencies.

For the acid systems, the geometries were confirmed to be the sole minima with respect to rotation about the biaryl bond by generating PES scans for all three systems (also at the B97-D3(BJ)/TZV(2d,2p) level).

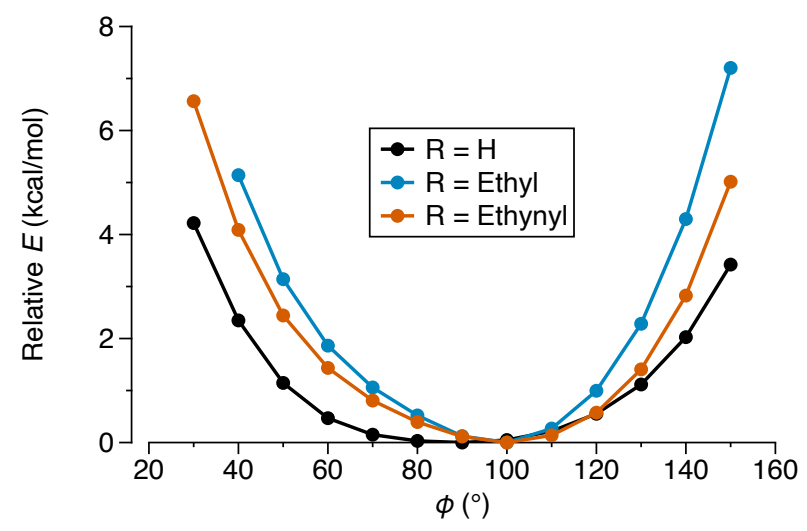

Figure S5. PES scans for DP-Ac1', DP-Ac2', and DP-Ac3' with respect to rotation about the biaryl bond ( $\varphi$ $=0$ corresponds to eclipsed $\mathrm{CO}_{2} \mathrm{H}$ groups). 


\section{Typical spectra for kinetic runs}

DP-Ac1/DP-An1 system in $D_{2} \mathrm{O}$

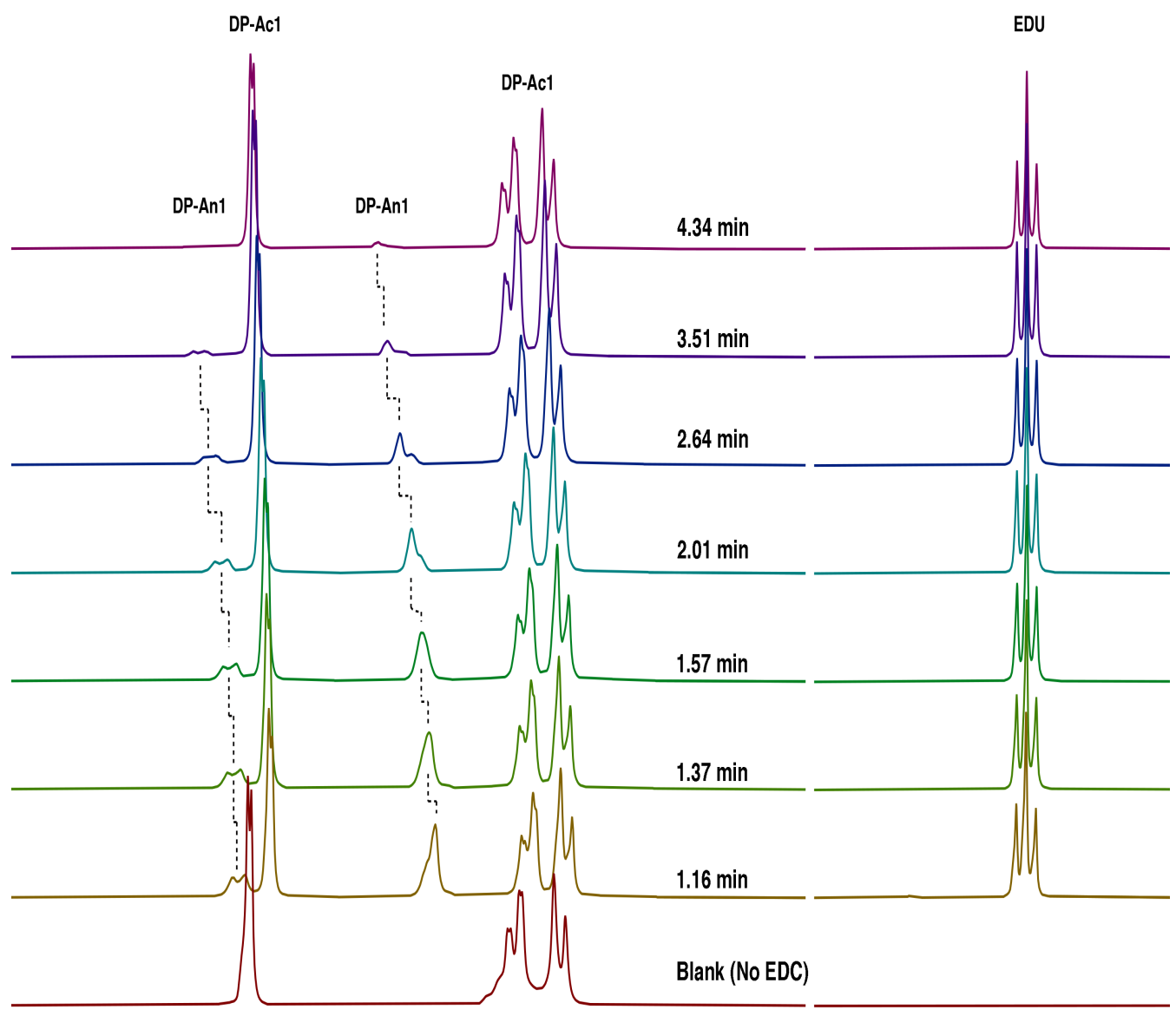

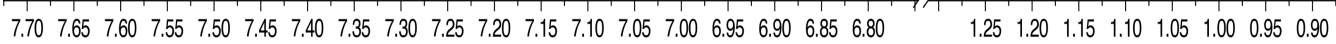
Chemical Shift (ppm)

Figure S6. ${ }^{1} \mathrm{H}$ NMR spectra of DP-An1 formation from DP-Ac1 treated with 0.5 eq. of EDC at $276 \mathrm{~K}$ in $\mathrm{D}_{2} \mathrm{O}$.

The spectra in Figure S6 show only EDU in the aliphatic region and no signals for EDC, which is an essential piece of concentration data to use our kinetic model. To slow down the EDC consumption, we initially tried increasing the starting EDC concentration (see Figure S7). 


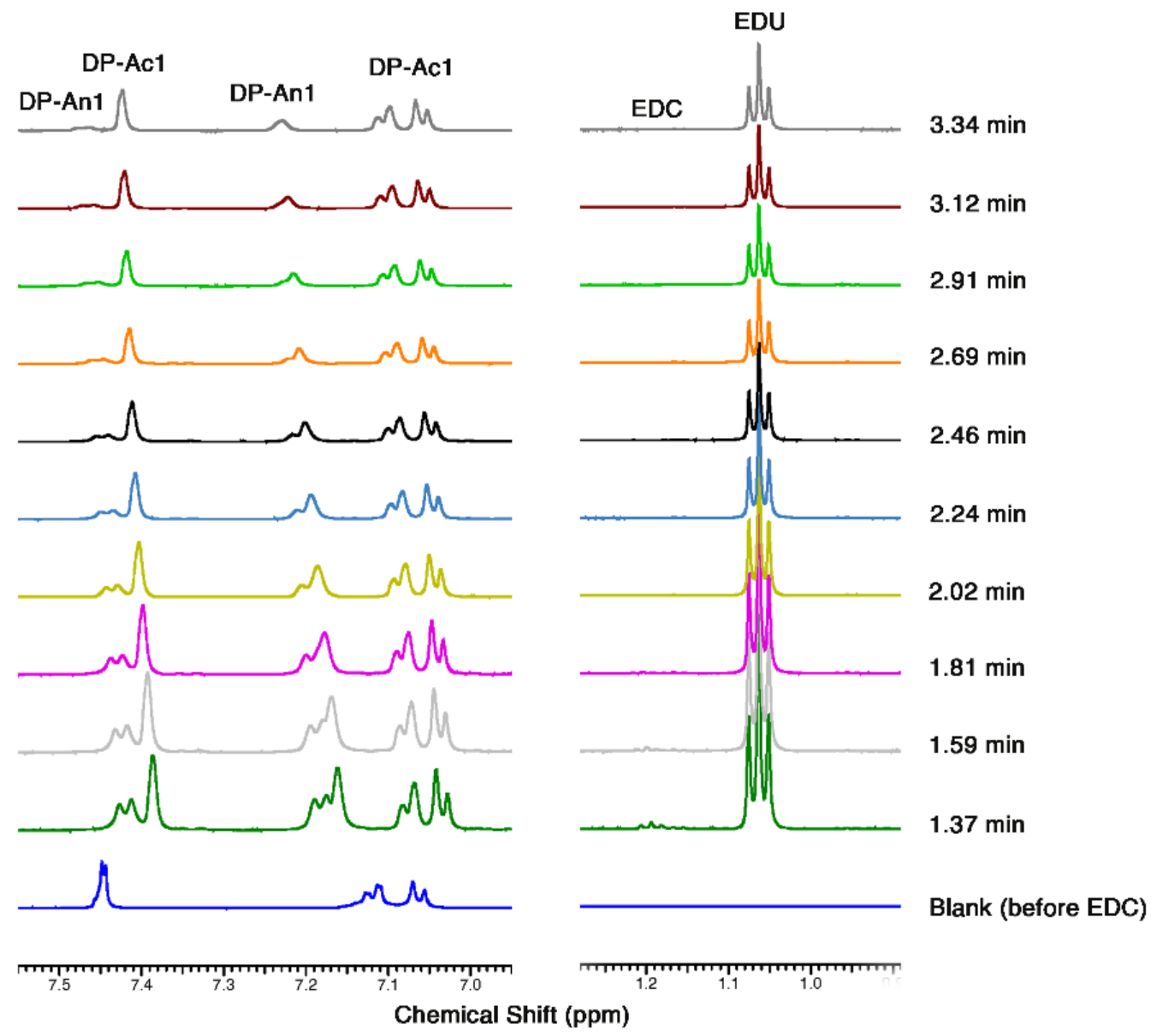

Figure S7. ${ }^{1} \mathrm{H}$ NMR spectra of DP-An1 formation from DP-Ac1 treated with 1 eq. of EDC at $276 \mathrm{~K}$.

Increasing the starting EDC concentration did not yield satisfactory results as shown in Figure S10. Instead, starting with a higher pD (4.5) slowed the rate of EDC hydration (see Figure S8). 


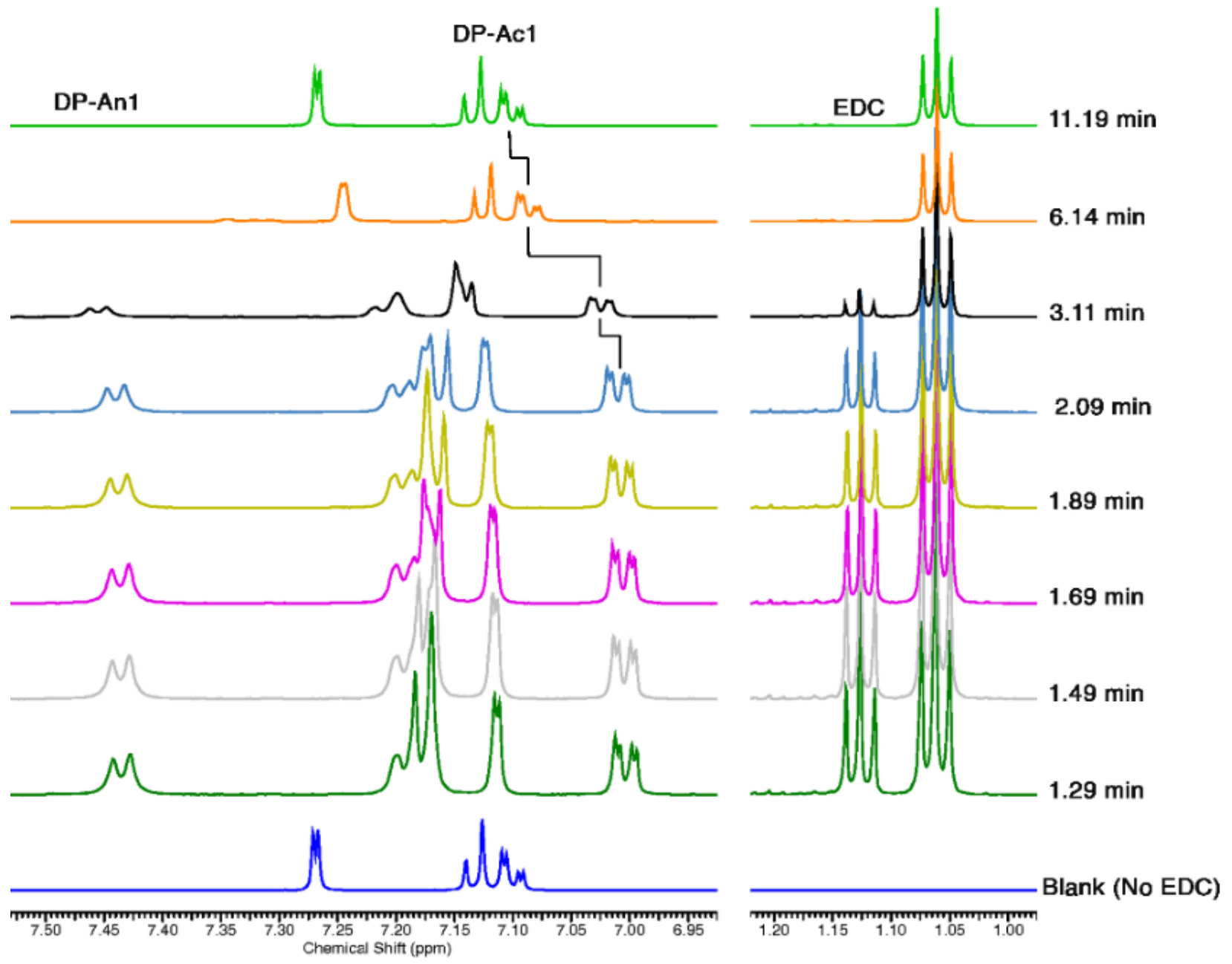

Figure S8. ${ }^{1} \mathrm{H}$ NMR spectra of DP-An1 formation from DP-Ac1 treated with 1.5 eq. of EDC after adjusting the initial $\mathrm{pD}$ to 4.5 at $276 \mathrm{~K}$. 


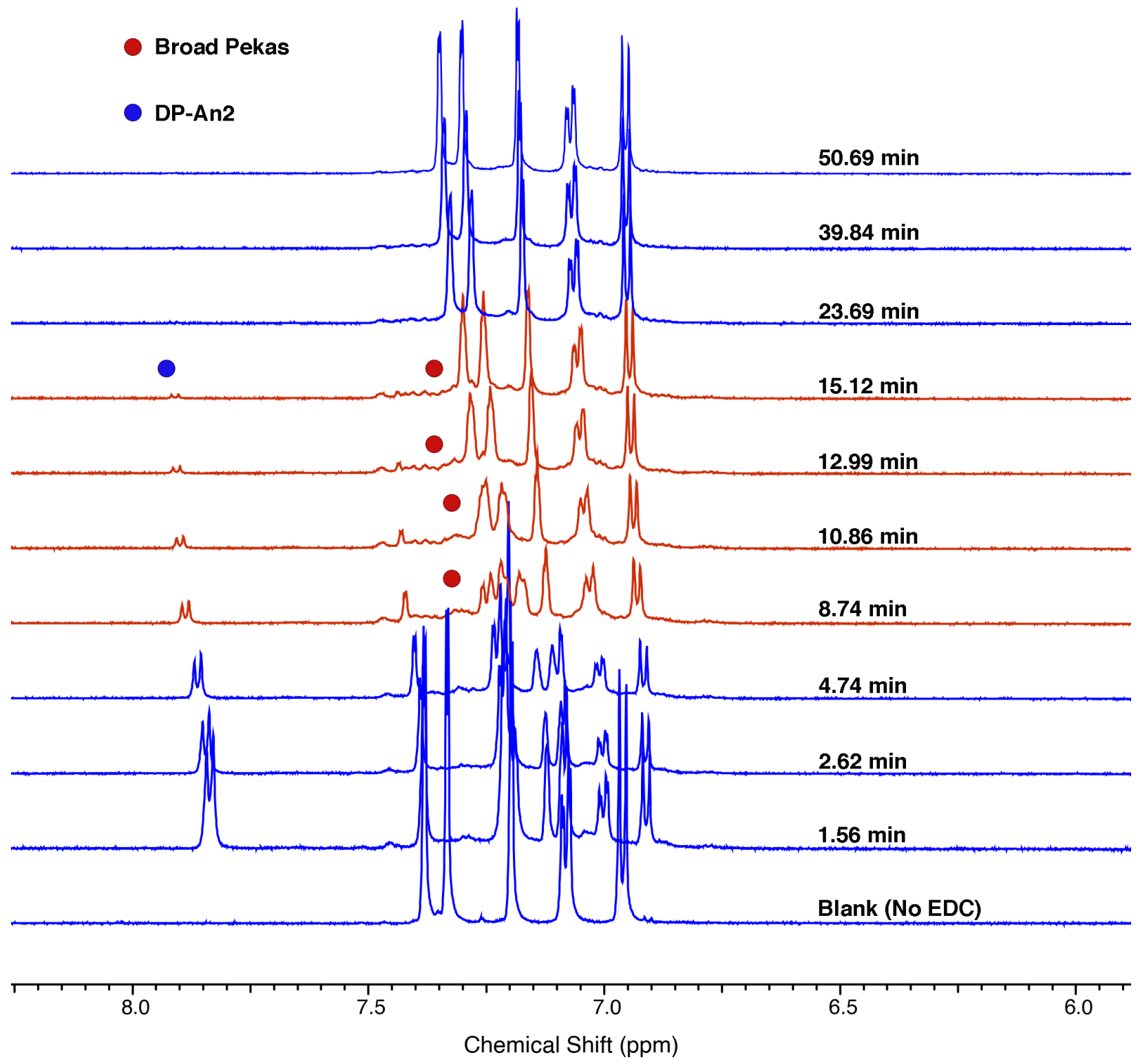

Figure S9. Appearance and disappearance of minor broad peaks in DP-Ac2/DP-An2 system. Spectra were recorded after treatment of DP-Ac2 with EDC 2.0 eq. in $\mathrm{D}_{2} \mathrm{O}$ acetone- $d_{6}$ at $276 \mathrm{~K}$. 


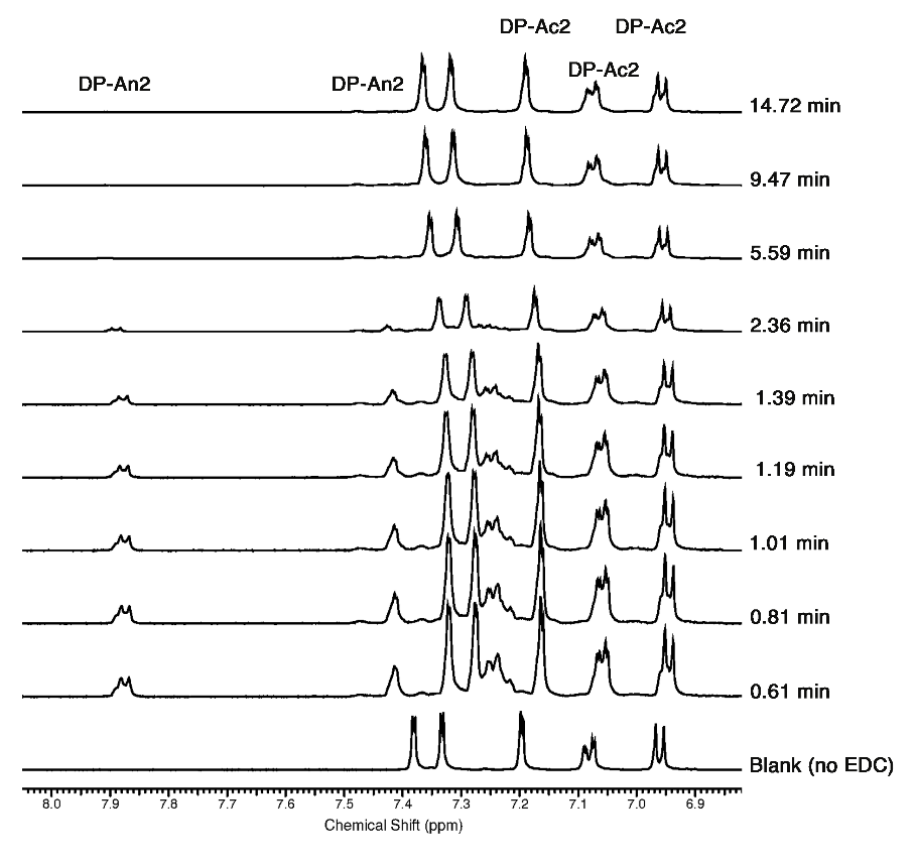

Figure S10. ${ }^{1} \mathrm{H}$ NMR spectra of DP-An2 formation from DP-Ac2 acquired during a typical kinetic run.

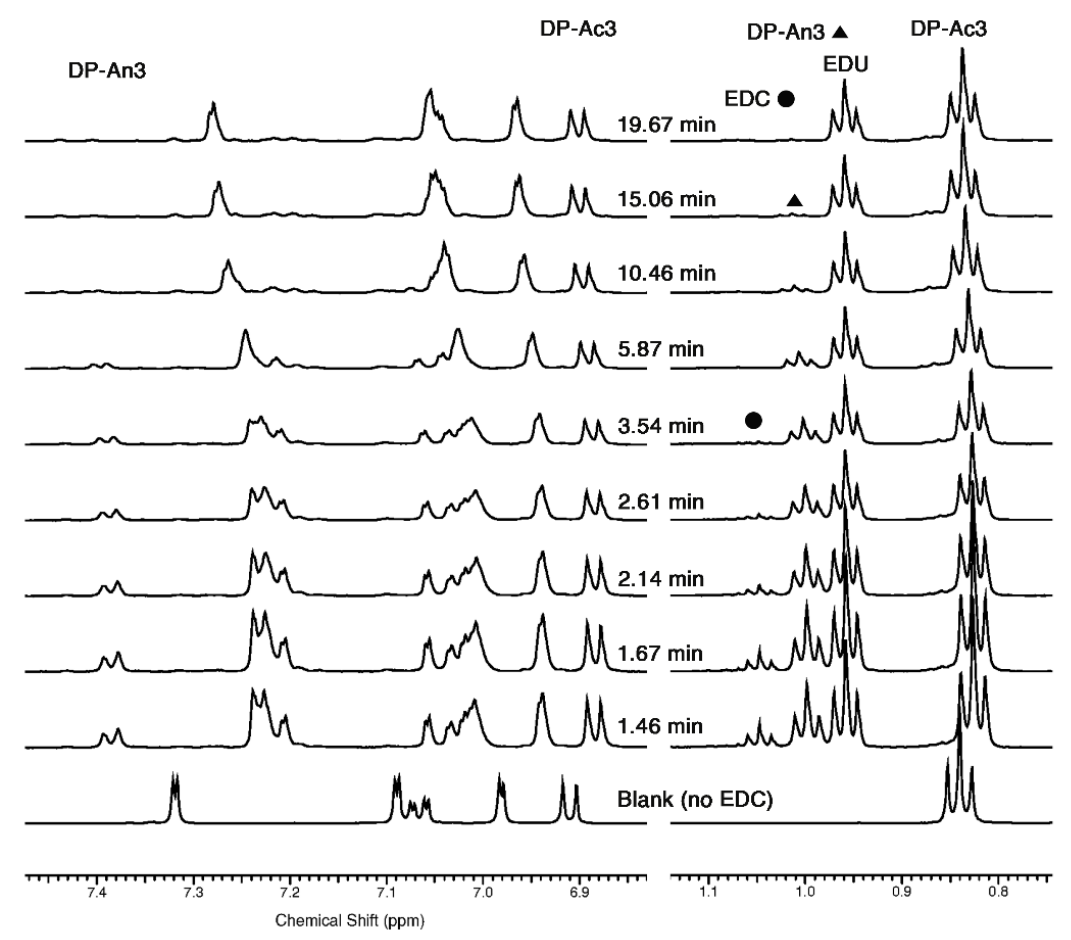

Figure S11. ${ }^{1} \mathrm{H}$ NMR spectra of DP-An3 formation from DP-Ac3 acquired during a typical kinetic run.

\section{Data Fitting}

As stated in the manuscript, the kinetic data were fit to the following mechanism: 


$$
\begin{aligned}
& \mathrm{DA}+\mathrm{EDC} \stackrel{k_{1}}{\rightarrow} \mathrm{I} \\
& \mathrm{I} \stackrel{k_{i}^{\mathrm{An}}}{\longrightarrow} \mathrm{An}+\mathrm{EDU} \\
& \mathrm{I} \stackrel{k_{i}^{\mathrm{DA}}}{\longrightarrow} \mathrm{DA}+\mathrm{EDU} \\
& \mathrm{An} \stackrel{k_{2}}{\longrightarrow} \mathrm{DA}
\end{aligned}
$$

Where DA is the acid, An is the anhydride, and I is the O-acylisourea intermediate, E is EDC, and EDU is the urea. The system is therefore described by the following set of differential equations:

$$
\begin{aligned}
\frac{d[\mathrm{DA}]}{\mathrm{d} t} & =-k_{1}[\mathrm{DA}][\mathrm{EDC}]+k_{i}^{\mathrm{DA}}[\mathrm{I}]+k_{2}[\mathrm{An}] \\
\frac{d[\mathrm{An}]}{\mathrm{d} t} & =+k_{i}^{\mathrm{An}}[\mathrm{I}]-k_{2}[\mathrm{An}] \\
\frac{d[\mathrm{I}]}{\mathrm{d} t} & =+k_{1}[\mathrm{DA}][\mathrm{E}]-k_{i}^{\mathrm{An}}[\mathrm{I}]-k_{i}^{\mathrm{DA}}[\mathrm{I}] \\
\frac{d[\mathrm{E}]}{\mathrm{d} t} & =-k_{1}[\mathrm{DA}][\mathrm{E}] \\
\frac{d[\mathrm{U}]}{\mathrm{d} t} & =+k_{i}^{\mathrm{An}}[\mathrm{I}]+k_{i}^{\mathrm{DA}}[\mathrm{I}]
\end{aligned}
$$

Assuming a steady-state in [I], we can derive:

$$
\begin{aligned}
\frac{d[\mathrm{DA}]}{\mathrm{d} t} & =-k_{1}[\mathrm{DA}][\mathrm{E}]+k_{2}[\mathrm{An}]+\frac{k_{1} \alpha[\mathrm{DA}][\mathrm{E}]}{1+\alpha} \\
\frac{d[\mathrm{An}]}{\mathrm{d} t} & =+\frac{k_{1}[\mathrm{DA}][\mathrm{E}]}{1+\alpha}-k_{2}[\mathrm{An}] \\
\frac{d[\mathrm{E}]}{\mathrm{d} t} & =-k_{1}[\mathrm{DA}][\mathrm{E}] \\
\frac{d[\mathrm{U}]}{\mathrm{d} t} & =+k_{1}[\mathrm{DA}][\mathrm{E}]
\end{aligned}
$$

where $\alpha=\frac{k_{i}^{\mathrm{Ac}}}{k_{i}^{\mathrm{An}}}$.

The "yield" in the main text refers to the total quantity of anhydride produced [An] net relative to the amount of EDC added $[\mathrm{EDC}]_{0} \cdot{ }^{3}$ The $[\mathrm{An}]_{\text {net }}$ cannot be observed directly, but it can be calculated for a particular set of starting concentrations using the kinetic parameters from a mechanistic simulation. For the above-described mechanism $[\mathrm{An}]_{\mathrm{net}}$, is given by either:

$$
\begin{aligned}
& {[\mathrm{An}]_{\mathrm{net}}=\int_{0}^{\infty} k_{1}[\mathrm{DA}][\mathrm{E}]\left[\frac{1-\alpha}{1+\alpha}\right] \mathrm{dt}} \\
& {[\mathrm{An}]_{\mathrm{net}}=\int_{0}^{\infty} k_{2}[\mathrm{An}] \mathrm{dt}}
\end{aligned}
$$

These two expressions above represent the total anhydride formed or destroyed, respectively.

The above data fitting was done using a custom program written in Python 3 (kinmodel). The features of this program and the resulting data simulations are discussed in our previous work. ${ }^{3}$ A copy of the version used for the current work is included separately. The code continues to be developed by our group, with the most recent version available on Github (https:/github.com/scotthartley/kinmodel). 


\section{Kinetics experiments}
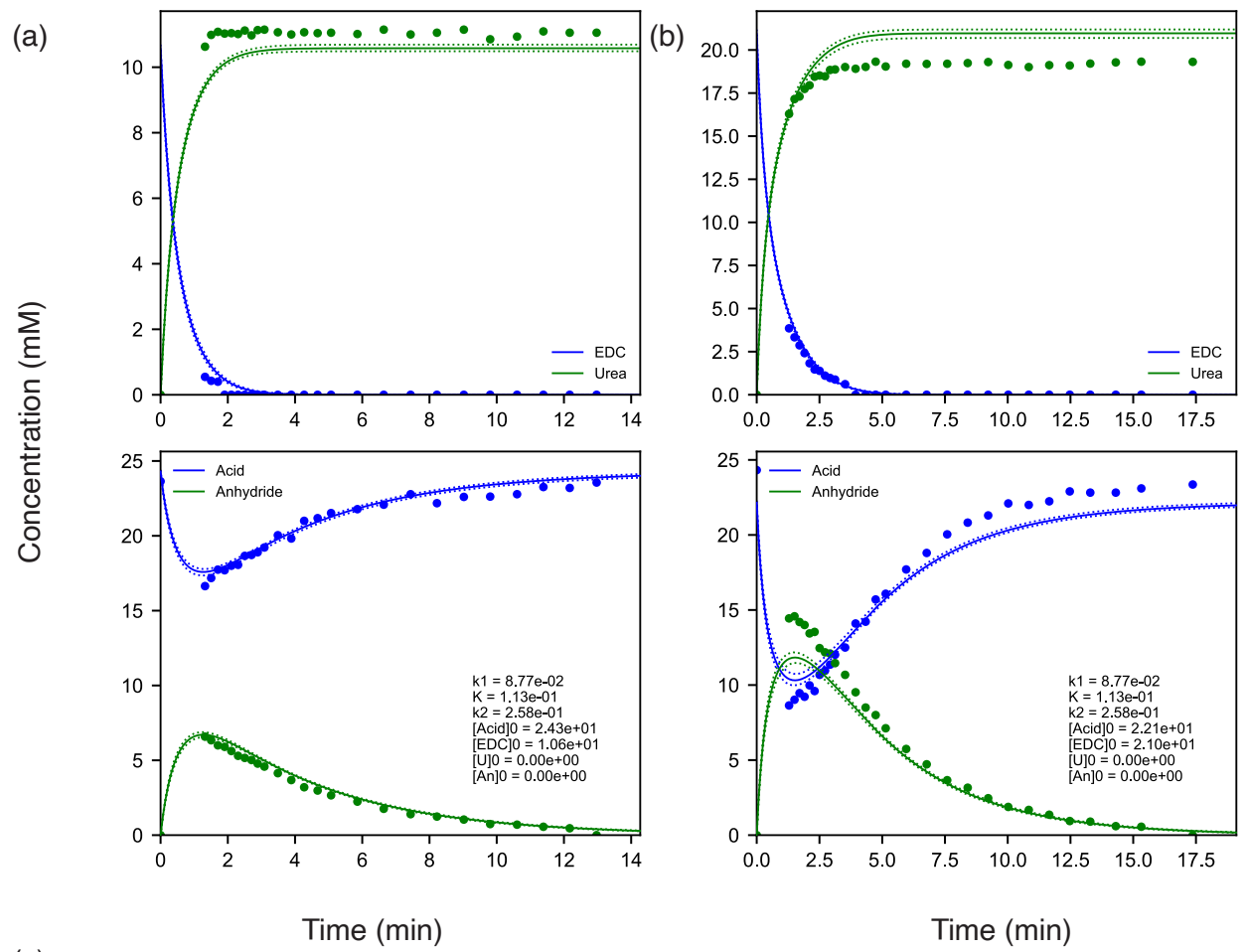

(c)
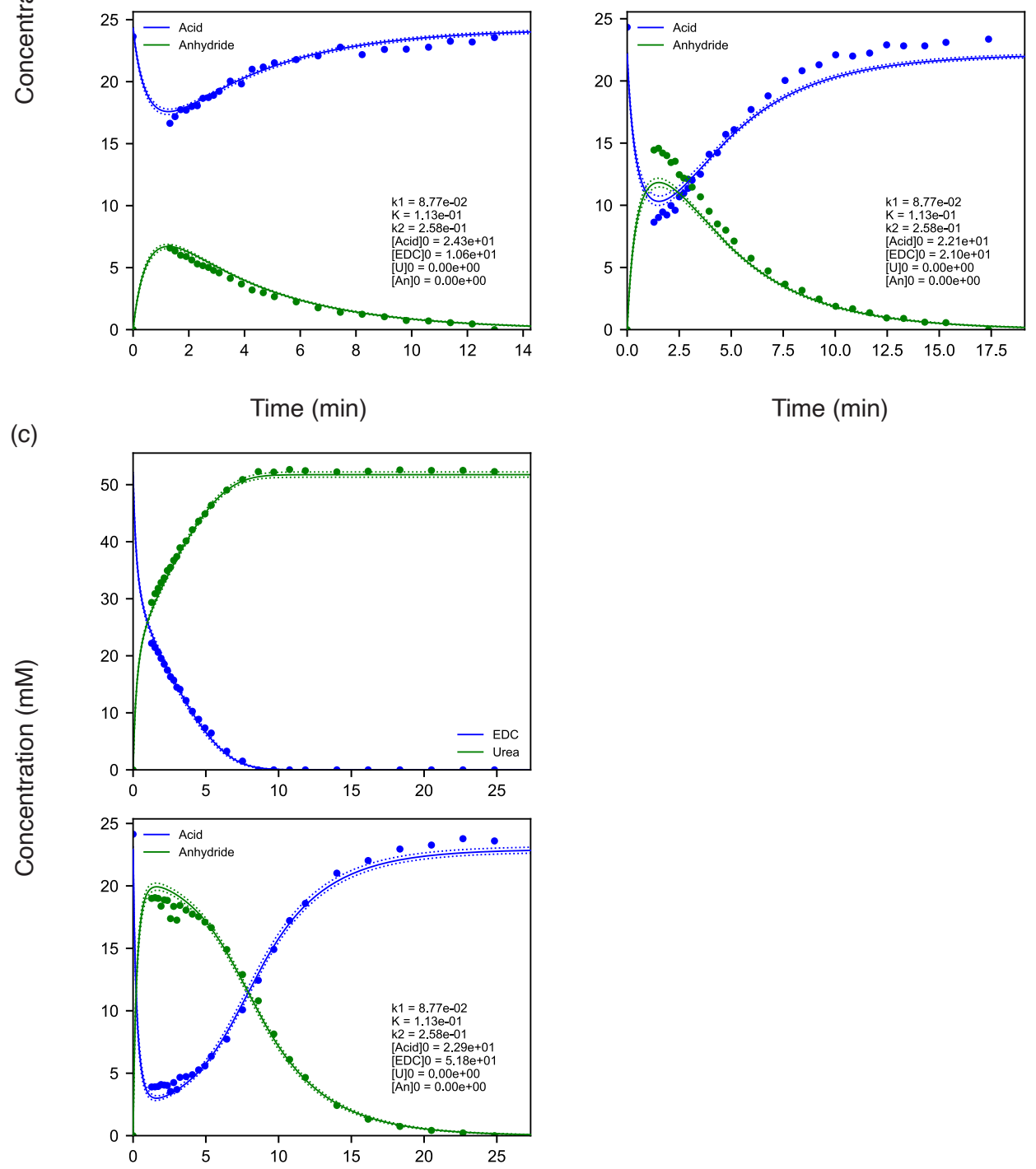

Time (min)

Figure S12. ${ }^{1} \mathrm{H}$ NMR spectroscopy monitoring of the treatment of $25 \mathrm{mM}$ DP-Ac1 with (a) $12 \mathrm{mM}$, (b) 20 $\mathrm{mM}$, (c) $50 \mathrm{mM}$ EDC. $\left(\mathrm{D}_{2} \mathrm{O}\right.$ :acetone- $\left.d_{6}, 276 \mathrm{~K}\right)$. The dashed lines represent $95 \%$ confidence intervals for the fits. 


\section{Fit Parameters}

Parameters extracted from the fits to the kinetic model for the DP-Ac1/DP-An1 system are summarized in Table S2. The 95\% confidence intervals were determined using a nonparametric bootstrapping method with 10,000 iterations, which has been discussed previously. ${ }^{3}$ Briefly, new datasets are randomly generated from the experimental data (i.e., by choosing from the experimental datapoints) and the fitting is rerun. ${ }^{4}$ The confidence intervals represent the variation in the resulting fits.

\begin{tabular}{lll}
\hline Parameter & Optimized value & $95 \%$ confidence interval \\
\hline$k_{1}$ & $8.77 \times 10^{-2} \mathrm{mM}^{-1} \mathrm{~min}^{-1}$ & $8.40 \times 10^{-2}, 9.15 \times 10^{-2}$ \\
$\alpha$ & $1.13 \times 10^{-1}$ & $8.30 \times 10^{-2}, 1.44 \times 10^{-1}$ \\
$k_{2}$ & $2.58 \times 10^{-1} \mathrm{~min}^{-1}$ & $2.50 \times 10^{-1}, 2.65 \times 10^{-1}$ \\
\hline
\end{tabular}

Table S2. Fit parameters for the DP-Ac1/DP-An1 system for anhydride formation and hydrolysis. The parameters are the means of four measurements with different EDC concentrations (Conditions: $\mathrm{D}_{2} \mathrm{O}$ : acetone- $d_{6} 7: 3$, initial acid conc. $=25 \mathrm{mM}$ at $\left.276 \mathrm{~K}\right)$.

The interdependence of the parameters was further tested by calculating confidence contours, in which the sum square error of the regression is calculated as a function of each kinetic parameter pair. ${ }^{5}$ In the plots below, the inverse error function is plotted. If the parameters are well-constrained by the data, the plots will show distinct maxima that correspond to the optimum parameter values. If they are not-that is, a change in one can compensate for a change in another, such that the fit quality is unchanged-this will be represented by a poorly defined maximum over a wide range of values. Their use in similar systems is discussed further in our previous work. ${ }^{3}$

These plots, plus the bootstrapping analysis discussed above, ensure that the parameters are well-constrained by the data.

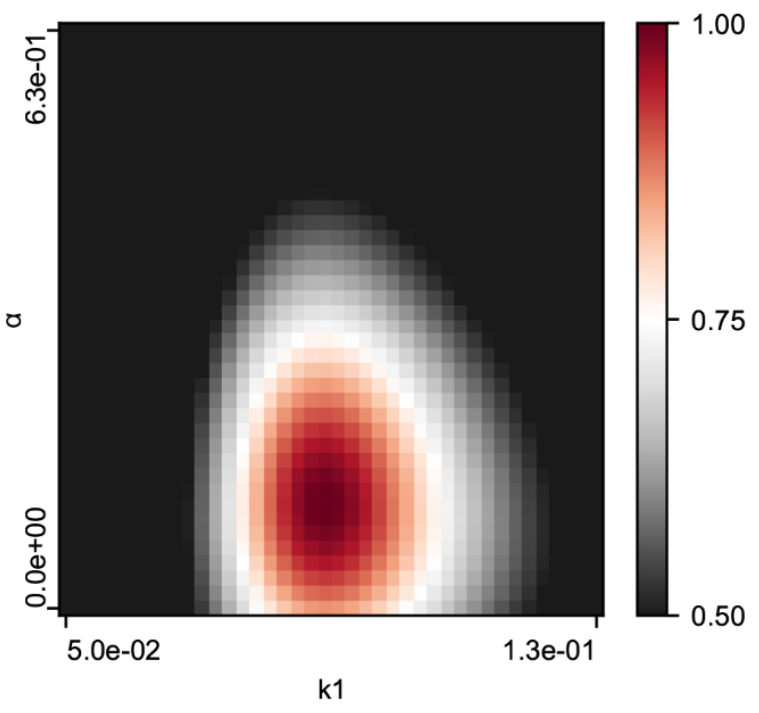

Figure S13. Heat map of the response of the regression error function to variation of $\alpha$ and $k_{1}$ for the DPAc1/DP-An1 system. The inverse error function is plotted, normalized against the value for the optimized system. 


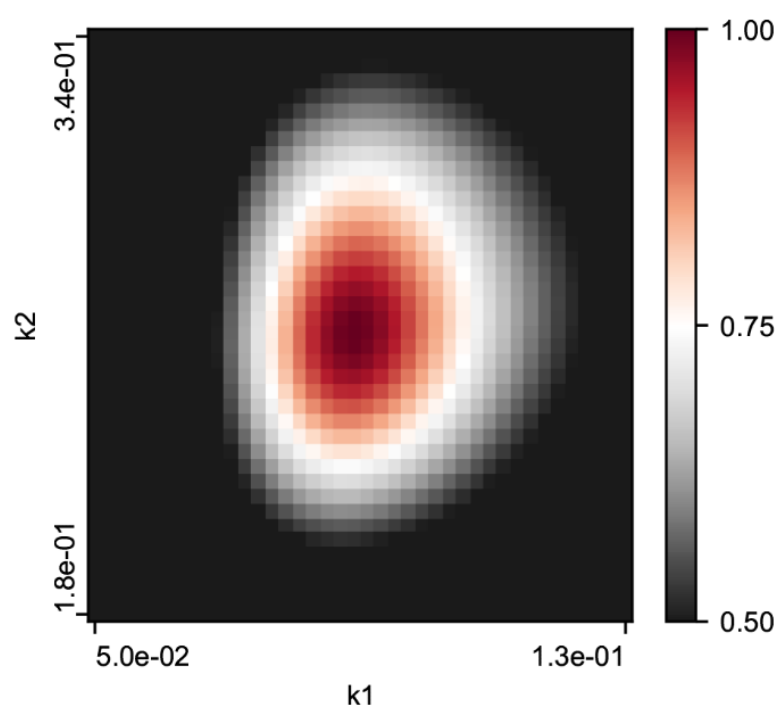

Figure S14. Heat map of the response of the regression error function to variation of $k_{1}$ and $k_{2}$ for the DPAc1/DP-An1 system. The inverse error function is plotted, normalized against the value for the optimized system.

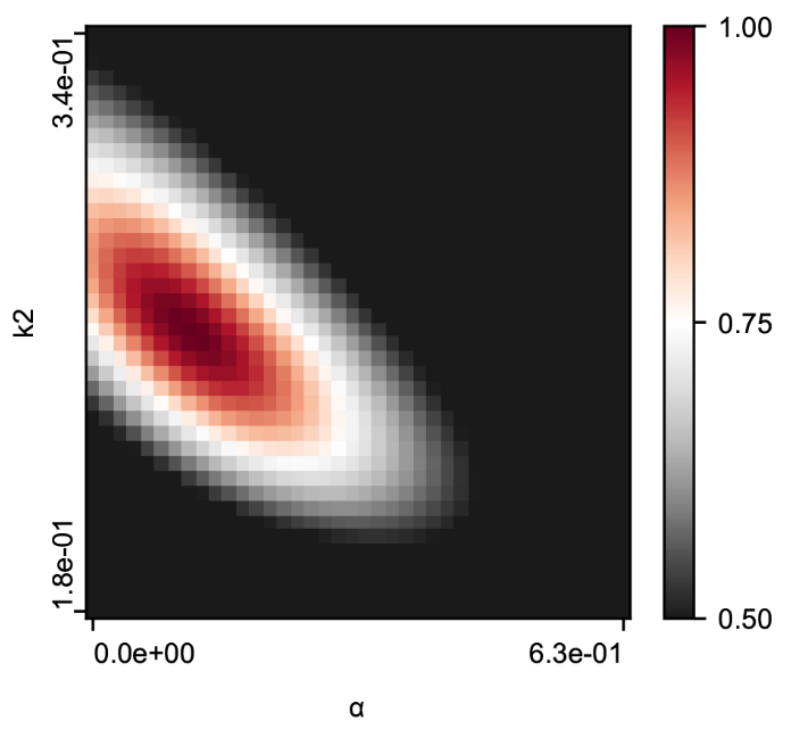

Figure S15. Heat map of the response of the regression error function to variation of for $k_{2}$ and $\alpha$ the DPAc1/DP-An1 system. The inverse error function is plotted, normalized against the value for the optimized system. 
(a)

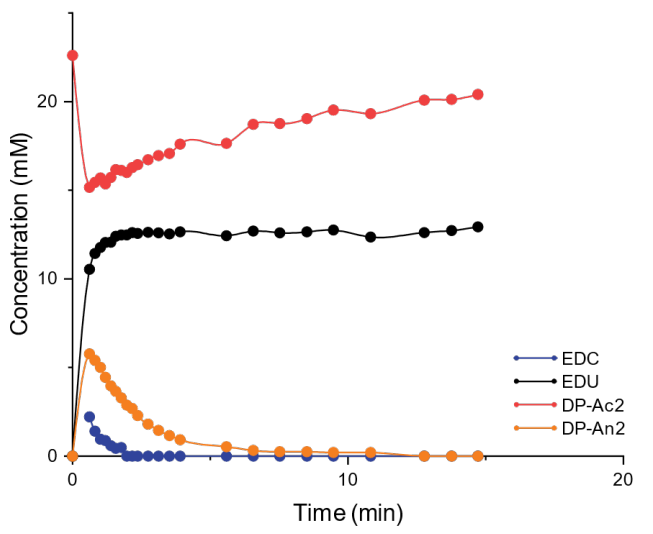

(b)

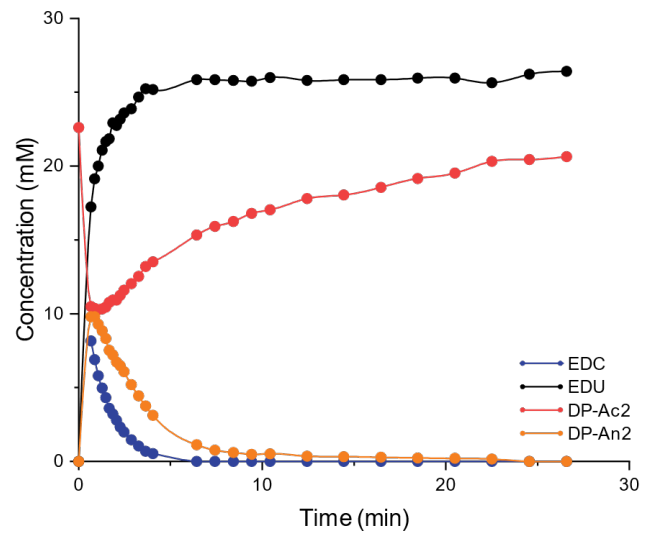

(c)

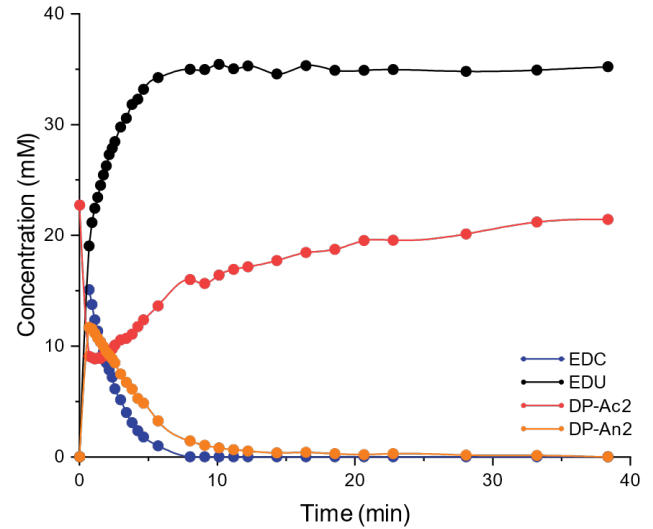

Figure S16. ${ }^{1} \mathrm{H}$ NMR spectroscopy monitoring of the treatment of DP-Ac2 with EDC (a) 0.5 eq. (b) 1.0 eq. (c) 1.5 eq. ( $\mathrm{D}_{2} \mathrm{O}$ :acetone- $\left.d_{6}, 276 \mathrm{~K}\right)$. 
(a)

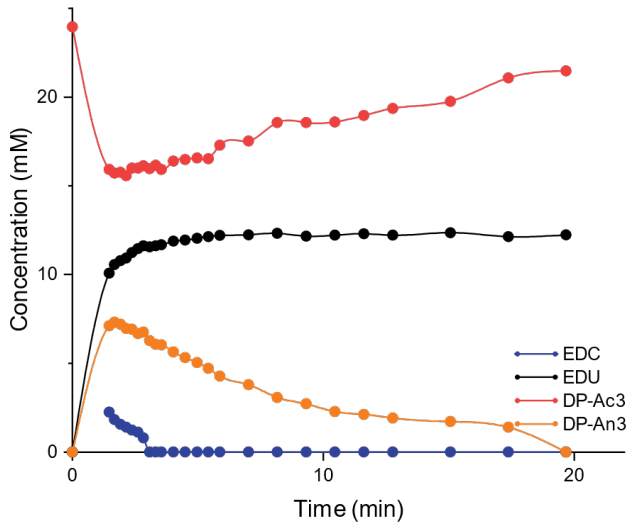

(b)

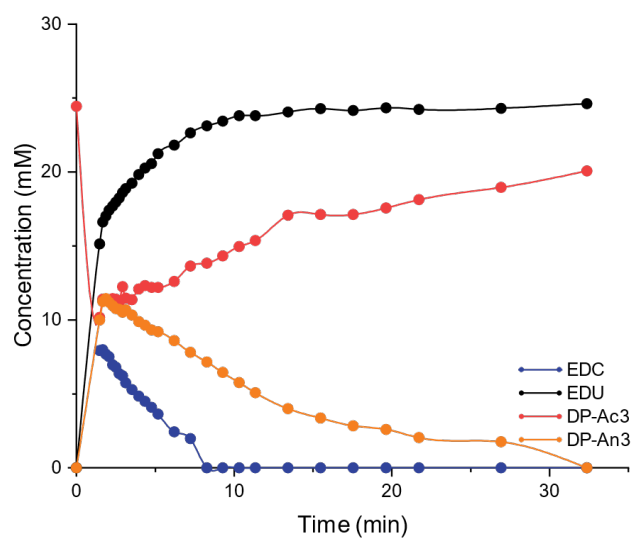

(c)

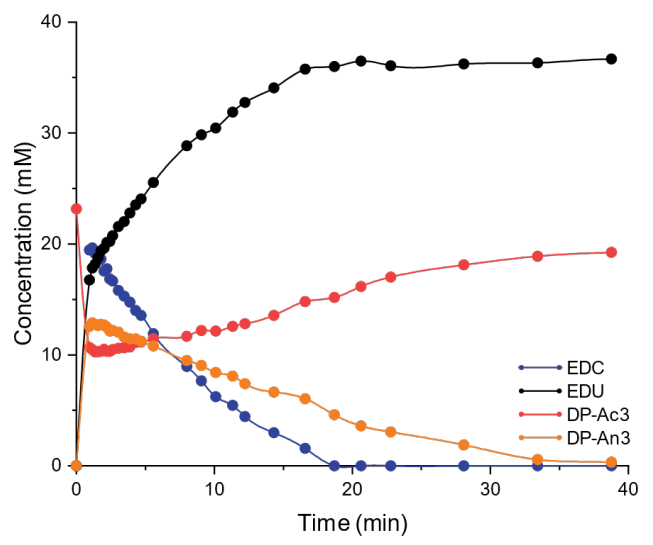

Figure S17. ${ }^{1} \mathrm{H}$ NMR spectroscopy monitoring of the treatment of DP-Ac3 with EDC (a) 0.5 eq. (b) 1.0 eq. (c) 1.5 eq. ( $\mathrm{D}_{2} \mathrm{O}$ :acetone- $\left.d_{6}, 276 \mathrm{~K}\right)$. 


\section{NMR spectra of synthesized compounds}

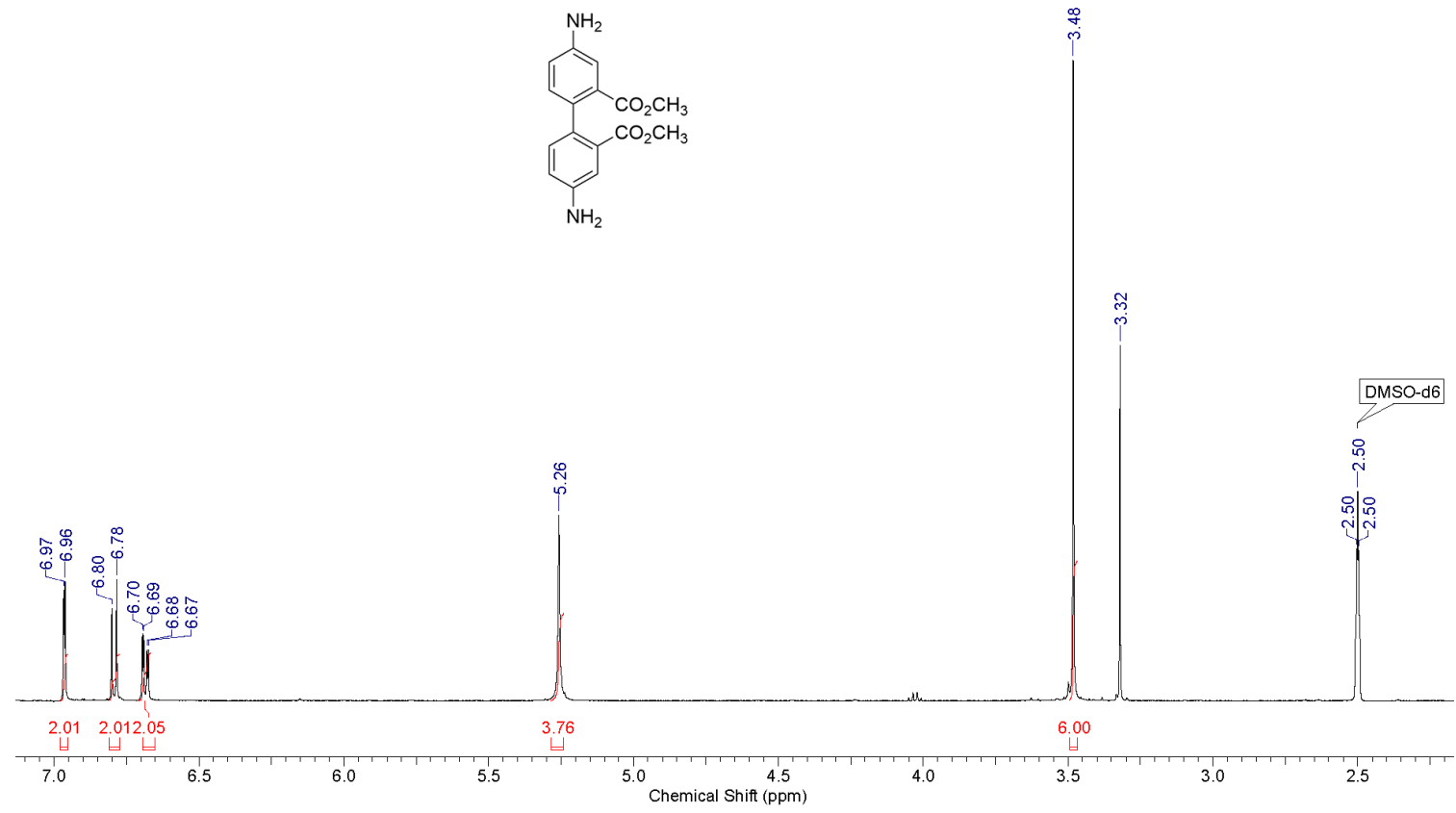

Figure S18. ${ }^{1} \mathrm{H}$ NMR spectrum (DMSO- $d_{6}, 500 \mathrm{MHz}$ ) of dimethyl 4,4'-diamino-2,2'-biphenyldicarboxylate (3).
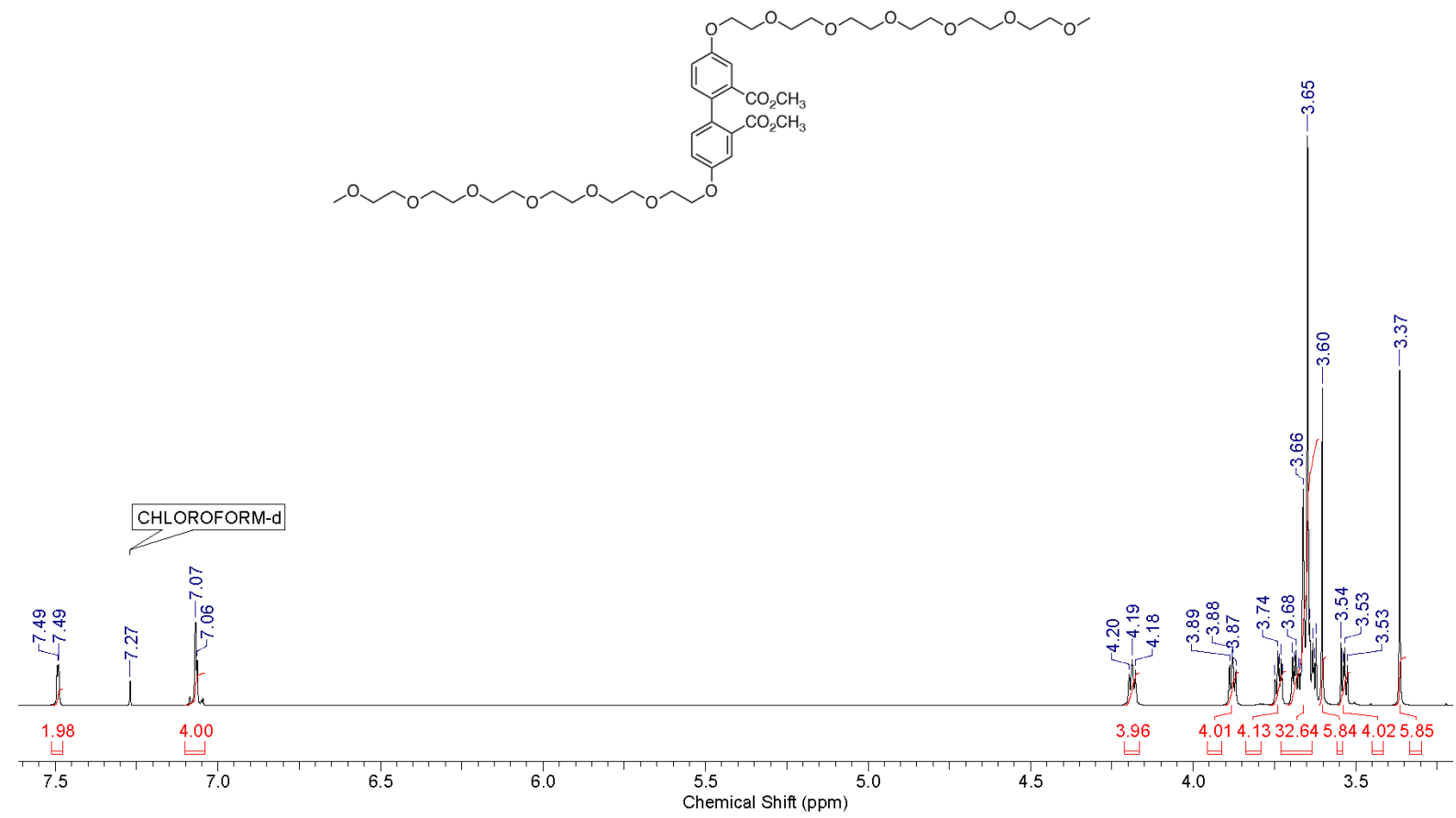

Figure S19. ${ }^{1} \mathrm{H}$ NMR spectrum $\left(\mathrm{CDCl}_{3}, 500 \mathrm{MHz}\right)$ of compound 5. 


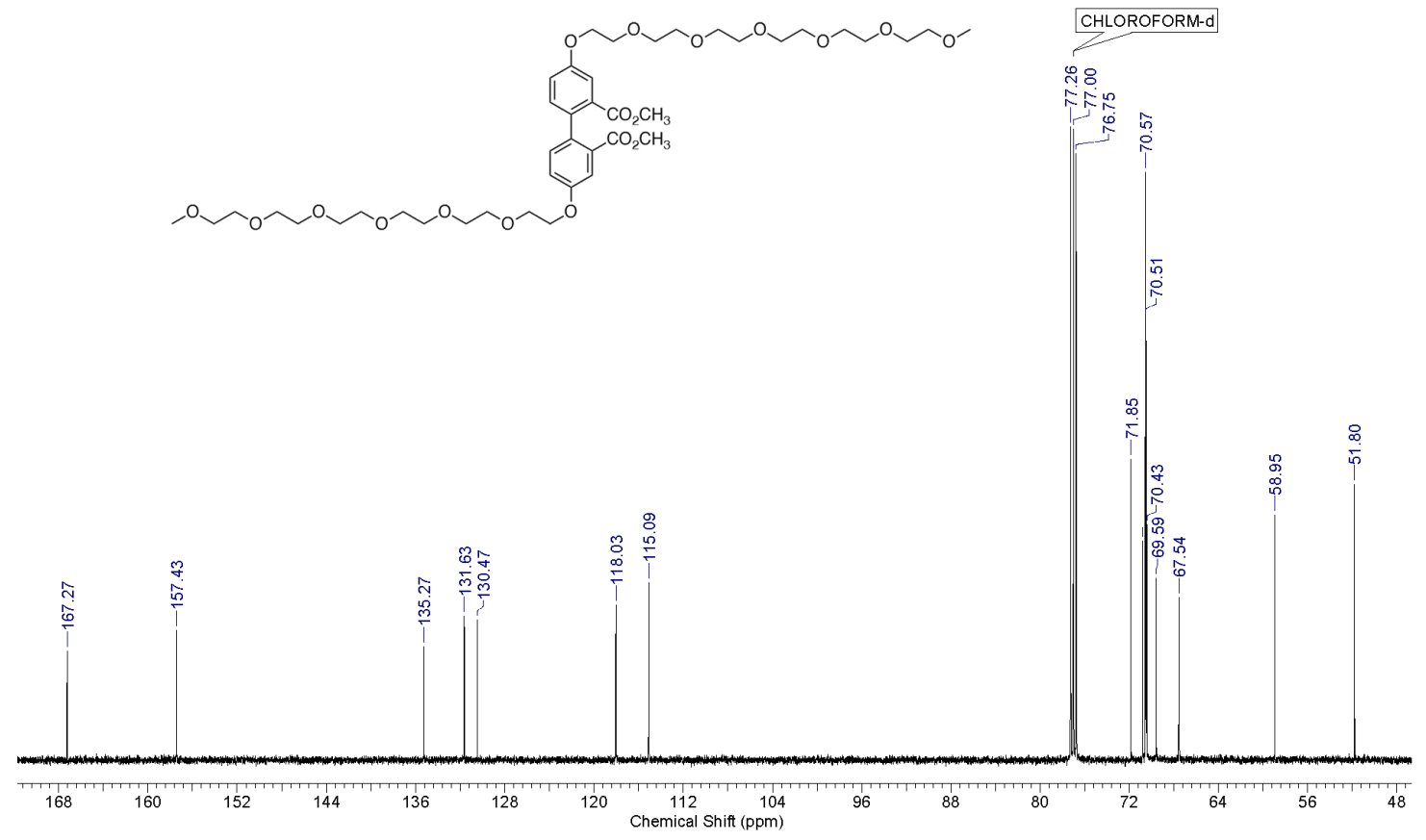

Figure S20. ${ }^{13} \mathrm{C}\left\{{ }^{1} \mathrm{H}\right\}$ NMR spectrum $\left(\mathrm{CDCl}_{3}, 126 \mathrm{MHz}\right)$ of compound 5 .
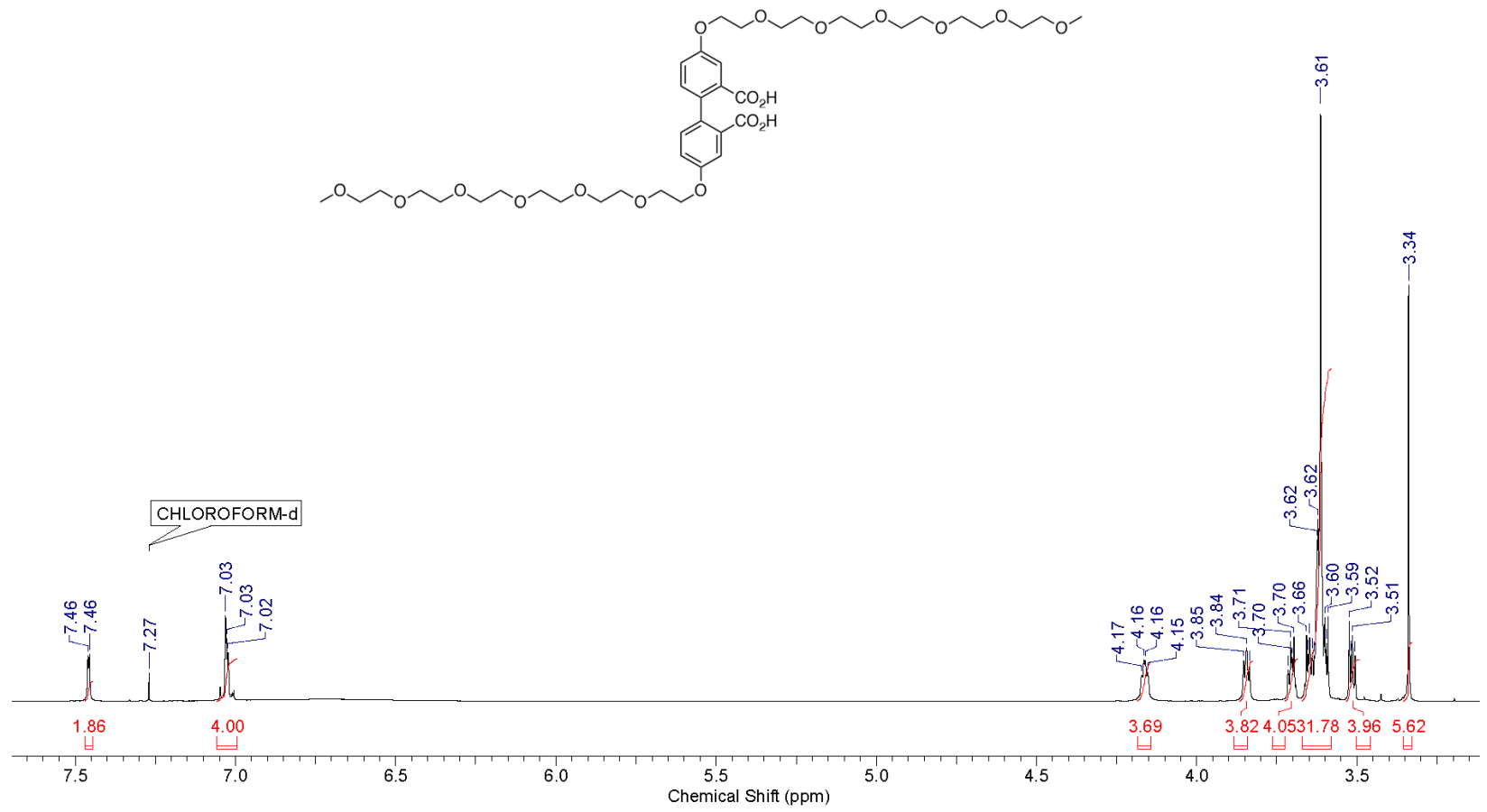

Figure S21. ${ }^{1} \mathrm{H}$ NMR spectrum $\left(\mathrm{CDCl}_{3}, 500 \mathrm{MHz}\right)$ of DP-Ac1. 


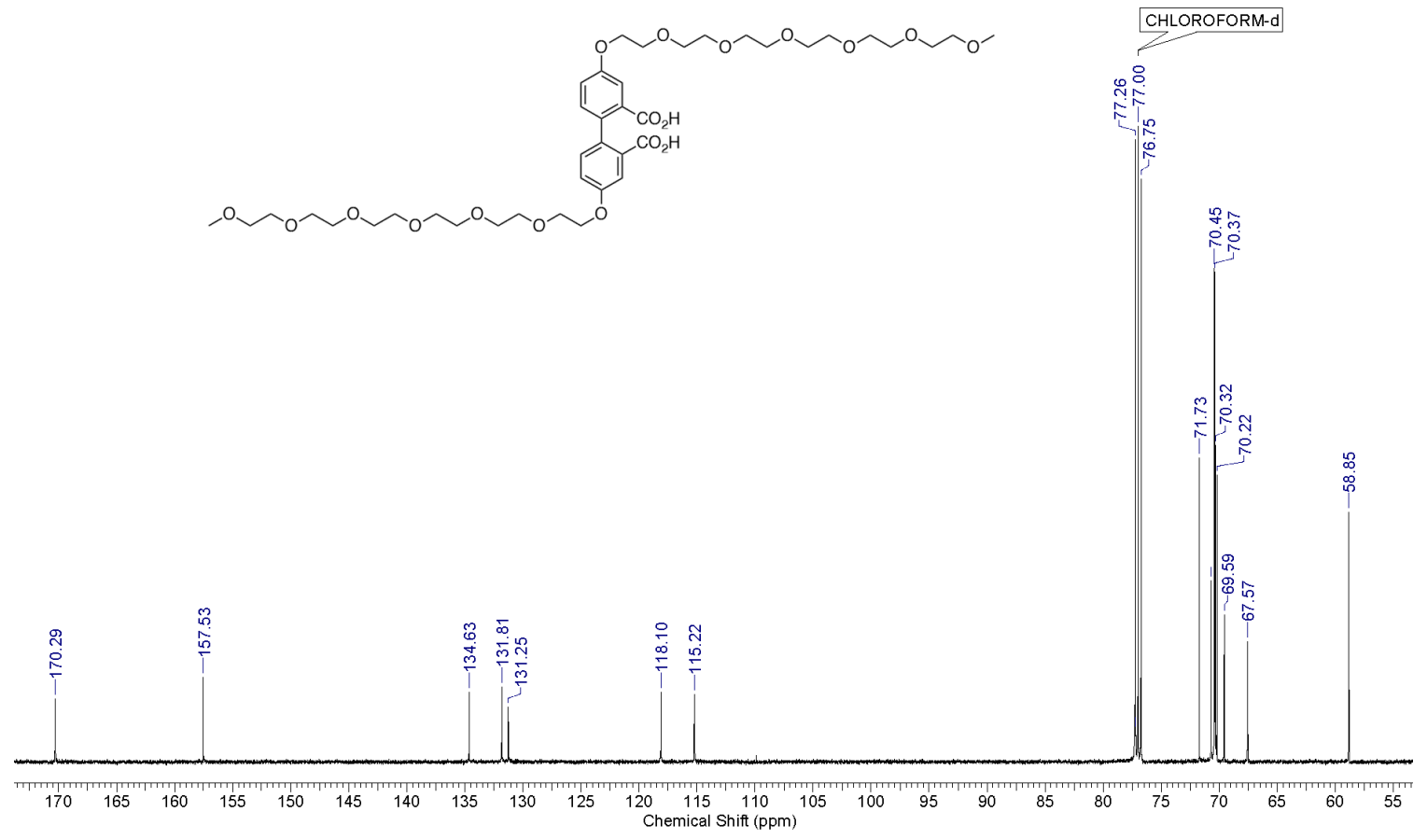

Figure S22. ${ }^{13} \mathrm{C}\left\{{ }^{1} \mathrm{H}\right\}$ NMR spectrum $\left(\mathrm{CDCl}_{3}, 126 \mathrm{MHz}\right)$ of DP-Ac1.

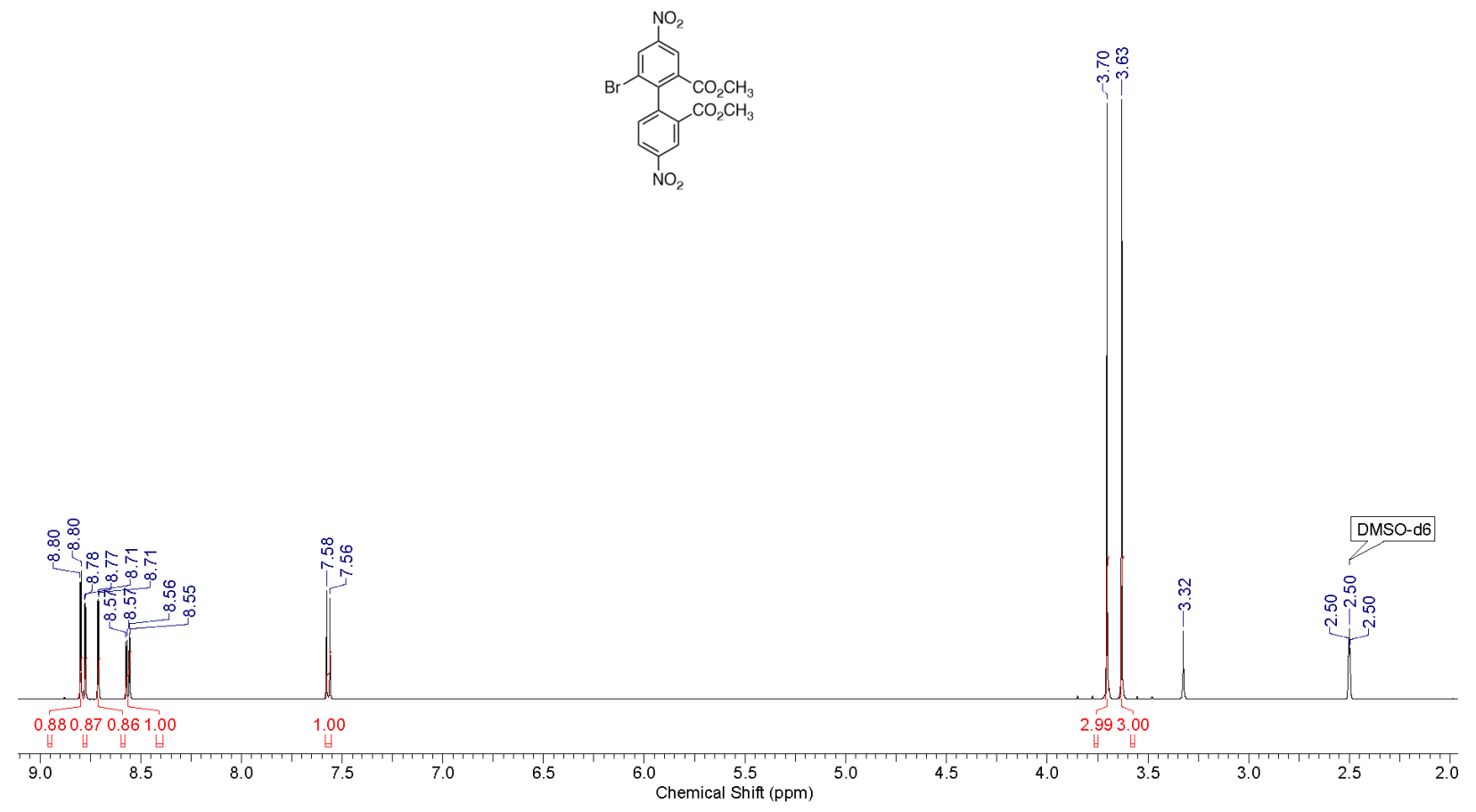

Figure S23. ${ }^{1} \mathrm{H}$ NMR spectrum (DMSO- $d_{6}, 500 \mathrm{MHz}$ ) of dimethyl 6-bromo-4,4'-dinitro-2,2'biphenyldicarboxylate (6). 

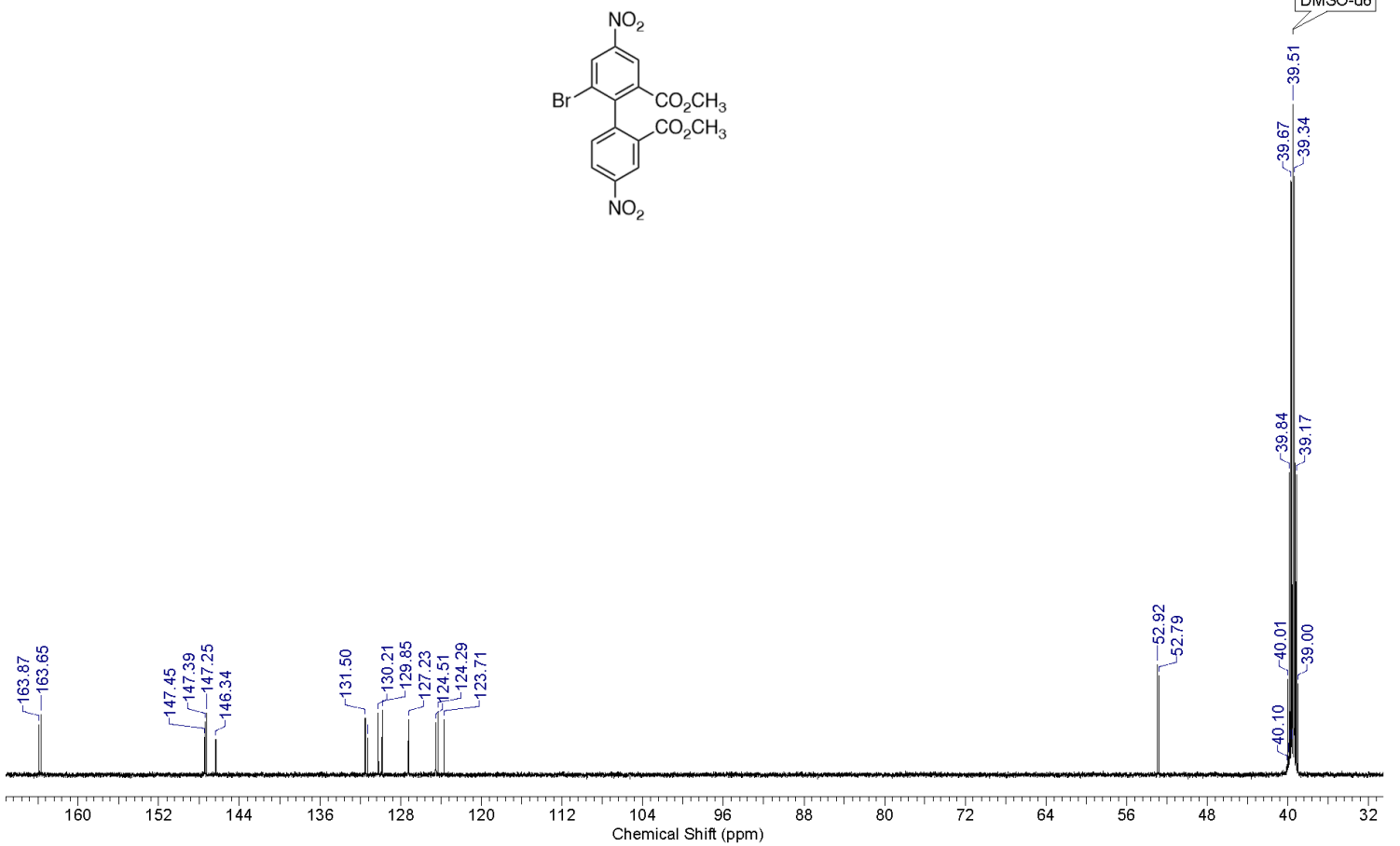

Figure S24. ${ }^{13} \mathrm{C}\left\{{ }^{1} \mathrm{H}\right\}$ NMR spectrum (DMSO- $d_{6}, 126 \mathrm{MHz}$ ) of dimethyl 6-bromo-4,4'-dinitro-2,2'biphenyldicarboxylate (6).
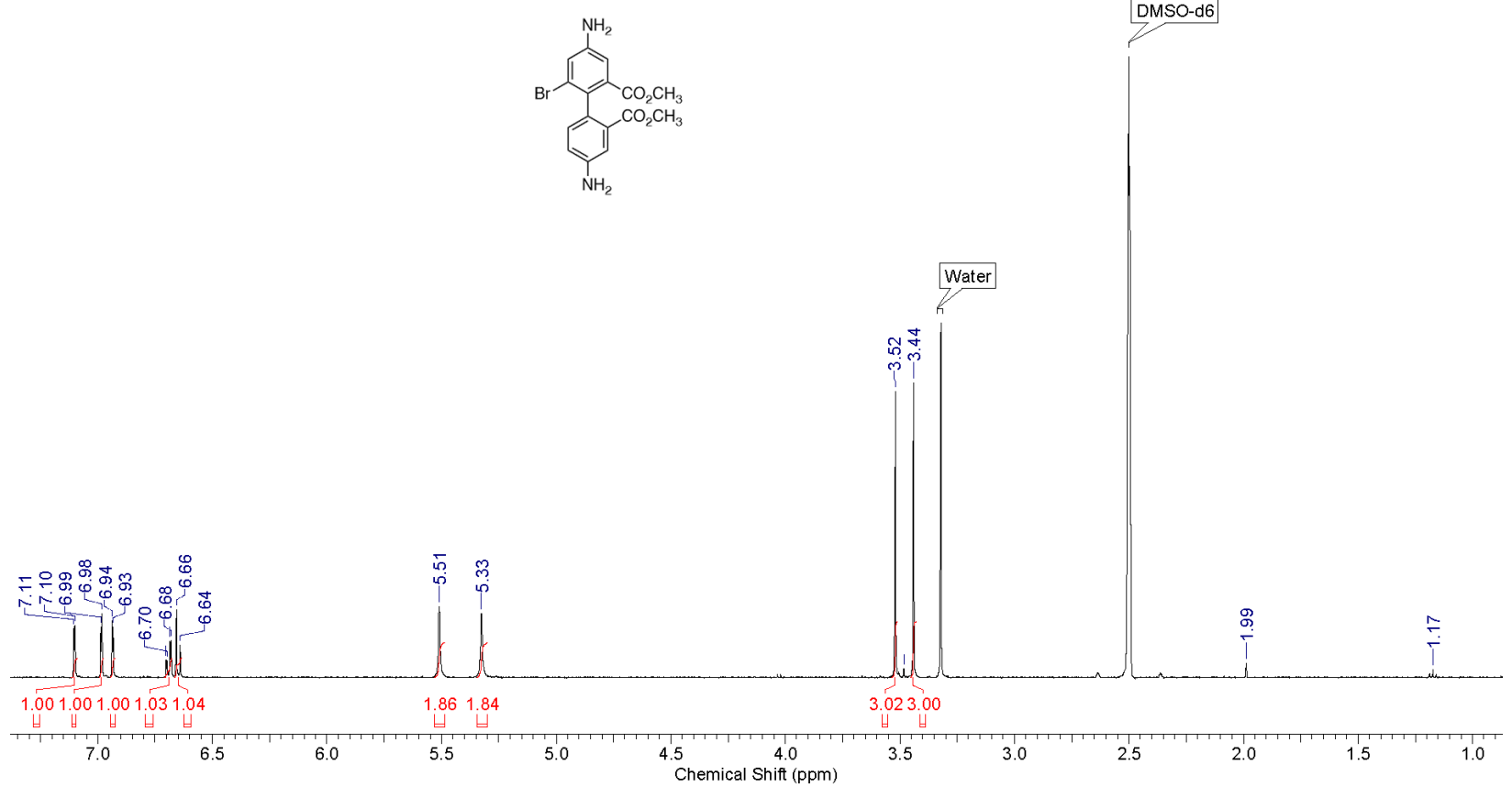

Figure S25. ${ }^{1} \mathrm{H}$ NMR spectrum (DMSO- $d_{6}, 500 \mathrm{MHz}$ ) of dimethyl 6-bromo-4,4'-diamino-2,2'biphenyldicarboxylate (7). 


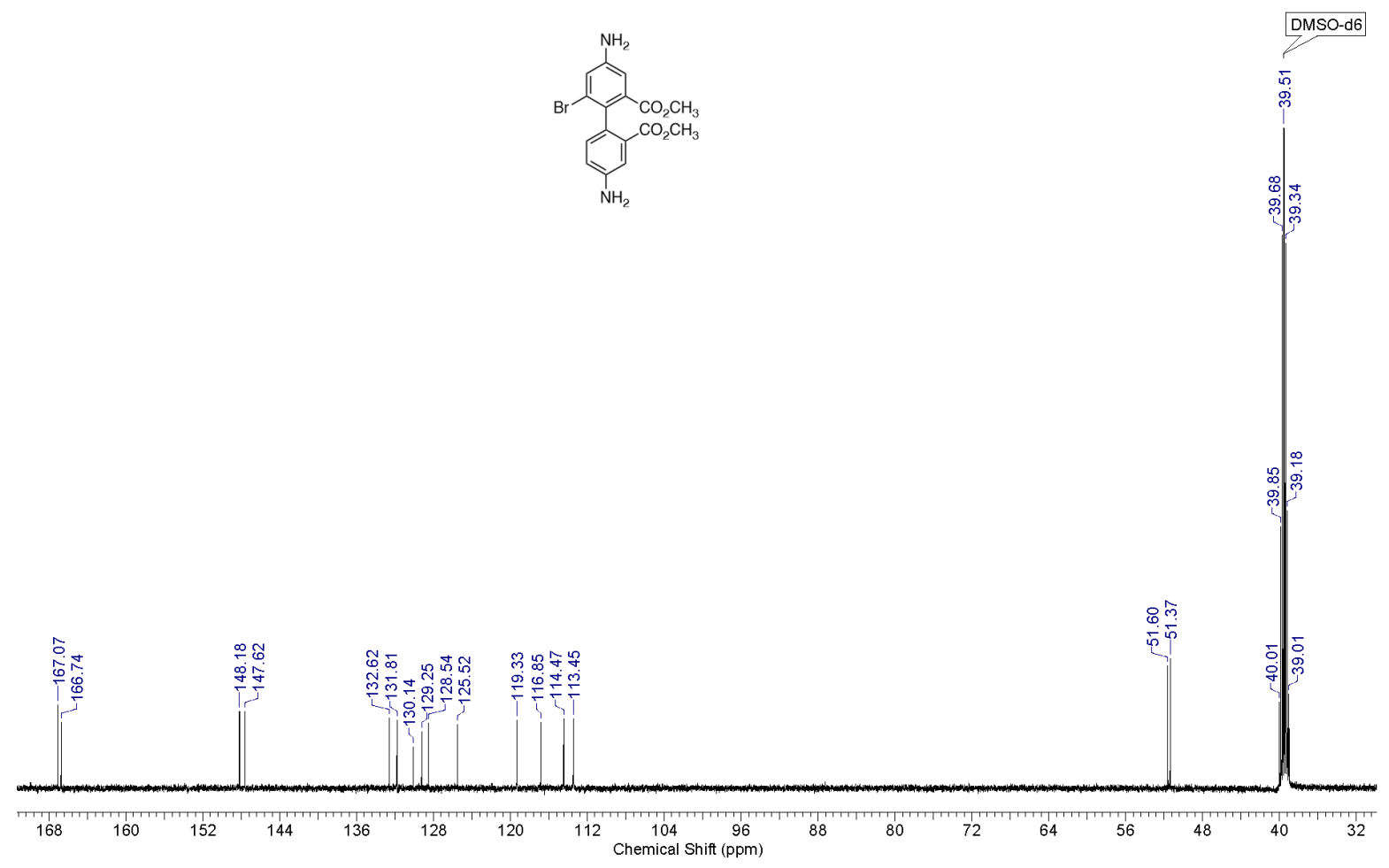

Figure S26. ${ }^{13} \mathrm{C}\left\{{ }^{1} \mathrm{H}\right\}$ NMR spectrum (DMSO- $d_{6}, 126 \mathrm{MHz}$ ) of dimethyl 6-bromo-4,4'-diamino-2,2'biphenyldicarboxylate (7).

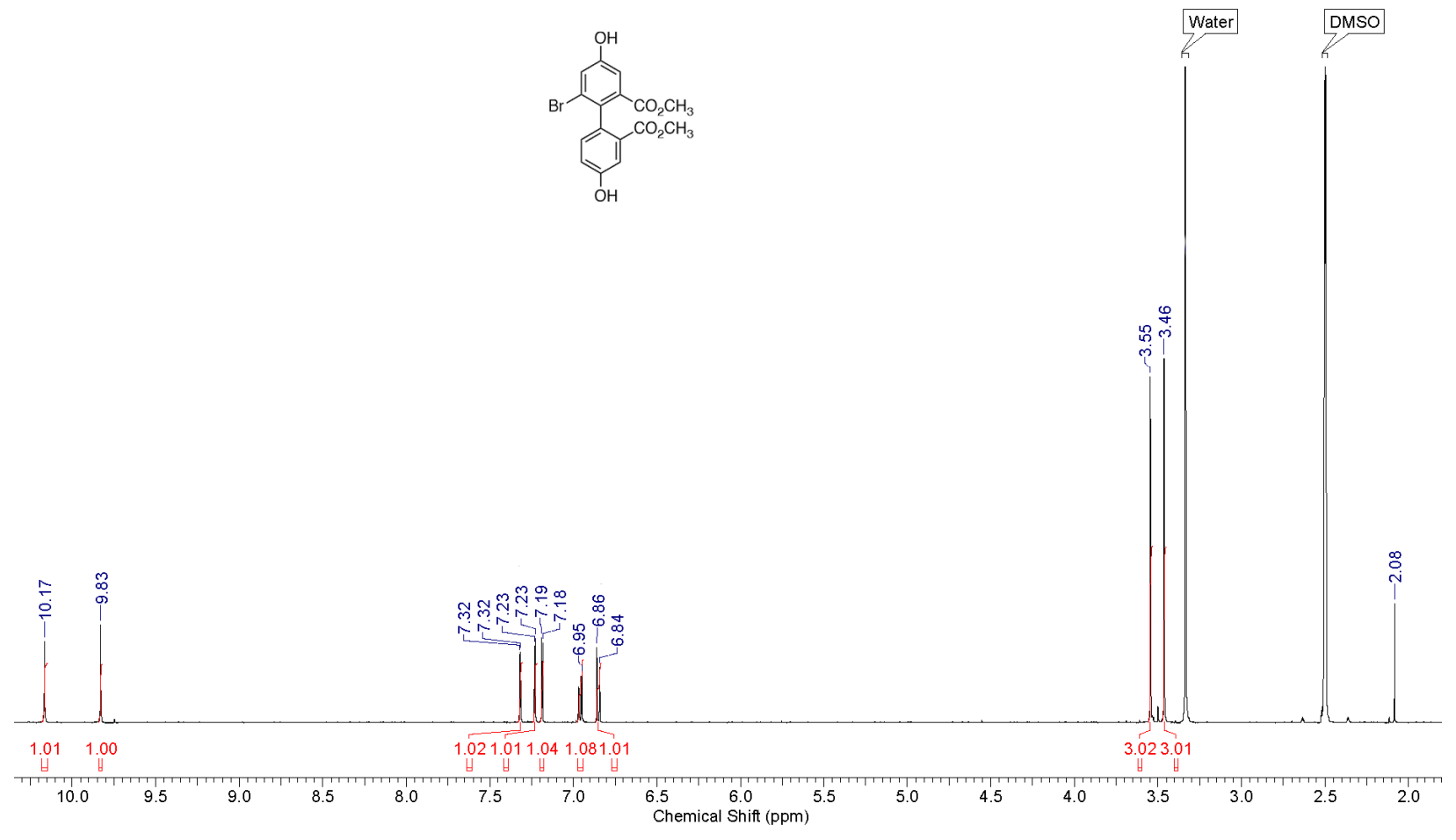

Figure S27. ${ }^{1} \mathrm{H}$ NMR spectrum (DMSO- $d_{6}, 500 \mathrm{MHz}$ ) of dimethyl 6-bromo-4,4'-dihydroxy-2,2'biphenyldicarboxylate (8). 


$$
\text { OH }
$$

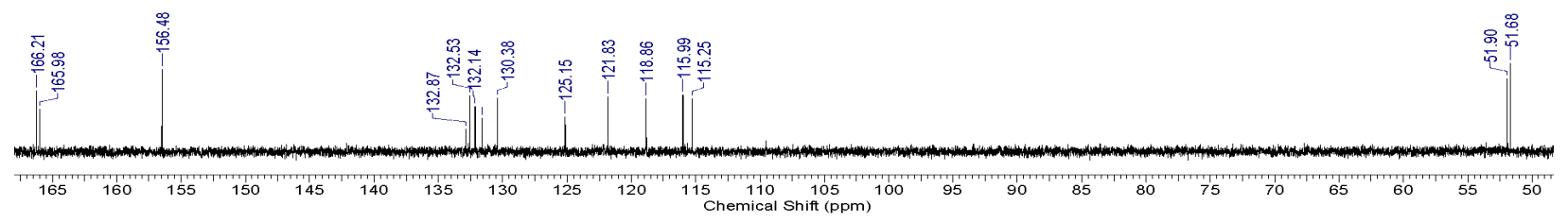

Figure S28. ${ }^{13} \mathrm{C}\left\{{ }^{1} \mathrm{H}\right\}$ NMR spectrum (DMSO- $d_{6}, 126 \mathrm{MHz}$ ) of dimethyl 6-bromo-4,4'-dihydroxy-2,2'biphenyldicarboxylate (8).

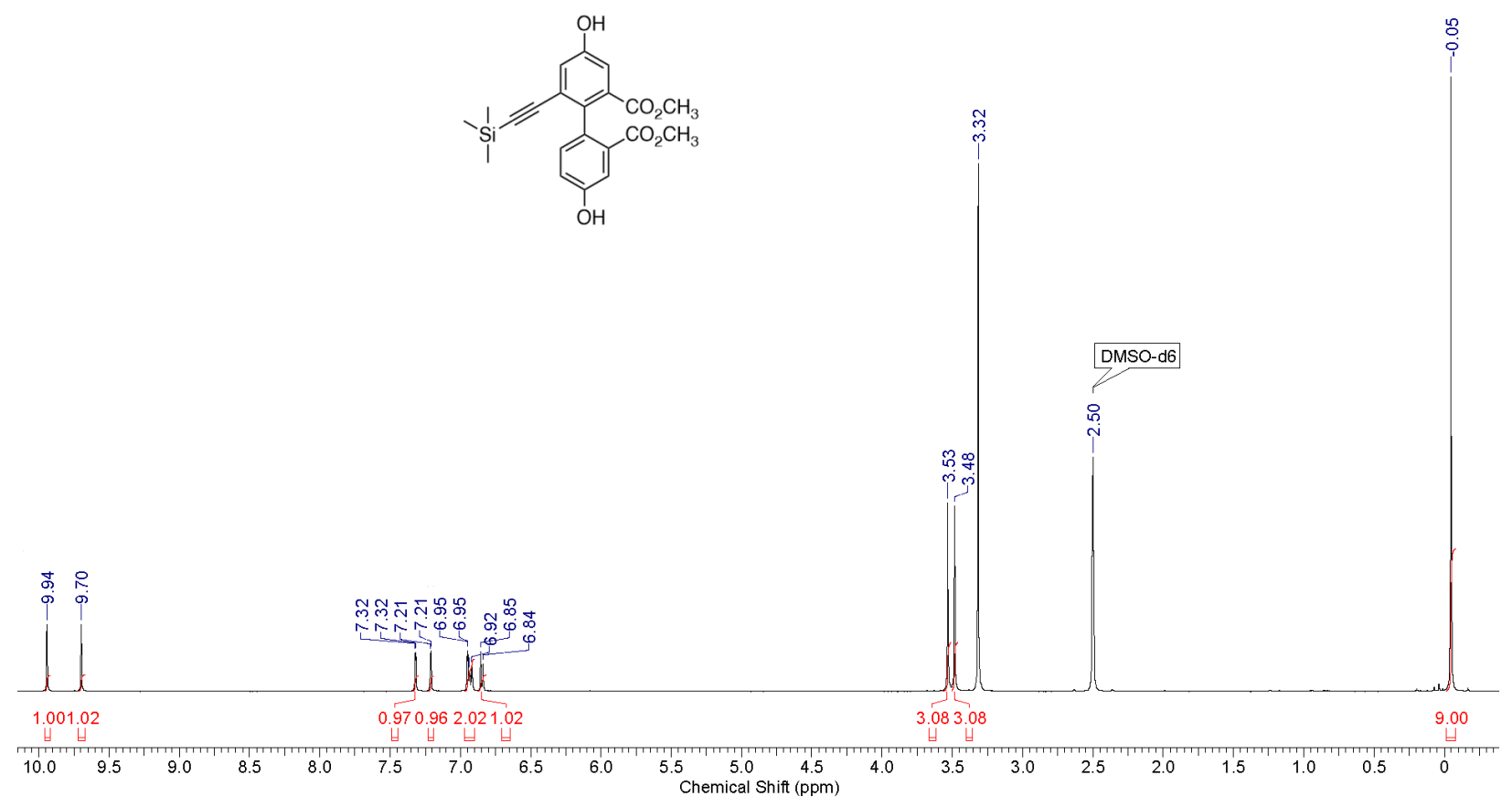

Figure S29. ${ }^{1} \mathrm{H}$ NMR spectrum (DMSO- $d_{6}, 500 \mathrm{MHz}$ ) of dimethyl 6-(trimethylsilyl)ethynyl-4,4'-dihydroxy2,2'-biphenyldicarboxylate (9) 


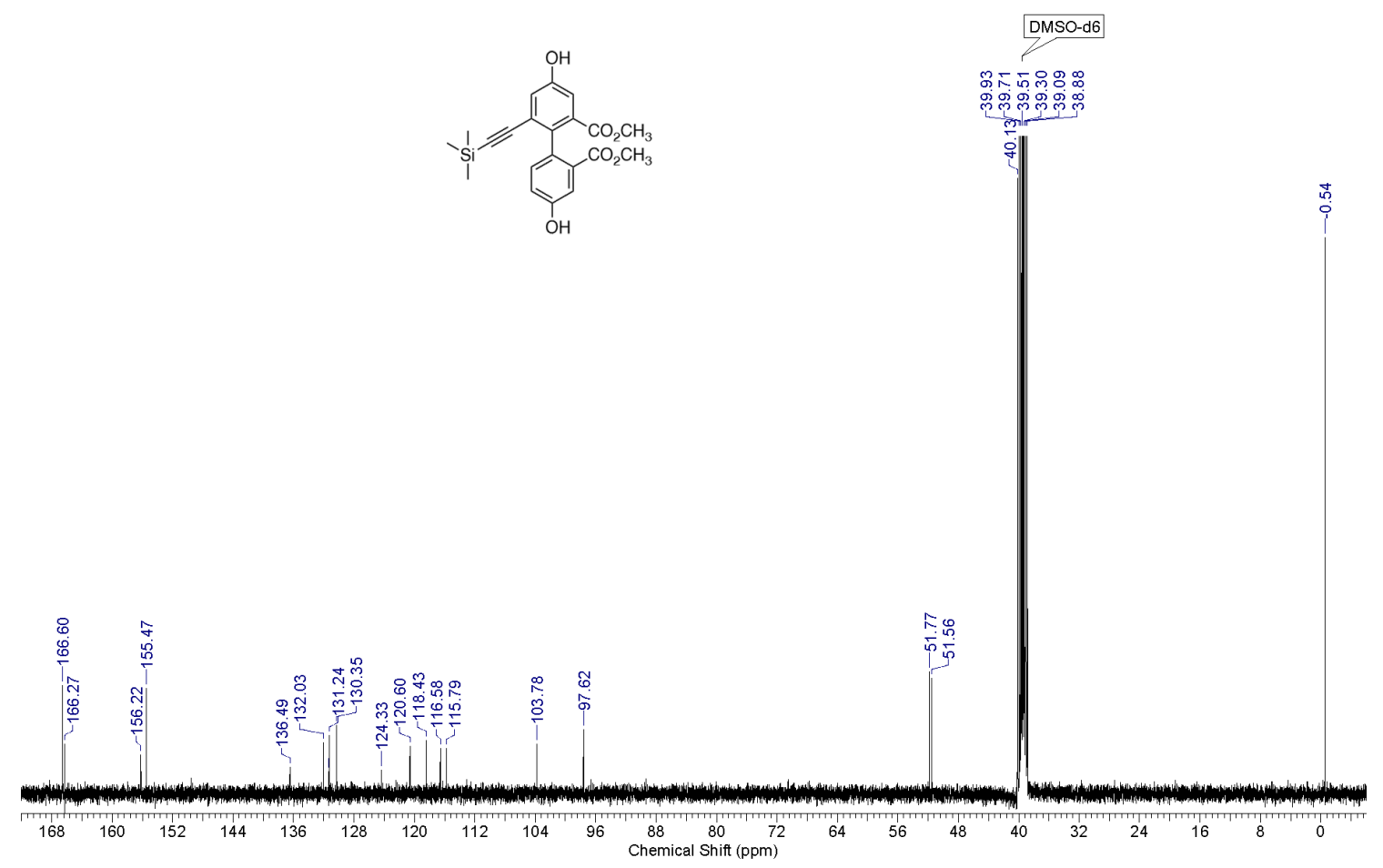

Figure S30. ${ }^{13} \mathrm{C}\left\{{ }^{1} \mathrm{H}\right\}$ NMR spectrum (10o MHz, DMSO- $d_{6}$ ) of dimethyl 6-(trimethylsilyl)ethynyl-4,4'dihydroxy-2,2'-biphenyldicarboxylate (9)

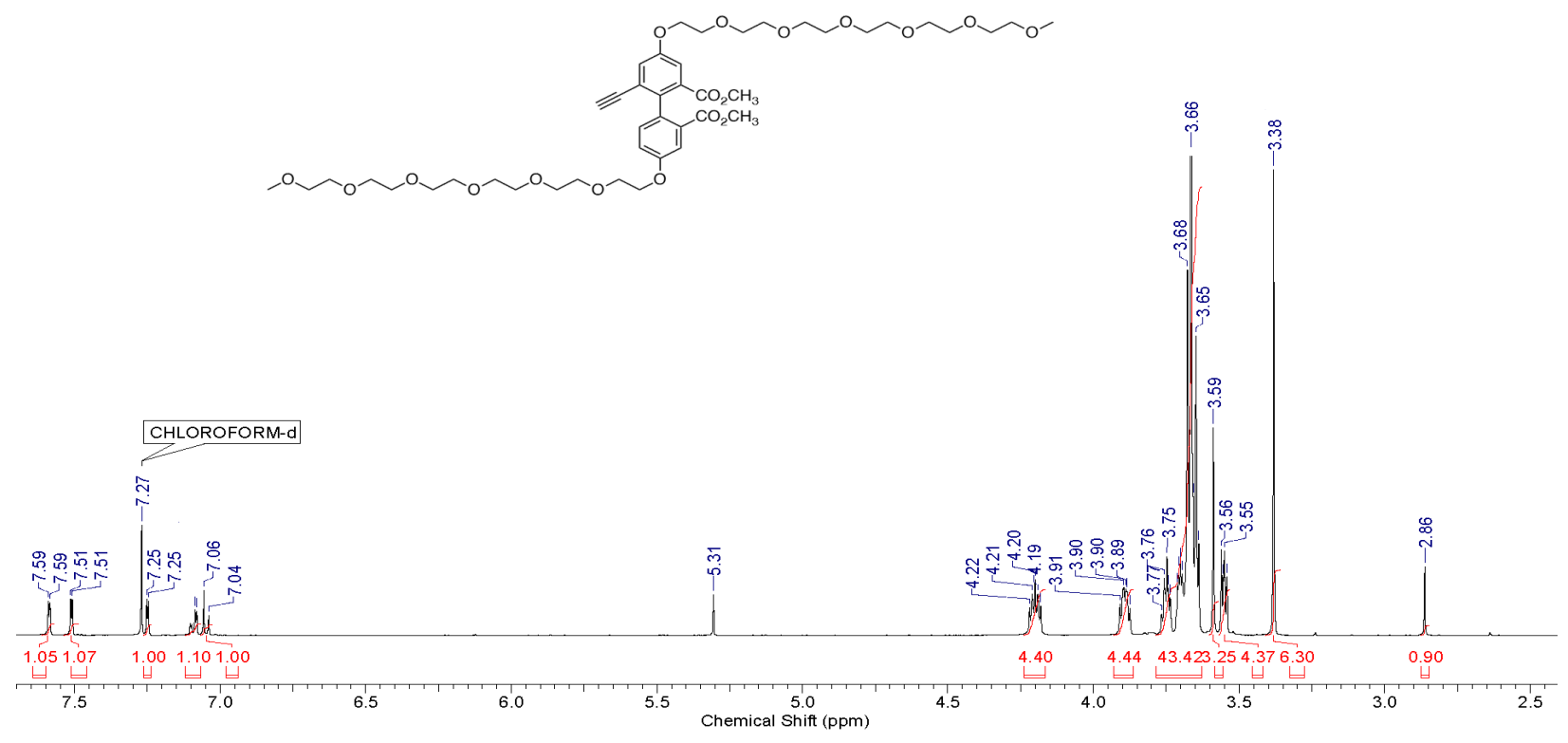

Figure S31. ${ }^{1} \mathrm{H}$ NMR spectrum $\left(\mathrm{CDCl}_{3}, 500 \mathrm{MHz}\right)$ of compound 10. 


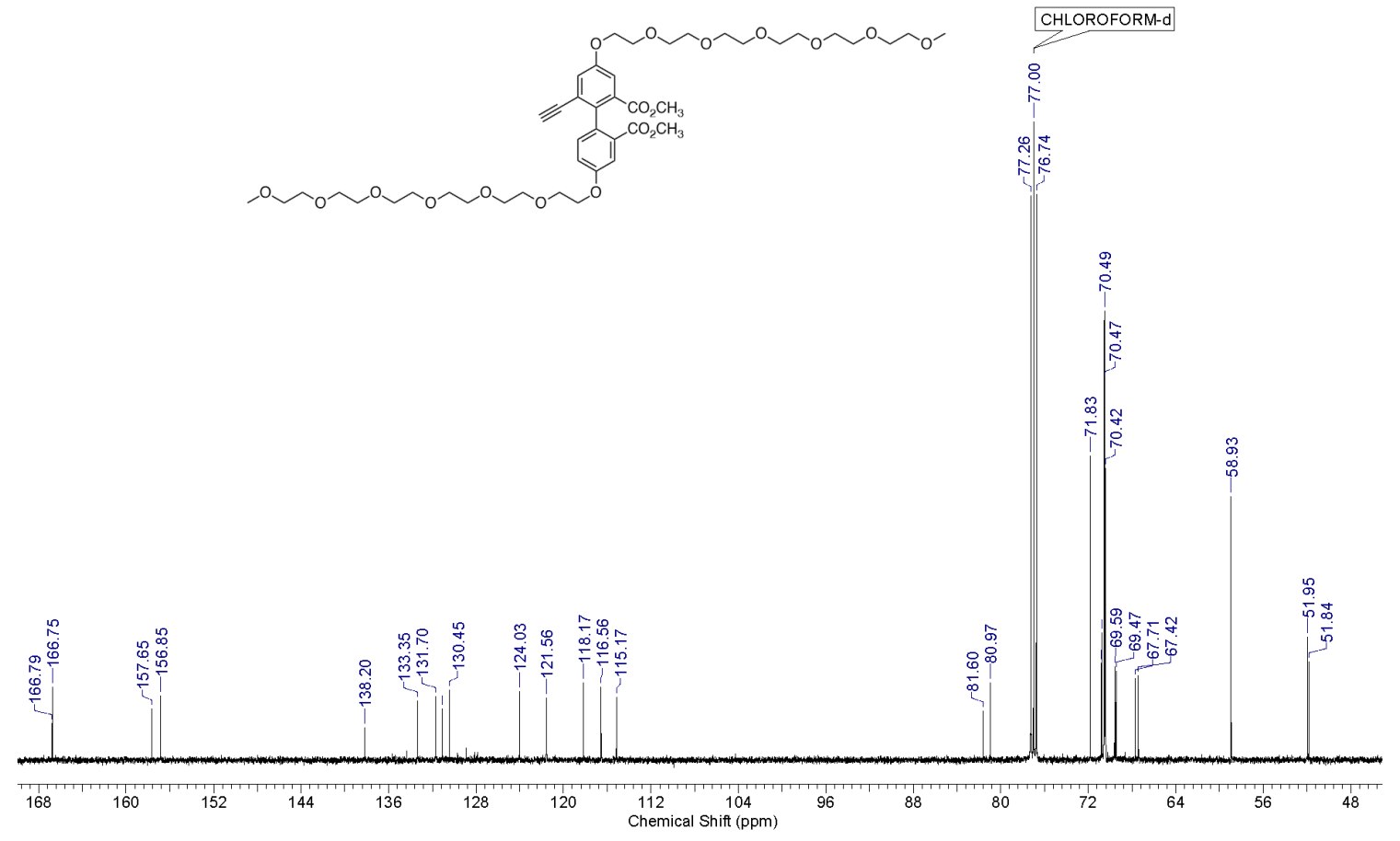

Figure S32. ${ }^{13} \mathrm{C}\left\{{ }^{1} \mathrm{H}\right\}$ NMR spectrum $\left(\mathrm{CDCl}_{3}, 126 \mathrm{MHz}\right)$ of compound 10.
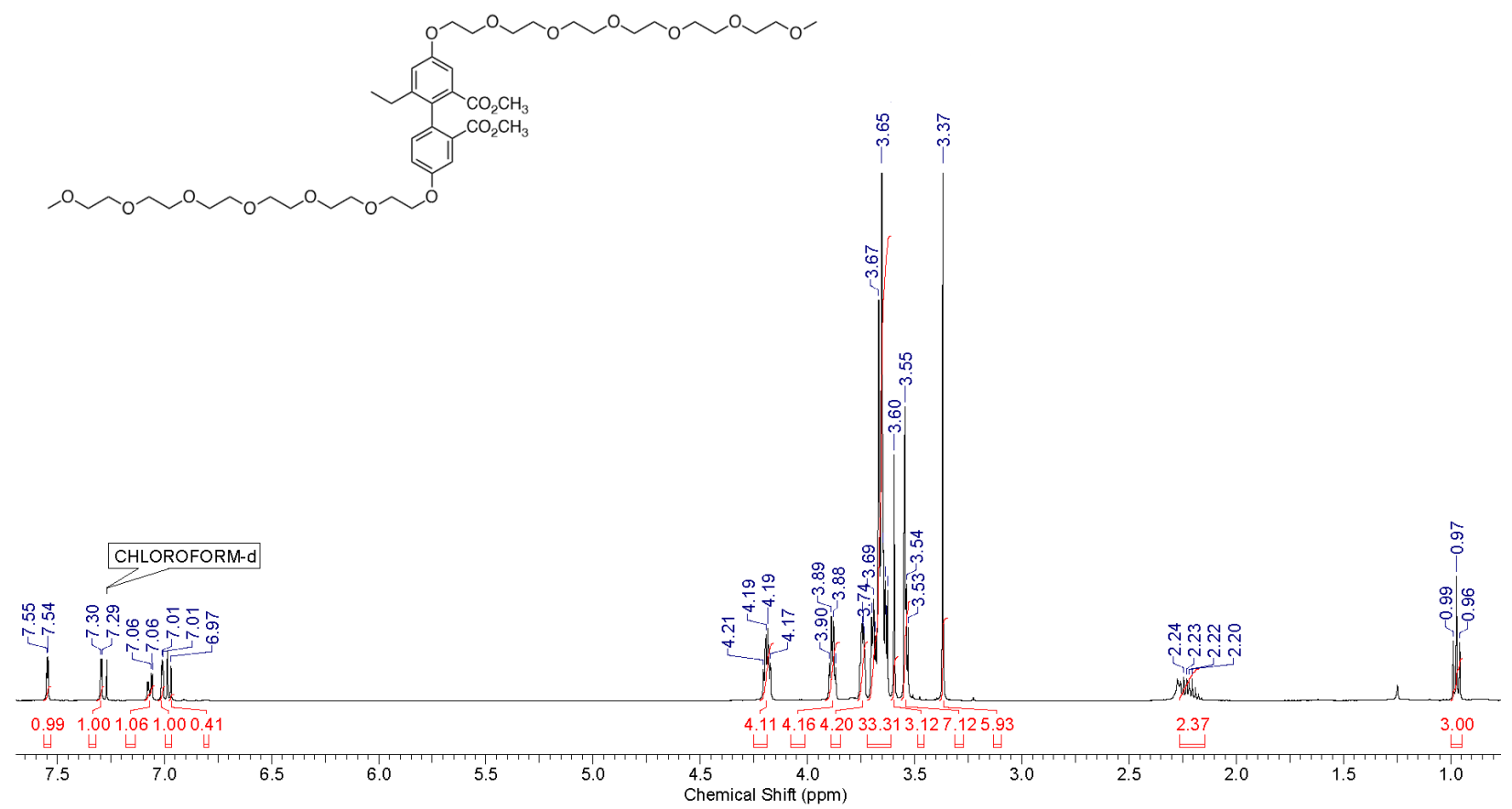

Figure S33. ${ }^{1} \mathrm{H}$ NMR spectrum $\left(\mathrm{CDCl}_{3}, 500 \mathrm{MHz}\right)$ of compound 11. 


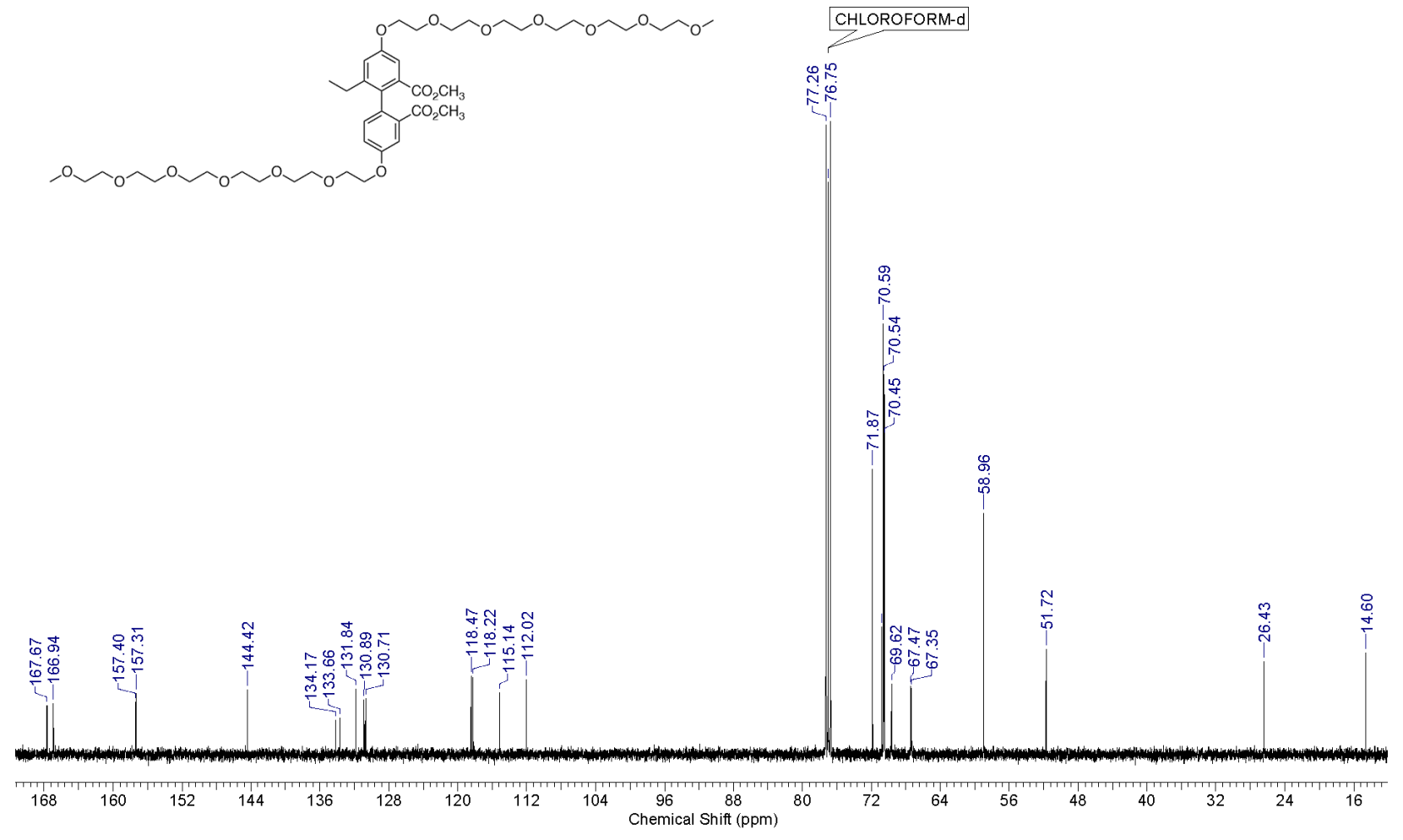

Figure S34. ${ }^{13} \mathrm{C}\left\{{ }^{1} \mathrm{H}\right\}$ NMR spectrum $\left(\mathrm{CDCl}_{3}, 126 \mathrm{MHz}\right)$ of compound 11.

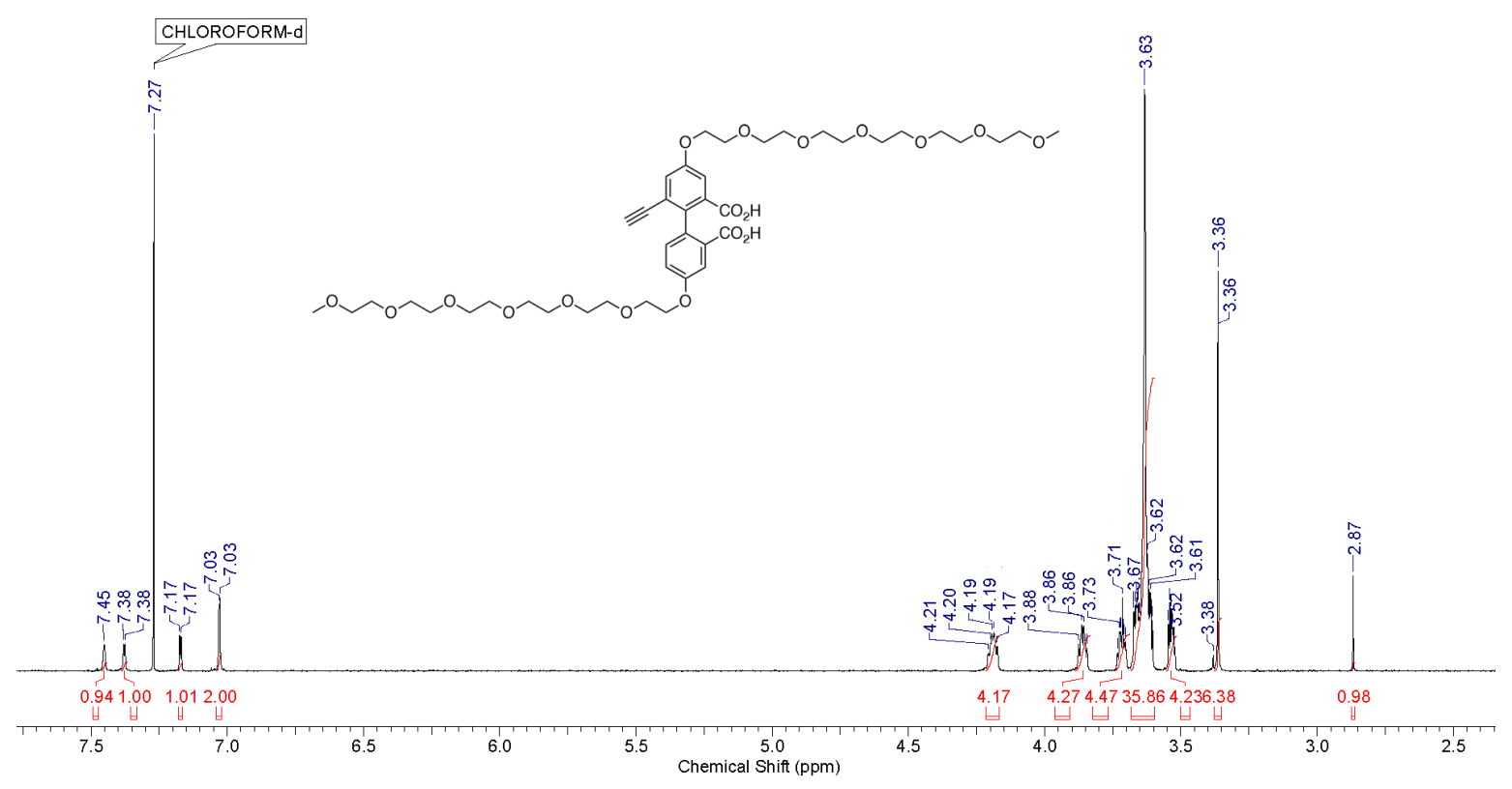

Figure S35. ${ }^{1} \mathrm{H}$ NMR spectrum $\left(\mathrm{CDCl}_{3}, 500 \mathrm{MHz}\right)$ of compound DP-Ac2. 


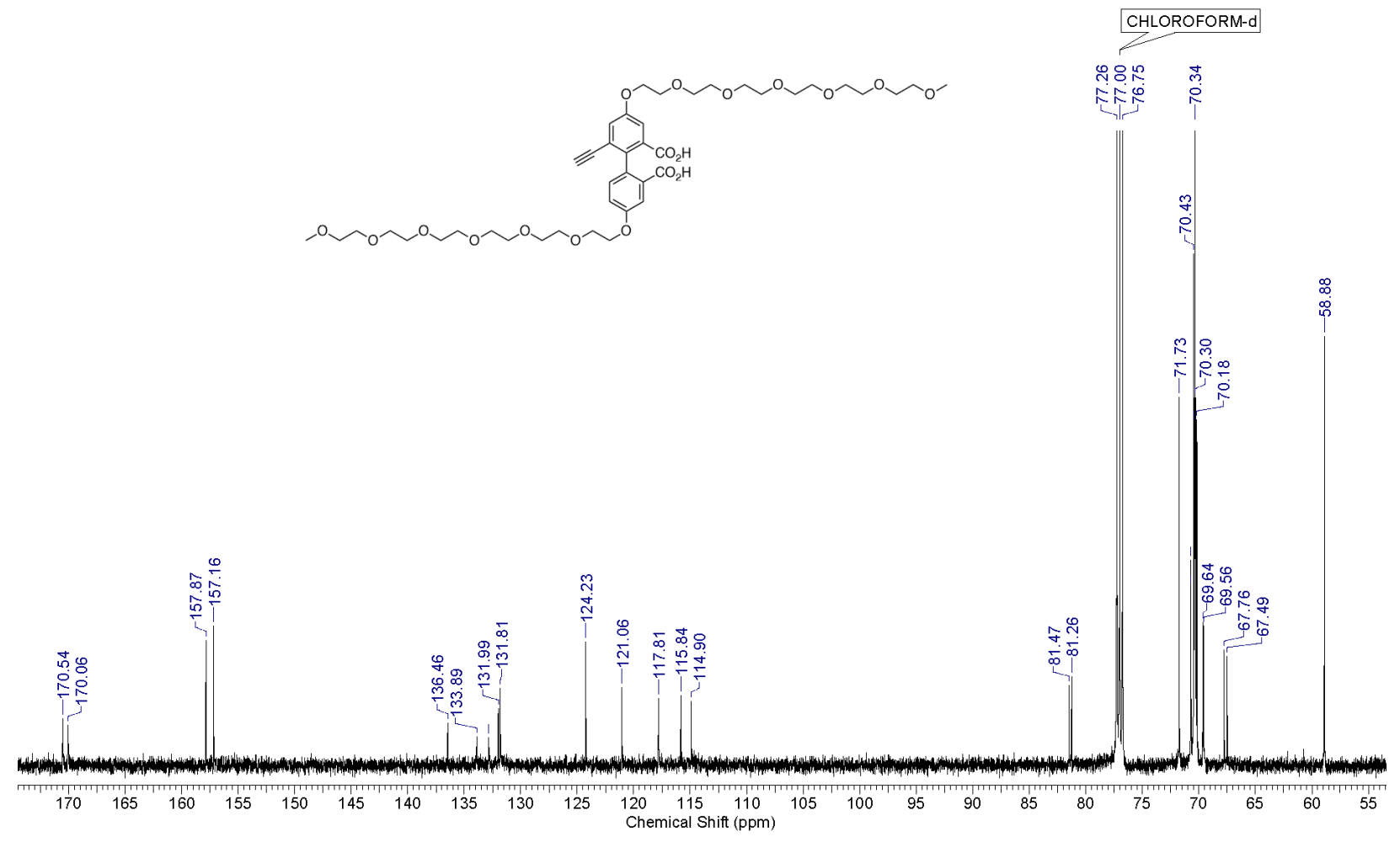

Figure S36. ${ }^{13} \mathrm{C}\left\{{ }^{1} \mathrm{H}\right\}$ NMR spectrum $\left(\mathrm{CDCl}_{3}, 126 \mathrm{MHz}\right)$ of DP-Ac2.
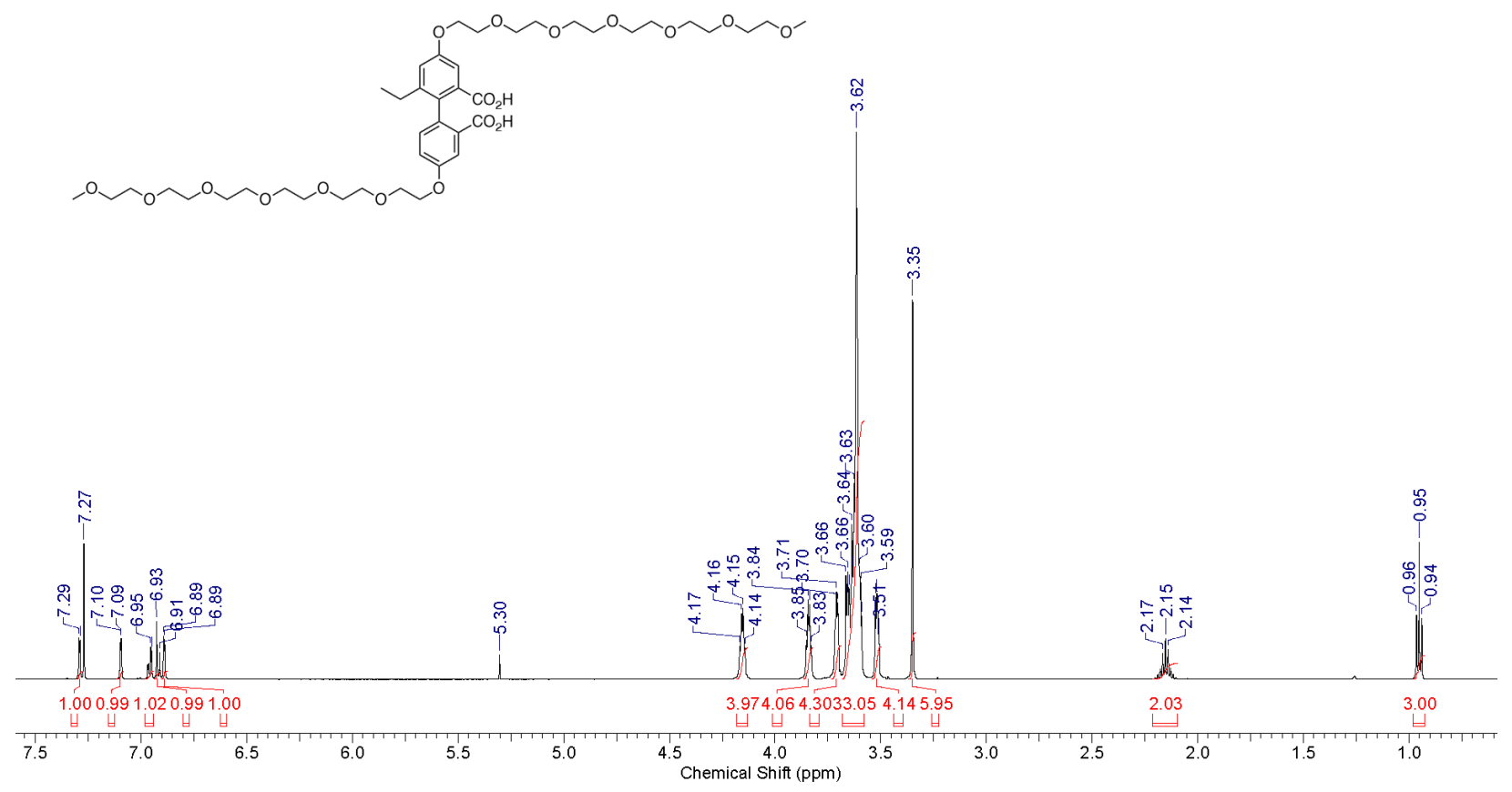

Figure S37. ${ }^{1} \mathrm{H}$ NMR spectrum $\left(\mathrm{CDCl}_{3}, 500 \mathrm{MHz}\right)$ of DP-Ac3. 

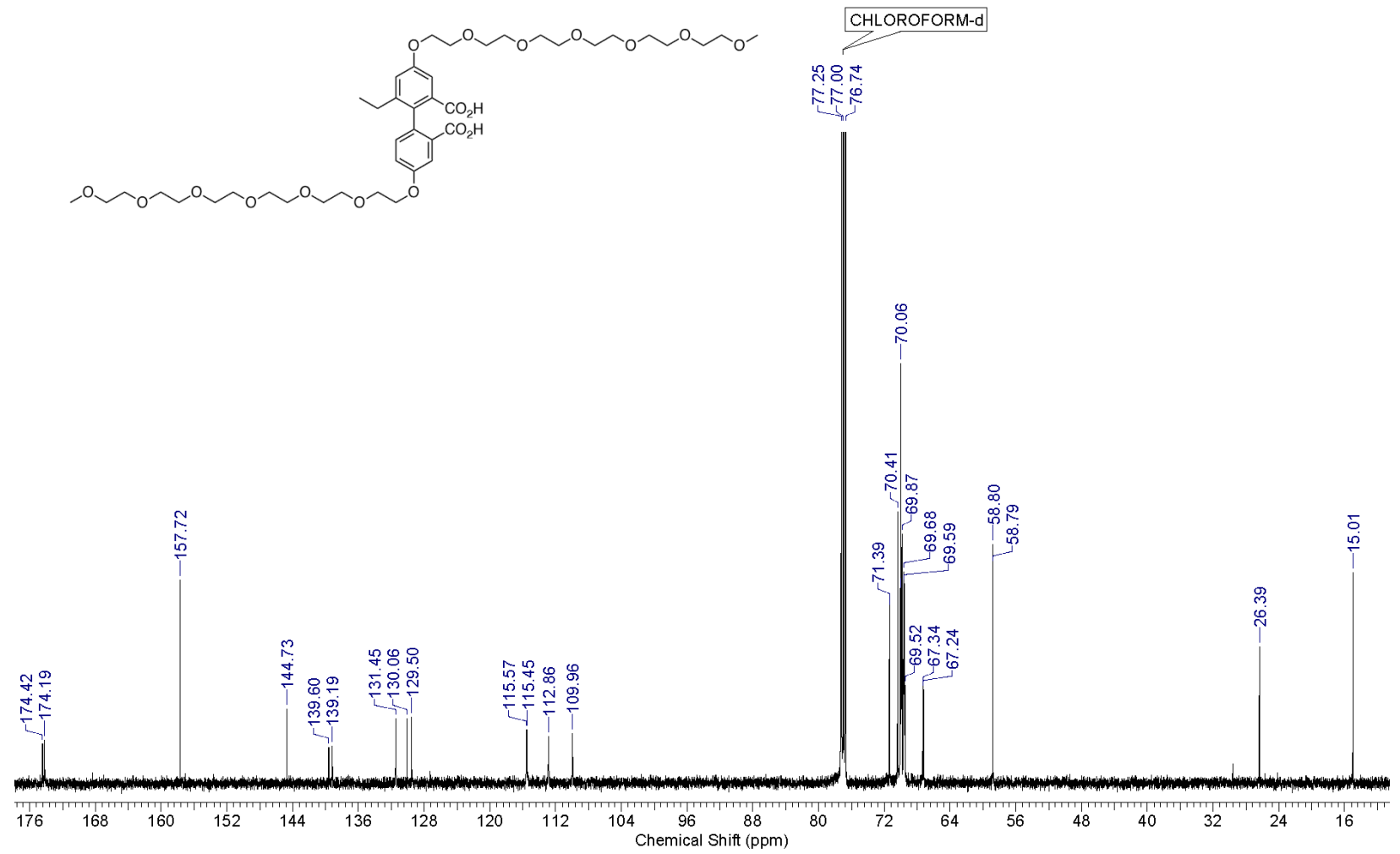

Figure S38. ${ }^{13} \mathrm{C}\left\{{ }^{1} \mathrm{H}\right\}$ NMR spectrum $\left(\mathrm{CDCl}_{3}, 126 \mathrm{MHz}\right)$ of DP-Ac3.

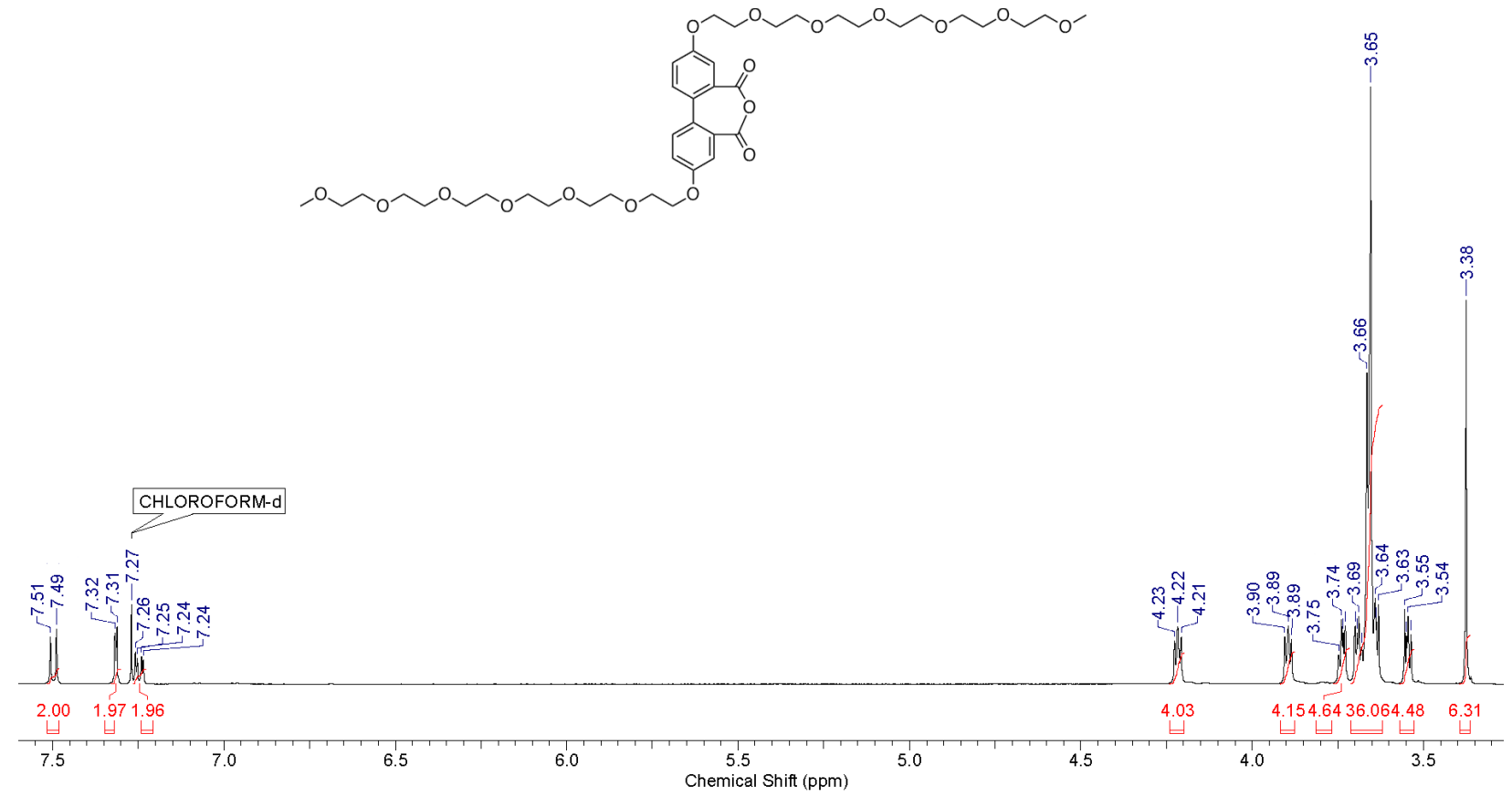

Figure S39. ${ }^{1} \mathrm{H}$ NMR spectrum $\left(\mathrm{CDCl}_{3}, 500 \mathrm{MHz}\right)$ of DP-An1. 

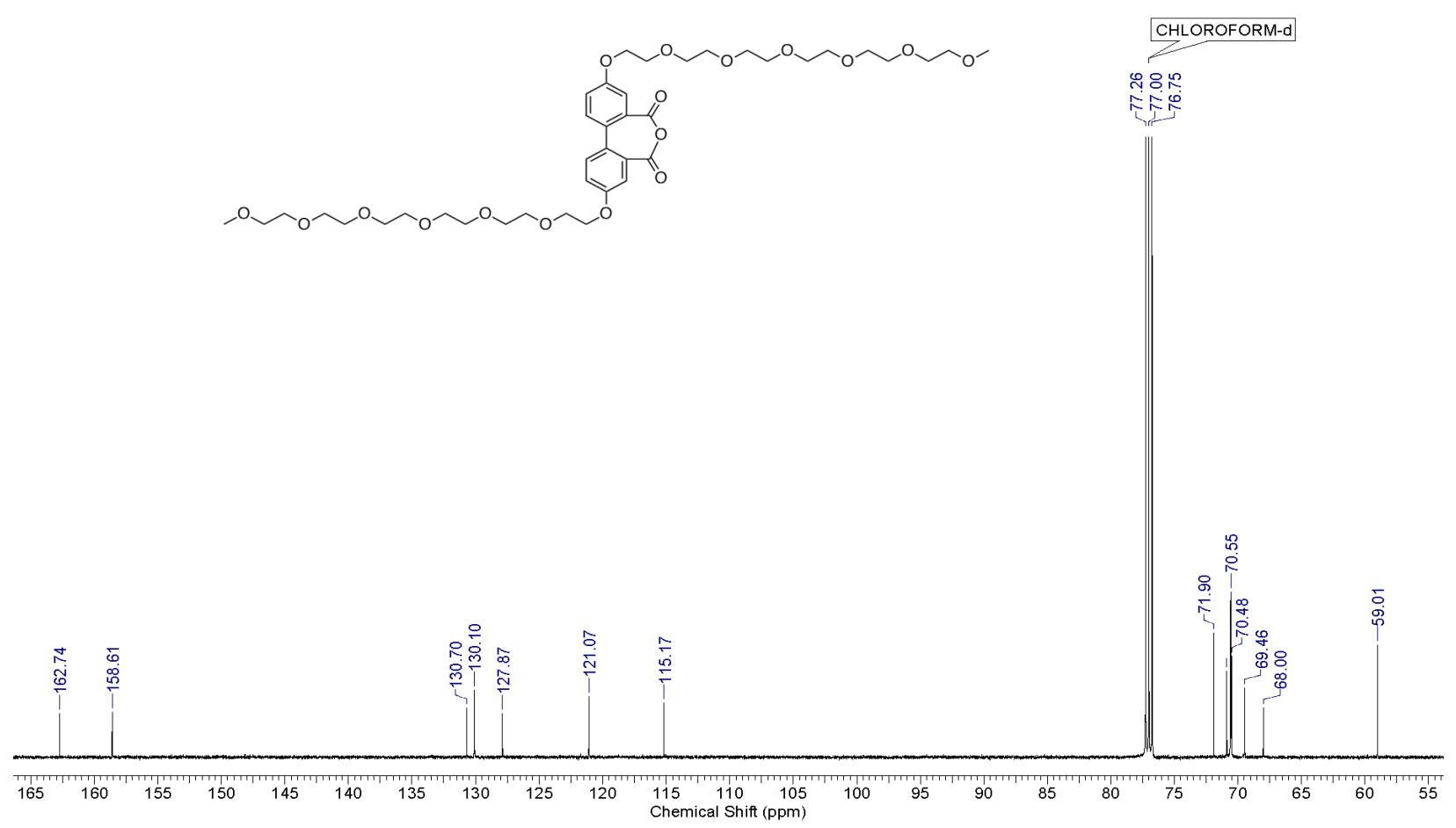

Figure S40. ${ }^{13} \mathrm{C}\left\{{ }^{1} \mathrm{H}\right\}$ NMR spectrum $\left(\mathrm{CDCl}_{3}, 126 \mathrm{MHz}\right)$ of DP-An1.

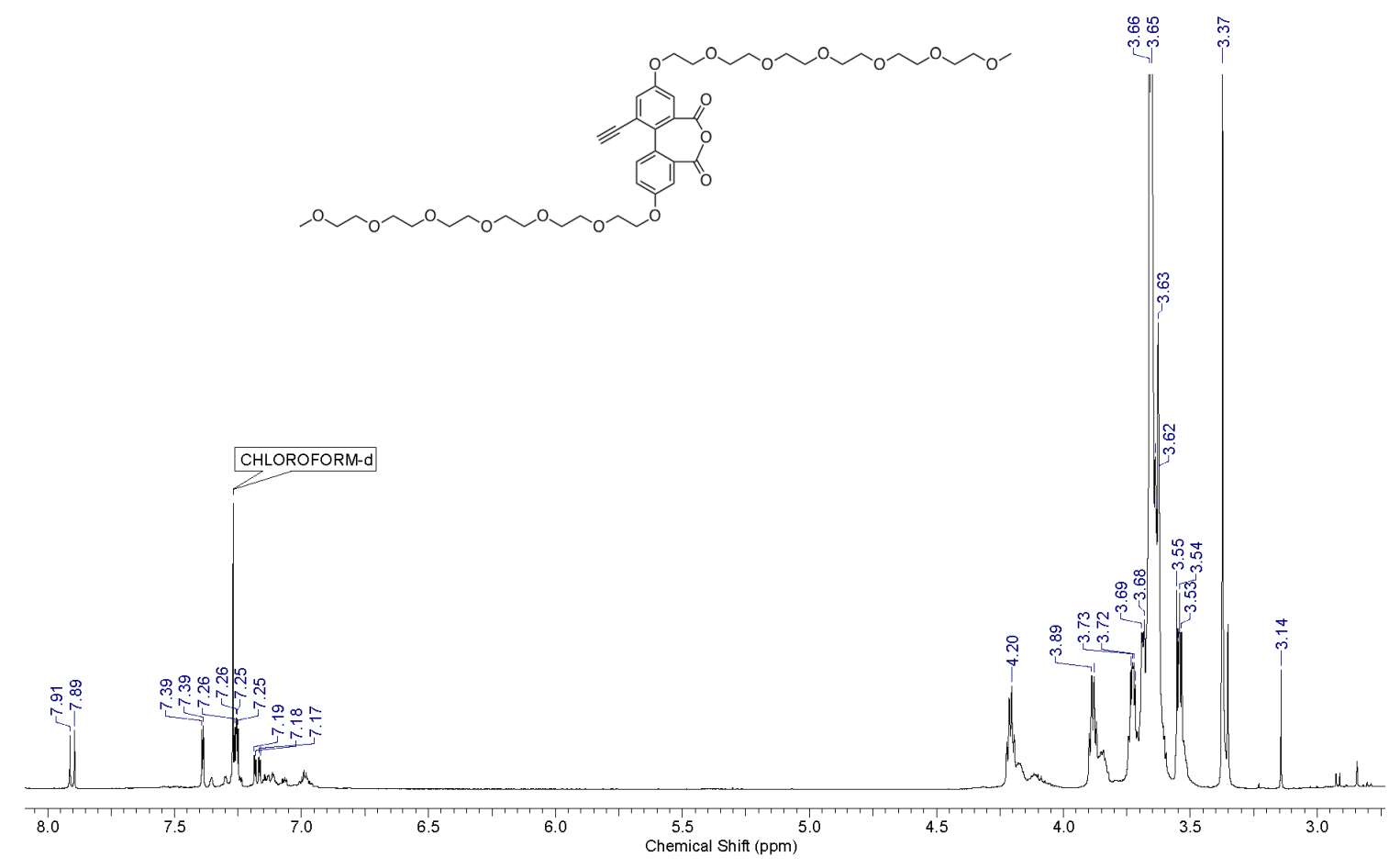

Figure S41. ${ }^{1} \mathrm{H}$ NMR spectrum $\left(\mathrm{CDCl}_{3}, 500 \mathrm{MHz}\right)$ of DP-An2 (major product in a mixture of acid and anhydride). 

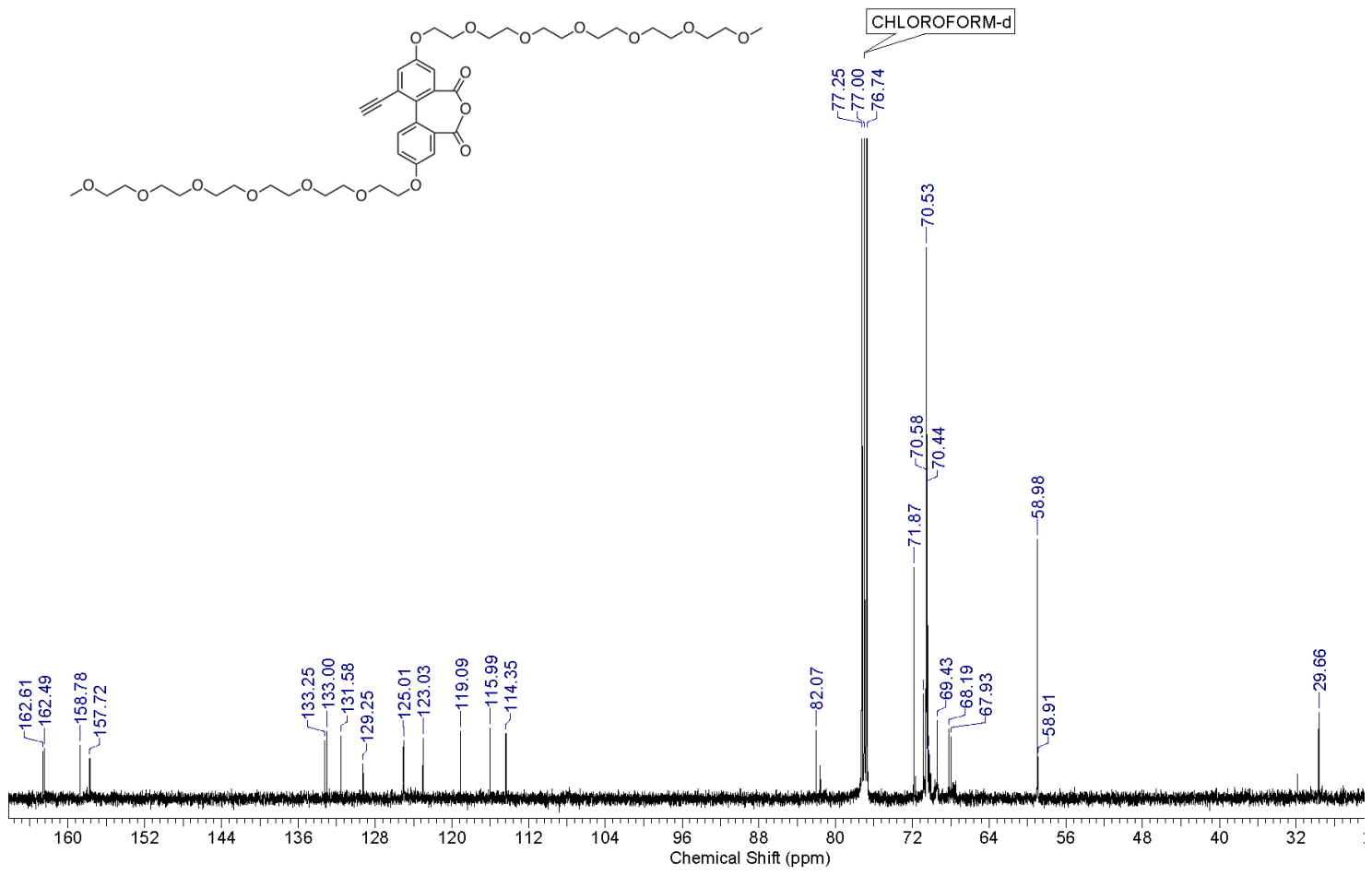

Figure $\mathrm{S} 42 .{ }^{13} \mathrm{C}\left\{{ }^{1} \mathrm{H}\right\}$ NMR spectrum $\left(\mathrm{CDCl}_{3}, 126 \mathrm{MHz}\right)$ of DP-An2.

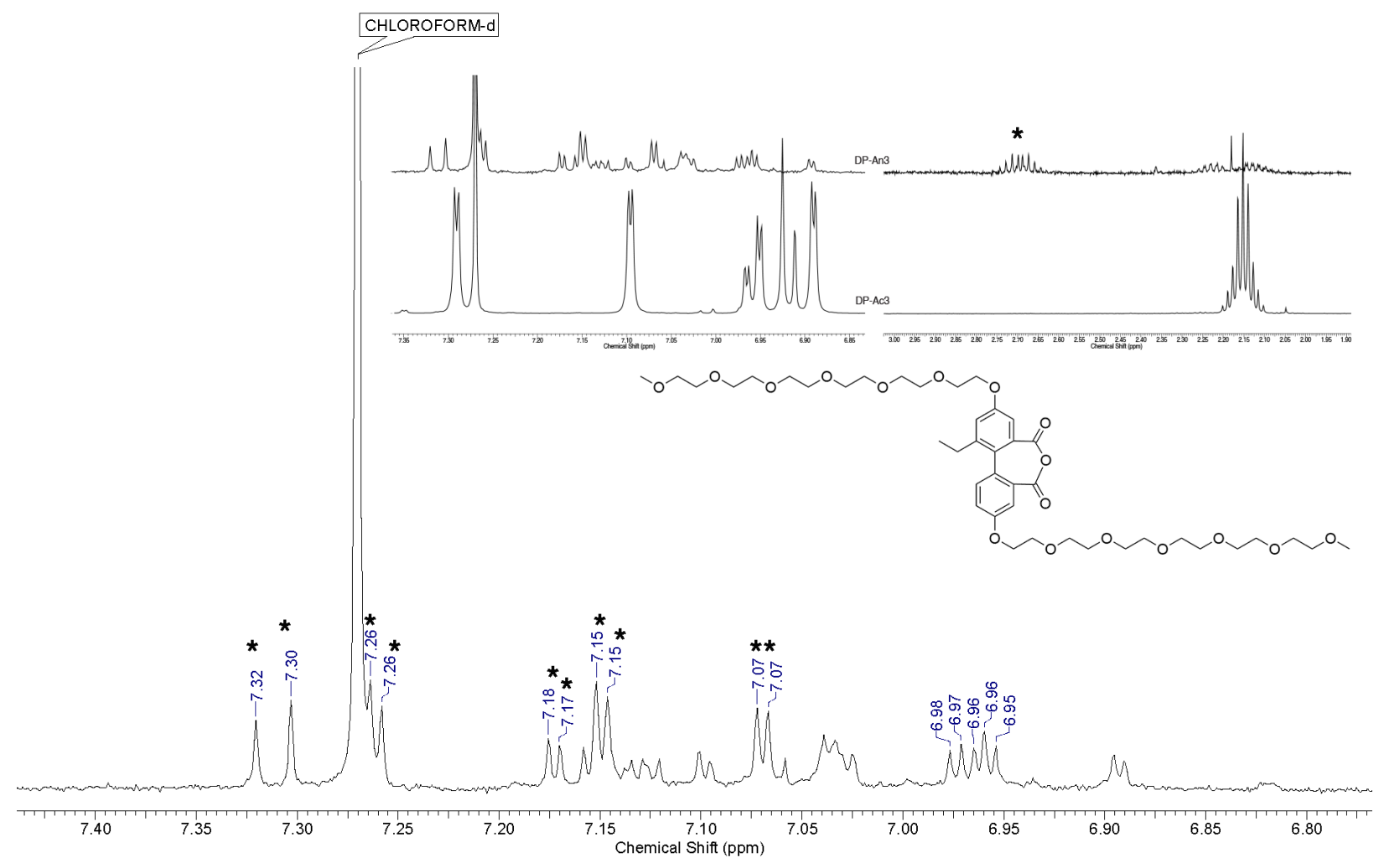

Figure S43. ${ }^{1} \mathrm{H}$ NMR spectrum (aromatic region) $\left(\mathrm{CDCl}_{3}, 500 \mathrm{MHz}\right.$ ) of DP-An3 (major product in a mixture, anhydride peaks are marked with asterisks). The inset is a comparison between the ${ }^{1} \mathrm{H}$ NMR signals from DP-Ac3 and as-synthesized DP-An3. 


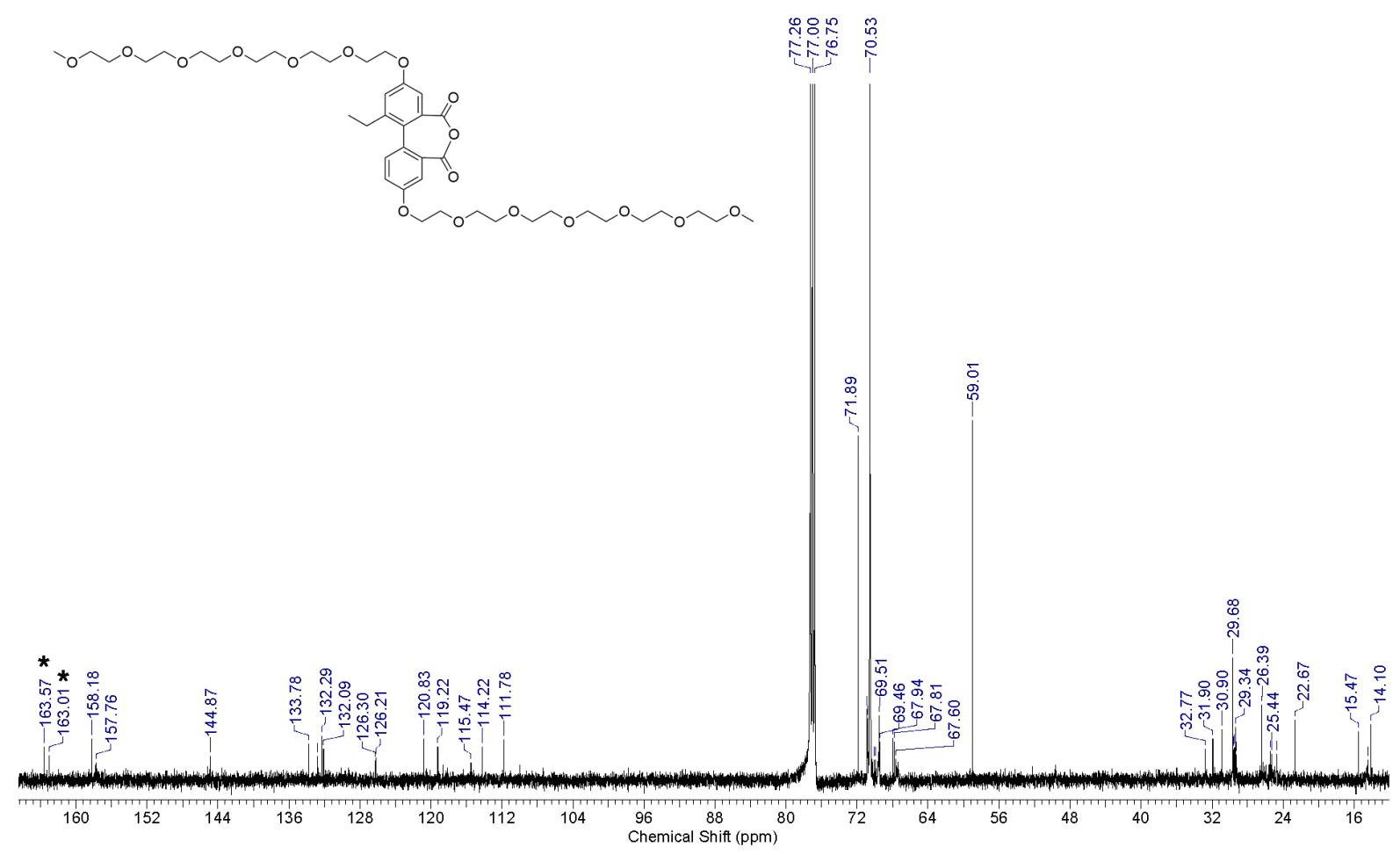

Figure S44. ${ }^{13} \mathrm{C}\left\{{ }^{1} \mathrm{H}\right\}$ NMR spectrum $\left(\mathrm{CDCl}_{3}, 126 \mathrm{MHz}\right)$ of DP-An3 (major product in a mixture, anhydride carbonyl peaks are marked with asterisks). 


\section{References}

(1) Wang, D. H.; Cheng, S. Z.; Harris, F. W. Polymer 2008, 49, 3020-3028.

(2) Bertran-Vicente, J.; Serwa, R. A.; Schümann, M.; Schmieder, P.; Krause, E.; Hackenberger, C. P. R. J. Am. Chem. Soc. 2014, 136, 13622-13628.

(3) Kariyawasam, L. S.; Kron, J. C.; Jiang, R.; Sommer, A. J.; Hartley, C. S. J. Org. Chem. 2020, 85, 682-690.

(4) Fox, J. In Applied Regression Analysis and Generalized Linear Models, 3rd Ed.; Sage Publishing: New York, 2016; Chapter 21, pp 587-606.

(5) Johnson, K. A.; Simpson, Z. B.; Blom, T. Anal. Biochem. 2009, 387, 30-41. 